Rafael de Deus Moura

Câncer de mama em mulheres muito jovens: estudo clinicopatológico de 149 pacientes $\leq 25$ anos de idade

Tese apresentada à Faculdade de Medicina da Universidade de São Paulo para obtenção do título de Doutor em Ciências.

Programa de Patologia.

Orientador: Prof. Dr. Carlos Eduardo

Bacchi 
Dados Internacionais de Catalogação na Publicação (CIP)

Preparada pela Biblioteca da

Faculdade de Medicina da Universidade de São Paulo

Creprodução autorizada pelo autor

Moura, Rafael de Deus

Câncer de mama em mulheres muito jovens : estudo clinicopatológico de 149 pacientes $\leq 25$ anos idade / Rafael de Deus Moura. -- São Paulo, 2015.

Tese(doutorado)--Faculdade de Medicina da Universidade de São Paulo. Programa de Patologia.

Orientador: Carlos Eduardo Bacchi.

Descritores: 1.Neoplasias 2.Mama 3.Adulto jovem 4.Imuno-histoquímica 5.Brasil 6.Sobrevida

USP/FM/DBD-227/15 
Dedicatória 
À minha querida família:

Wagner e Lúcia, fontes de inspiração.

Marina e Isabela, sempre ao meu Lado.

Carla e João, por darem sentido a tudo. 
Agradecimentos 
Muitos são os que ensinam por profissão. Poucos são os que ensinam por generosidade. Agradeço ao Prof. Dr. Carlos Eduardo Bacchi, pela inestimável oportunidade de convivência e por ter se tornado meu grande mestre ao longo destes anos.

À Prof. Dra. Filomena M. Carvalho, por sua contribuição científica nesta tese, auxílio na redação do artigo publicado e ativa participação no exame de qualificação.

Aos médicos patologistas do Hospital das Clínicas da Faculdade de Medicina da USP, personificados na pessoa da Dra. Sheila Aparecida Coelho Siqueira, pelo apoio, ensinamentos e carinho durante os anos felizes de residência médica.

Aos amigos médicos patologistas do Laboratório Bacchi/Consultoria em Patologia, Maura M. Bacchi, Cristiane G. Cançado, Sheila C. Wludarski, Lisandro F. Lopes, Eduardo M. Queiroga, Bruna Estrozi, Ívison Xavier Duarte, Donizete Scudeler, Gabriela Gualco e Marcelo Moraes.

À Dra. Pollyanna Duarte, médica hematologista, e Dra. Nilshelena Bezerra, médica oncologista, por suas importantes contribuições quanto à análise das informações dos esquemas de quimioterapia recebida pelas pacientes deste estudo.

Aos técnicos do laboratório de histologia e imuno-fistoquímica do Laboratório Bacchi/Consultoria em Patologia pela contribuição essencial à realização deste trabalho. 
Aos professores Dr. Venâncio Avancini Ferreira Alves e Dr. Carlos A. Ruiz, pela contribuição científica no exame de qualificação.

Às pacientes e aos médicos oncologistas, mastologistas e patologistas, por viabilizarem a análise de dados e materiais sem os quais este estudo não poderia ter sido realizado. 
Sumário 


\section{Lista de Abreviaturas}

\section{Lista de Tabelas}

\section{Lista de Figuras}

\section{RESUMO}

\section{ABSTRACT}

1. INTRODUÇÃO.

1.1 Epidemiologia do Câncer de mama............................................................. 24

1.2 Tendências na incidência do câncer de mama............................................ 25

1.3 Fatores de risco para câncer de mama......................................................... 27

1.4 Características anatomopatológicas e imuno-histoquímicas do câncer de mama.

1.5 Genética do câncer de mama

1.6 Câncer de mama em mulheres jovens: prognóstico.

1.7 Câncer de mama em mulheres muito jovens ( $\leq 25$ anos de idade).

2. OBJETIVOS.

3. MATERIAIS E MÉTODOS

3.1 Considerações éticas.

3.2 Seleção de casos.

3.3 Avaliação morfológica.

3.4 Construção de blocos de TMA e análise imuno-histoquímica.

3.5 Análise estatística.

4.1 Características clínicas e patológicas.

4.2 Características imuno-histoquímicas e subtipos moleculares 


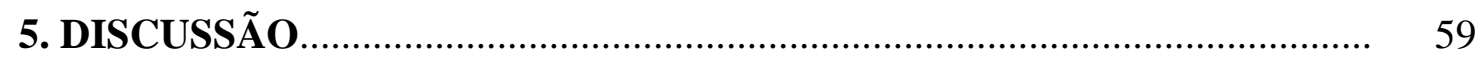

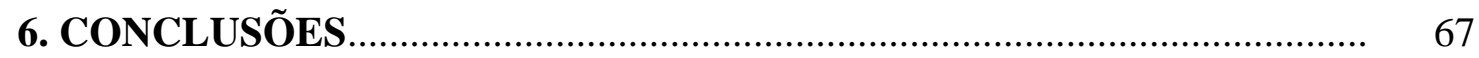

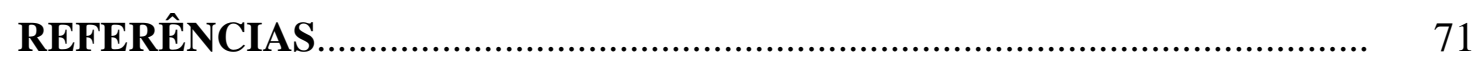

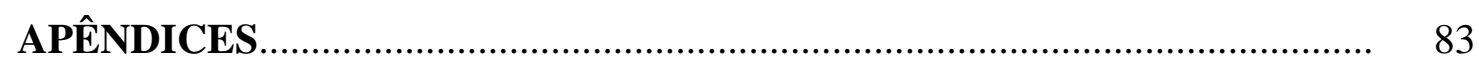

Apêndice 1 - Ficha para coleta de dados anatomoclínicos............................ 84

Apêndice 2 - Planilha com dados anatomoclínicos das pacientes................... 85

Apêndice 3 - Artigo Publicado (Breast Cancer in Very Young Woman)..... 122

ANEXO

Anexo 1 - Aprovação do Comite de Ética em Pesquisa.............................. 130 


\section{Lista de Abreviaturas}




$\begin{array}{ll}\text { ASCO } & \text { American Society of Clinical Oncology } \\ \text { CAP } & \text { Colégio Americano de Patologistas } \\ \text { CDIS } & \text { carcinomas ductais in situ } \\ \text { CLIS } & \text { carcinomas lobulares in situ } \\ \text { EUA } & \text { Estados Unidos da América } \\ \text { IMC } & \text { Índice de Massa Corpórea } \\ \text { INCA } & \text { Instituto Nacional do Câncer } \\ \text { RE } & \text { Receptor de Estrógeno } \\ \text { RP } & \text { Receptor de Progesterona } \\ \text { SEER } & \text { Surveillance, Epidemiology, and End Results }\end{array}$


Lista de Tabelas 
Tabela 1. Critérios para avaliação do grau histológico em câncer de mama....... 41

Tabela 2. Detalhes da análise imuno-histoquímica........................................... 44

Tabela 3. Critérios utilizados para a classificação molecular aproximada de acordo com o painel imuno-histoquímico.

Tabela 4. Características clinico-patológicas do câncer de mama em mulheres muito jovens ( $\leq 25$ anos).

Tabela 5. Relação entre tamanho tumoral e grupos moleculares........................ 55

Tabela 6. Relação entre grau histológico e grupos moleculares........................... 56

Tabela 7. Sobrevida geral de acordo com os grupos moleculares...................... 57 
Lista de Figuras 
Figura 1. Mapa de TMA para identificação dos casos para análise dos resultados de imuno-histoquímica.

Figura 2. Sobrevida geral das pacientes de acordo com os grupos

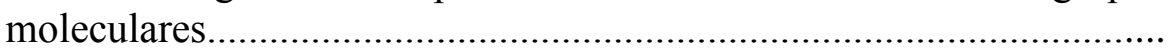


Resumo 
Moura RD. Câncer de mama em mulheres muito jovens: estudo clinicopatológico de 149 pacientes $\leq 25$ anos de idade [Tese]. São Paulo: Faculdade de Medicina, Universidade de São Paulo; 2015.

Câncer de mama em mulheres jovens tem características clínicas e patológicas distintas e comportamento mais agressivo quando comparado a carcinomas de mama em mulheres mais velhas. Entretanto, informações são escassas em mulheres muito jovens ( $\leq 25$ anos). O objetivo deste estudo foi investigar as características patológicas do câncer de mama em 149 mulheres brasileiras com idade de até 25 anos no momento do diagnóstico. Neste estudo, amostras de tumores diagnosticados entre 2003 e 2009 foram analisados dos arquivos da Consultoria em Patologia. Em nossa série de 149 mulheres brasileiras com até 25 anos de idade, $0,4 \%$ de todos os casos de câncer de mama ocorreram em pacientes de até 25 anos. Neoplasia apenas in situ ocorreu em 8,7\% (13/149). Dos 136 casos de carcinomas invasivos, 125 (91,9\%) eram do tipo ductal, e 62 $(45,6 \%)$ eram grau III histológico. Receptor de estrógeno foi positivo em 59,6\% dos casos e superexpressão de HER2 foi detectada em 32,8\% dos carcinomas invasivos. Foi observada uma baixa frequência de casos Luminal A e elevada frequência de casos Triplo Negativos. Análise estatística mostrou que os grupos HER2 e Basal-like apresentaram uma menor expectativa de sobrevida geral. Dados de seguimento mostraram elevada frequência de metástases para linfonodos regionais $(62,3 \%)$, de metástases à distância $(52,4 \%)$ e de óbitos relacionados ao tumor $(34,0 \%)$. O presente estudo representa a maior série de carcinomas de mama originando-se em mulheres $\leq 25$ anos e estabelece as principais características clínicas, patológicas, imuno-histoquímicas e de seguimento nessa população.

Descritores: neoplasias; mama; adulto jovem; imuno-histoquímica; Brasil; sobrevida. 
Abstract 
Moura RD. Breast cancer in very young women: Clinicopathological study of 149 patients $\leq 25$ years [Thesis]. São Paulo: "Faculdade de Medicina, Universidade de São Paulo"; 2015.

Background: Breast cancer in young women has different clinical and pathologic features and a more aggressive biological behavior when compared to breast cancers in older women. However, information is limited in very young women ( $\leq 25$ years). Objectives: The aim of the present study was to investigate the pathological characteristics of breast cancer in 149 Brazilian women who were $\leq 25$ years old at the time of breast cancer diagnosis. Matherials and Methods: Tumor samples diagnosed between 2003 and 2009 were analyzed from the archives of the Consultoria em Patologia. Results: Our series of 149 Brazilian women $\leq 25$ years corresponded to $0,4 \%$ of all breast cancers diagnosed in the same period. $8.7 \%$ presented with in situ disease only. Of 136 invasive carcinomas, $91.9 \%$ were of the ductal type and $45.6 \%$ were of histological grade III. Overall, estrogen receptor was positive in 59.6\% cases and HER2 overexpression was detected in $32.8 \%$. We also found a low prevalence of Luminal A cases and a high prevalence of Triple Negative cases. Statistical analysis showed that HER2 and basal-like groups had a lower overall survival expectation. Follow-up data showed high frequencies of regional lymph node metastasis, distant metastasis and tumor-related deaths. Conclusion: The present study represents the largest series of breast cancer arising in women $\leq 25$ years and establishes the main clinical, pathological, immunohistochemical and follow-up features of this population.

Descriptors: neoplasms; breast; young adult; immunohistochemistry; Brazil; survivorship (Public Health). 
1. Introdução 


\subsection{Epidemiologia do câncer de mama}

Câncer de mama representa a neoplasia maligna mais frequente em mulheres no mundo, à exceção de câncer de pele não melanoma. Estima-se que 231.840 novos casos de câncer de mama em mulheres serão diagnosticados em 2015 (29\% de todos os novos casos de câncer em mulheres) ${ }^{1}$. As taxas de incidência variam bastante nas diferentes regiões do mundo e são mais elevadas em regiões mais desenvolvidas em comparação a regiões em desenvolvimento, variando de 27 por 100.000 mulheres na África Central a 96 por 100.000 mulheres na Europa Ocidental. Por outro lado, as taxas de mortalidade variam menos que as de incidência, pois as regiões com maior incidência, mais desenvolvidas, têm sobrevida mais favorável ${ }^{2}$.

No Brasil, o carcinoma de mama é o tipo de câncer feminino mais comum, bem à frente do segundo colocado, que corresponde ao câncer de cólon/reto. O Ministério da Saúde/Instituto Nacional do Câncer (INCA) estima que foram diagnosticados cerca de 57.120 novos casos de câncer de mama em 2014, com uma incidência estimada de 56 casos a cada 100 mil mulheres. Nos estados brasileiros, as taxas de incidência variam bastante, sendo a menor observada no Acre (10/100mil) e a maior no Rio de Janeiro (96/100mil). Essas diferenças estão provavelmente relacionadas ao grau de eficiência de detecção e notificação de $\operatorname{casos}^{3}$.

Nos Estados Unidos da América (EUA), a probabilidade de uma mulher desenvolver câncer de mama antes dos 50 anos de idade é de 1,9\% e 12,3\% ao longo de toda a vida. Interessante observar que, até os 49 anos, carcinoma mamário é, com larga margem, o mais comum dentre todos os outros tipos de câncer ${ }^{1}$. De acordo com o 
banco de dados do SEER (Surveillance, Epidemiology, and End Results), nos Estados Unidos, $1,8 \%$ de todos os cânceres de mama ocorrem em mulheres abaixo de 35 anos, em comparação com 3,6\% de todas as neoplasias malignas ${ }^{4}$. No Brasil, são escassos os dados epidemiológicos sobre câncer de mama. Em estudo prévio de nosso grupo, avaliamos 15.000 casos consecutivos, incluindo todas as regiões geográficas do país. Encontramos uma idade média ao diagnóstico de 54,4 anos e a proporção de casos diagnosticados em mulheres com idade $\leq 35$ anos correspondia a $6,6 \%$ dos casos ${ }^{5}$.

\subsection{Tendências na incidência do câncer de mama}

Nos EUA, a incidência de câncer de mama reduziu-se entre 1999 e 2004 (em torno de $2 \%$ ao ano) e permaneceu estável entre 2004 e $2011^{1}$. Em contraste, a incidência de câncer de mama metastático em mulheres com menos de 40 anos de idade tem aumentado nos EUA. Segundo dados do SEER, estratificando-se a evolução da incidência anual de câncer de mama nos EUA por extensão da doença (localizada, regional ou metastática) e grupos etários (25-39, 40-54 e 70-84 anos de idade), nota-se que não houve tendência de elevação ou redução significativas em nenhum grupo etário ou estadio, com uma exceção: a incidência de câncer metastático em mulheres mais jovens que 40 tem aumentado nos EUA (aumento médio de 2\% ao ano entre 1976 e 2009). Essa elevação foi detectada em todas as raças e etnias, mas principalmente entre mulheres brancas não hispânicas e em afroamericanas, e isso ocorreu tanto em áreas metropolitanas quanto não metropolitanas. A incidência para mulheres com subtipos positivos para receptor de estrógeno (RE) apresentou maior aumento em comparação à 
observada em subtipos negativos para RE. O aumento dessa incidência mostrou-se mais pronunciada em pacientes afroamericanas, em brancas não-hispânicas e em mulheres com neoplasias positivas para RE. Aspecto importante observado foi que não houve tendência para desaceleração da taxa de incidência em mulheres jovens ${ }^{6}$.

Em Geneva, Suíça, a incidência de câncer de mama em mulheres com idade inferior a 40 anos mais que dobrou entre 1995 e 2004. No grupo etário de 25 a 39 anos, a incidência aumentou de 19,7 para 53,9, o que significa que, enquanto em 1995, a faixa etária de 25-39 anos representava 3,4\% de todos os cânceres de mama, em 2004 esse grupo já respondia por $7,2 \%$. No período, o aumento anual médio foi de $8,7 \%$ entre as pacientes jovens. Se considerarmos apenas os 3 últimos anos do estudo, apenas o grupo de 25-39 apresentou aumento significativamente estatístico, que foi de 46,7\%, bem acima do aumento médio de $8,7 \%$ do período de 1995 a $2004^{7}$. Na Espanha, a incidência de câncer de mama entre mulheres com idade inferior a 45 anos de idade aumentou de forma estável ao longo do período entre 1980 e 2004. Em contraste, em mulheres de 45 a 64 anos de idade, houve queda abrupta na taxa de incidência no ano de 2001. Em mulheres com idade igual ou superior a 65 anos, a tendência de aumento gradualmente perdeu força a partir de 1995, permanecendo relativamente estável após esse ano ${ }^{8}$. Em São Paulo, uma tendência de crescente aumento também tem sido detectada no câncer de mama em mulheres jovens desde os anos 80. Em mulheres de 25 a 29 anos, as taxas de incidência aumentaram de 6,4/100.000 em 1983 para 7,8/ 100.000 em 2000. Entre mulheres de 30 a 34 anos, as taxas de incidência aumentaram de 19 para 27,6/100.000. E entre mulheres de 35 a 39 anos, as taxas aumentaram de 40,2 para 67,4 por 100.000. Os autores desses estudos sugerem que a tendência de aumento na incidência do câncer de mama em mulheres jovens pode ser explicada por melhoras na 
notificação de casos, nas técnicas diagnósticas por imagem e recentes alterações no estilo de vida e fatores reprodutivos ${ }^{9,10}$.

\subsection{Fatores de risco para câncer de mama}

Gênero e idade são os fatores de risco mais relevantes para câncer de mama. As taxas de incidência aumentam rapidamente até a idade de 50 anos e então continuam a aumentar em um ritmo menor. Outros fatores de risco são história familiar, menarca precoce, nuliparidade, infertilidade, adiposidade e consumo de álcool ${ }^{11}$.

Existem determinadas características que apresentam interações mais complexas, exibindo o chamado efeito crossover. Esse efeito significa que essas características são protetoras até determinada idade e, depois, tornam-se fatores de risco (ou vice-versa). As 3 principais características com efeito crossover são adiposidade, nuliparidade e raça. Em relação à adiposidade, a maioria dos estudos indicam uma relação inversa entre índice de massa corpórea (IMC) e o risco de desenvolver câncer de mama pré-menopáusico. Por outro lado, mulheres obesas pós-menopáusicas têm risco aumentado de câncer de mama. Possível explicação seria que mulheres prémenopáusicas com maior índice de massa corpórea tendem a ter ciclos mentruais mais irregulares, sugerindo que seu menor risco pode ser devido a menor frequência de ciclos ovulatórios e menor exposição a hormônios ovarianos ${ }^{12}$. Nuliparidade também exibe interações etárias tipo crossover, com redução do risco para câncer de mama entre mulheres jovens (25-39 anos de idade) e risco aumentado entre mulheres mais velhas (40-79 anos de idade) ${ }^{11}$. Nos EUA, outro efeito crossover na incidência de câncer de 
mama foi observado entre mulheres negras e brancas. Mulheres negras apresentam incidência de câncer de mama significativamente maior até a idade de 40 anos e incidência significativamente menor após a idade de 50 anos, quando comparadas com mulheres brancas nas faixas etárias correspondentes. Para doença com metástase à distância, mulheres negras de todas as idades apresentam maior incidência quando comparadas a mulheres brancas ${ }^{13}$.

\subsection{Características anatomopatológicas e imuno-histoquímicas do câncer de mama}

A classificação histopatológica dos carcinomas de mama é baseada no padrão arquitetural assim como nas características citológicas do tumor. Carcinoma ductal invasivo (carcinoma invasivo de tipo não especial) é o tipo mais comum e engloba um grupo heterogêneo de tumores que não podem ser classificados como tipos especiais de carcinoma de mama. O diagnóstico histopatológico do carcinoma ductal invasivo depende, portanto, da exclusão dos tipos especiais de carcinomas de mama. Assim, suas características histológicas são bastante variáveis, podendo apresentar margens infiltrativas ou expansivas, arquitetura em cordões, blocos sólidos ou estruturas tubulares e núcleos regulares e uniformes ou altamente pleomórficos ${ }^{14}$.

Vários tipos especiais de carcinoma de mama são reconhecidos na atual classificação da Organização Mundial de Saúde ${ }^{14}$. Dentre os diversos tipos especiais, alguns serão destacados a seguir. O carcinoma lobular da mama é o segundo tipo mais comum de carcinoma de mama. São caracterizados por maior frequência de multifocalidade e bilateralidade que outros tipos de carcinomas invasivos de mama. Em 
sua forma clássica, o carcinoma lobular é constituído de células neoplásicas pouco coesas, geralmente arranjadas em fileiras. O carcinoma tubular é um tipo especial com limitado potencial metastático e prognóstico particularmente favorável em relação aos outros tipos histológicos de carcinomas de mama. É constituído de estruturas tubulares bem diferenciadas com camada única de células epiteliais de baixo grau nuclear. $\mathrm{O}$ carcinoma com características medulares é caracterizado por bordas expansivas, padrão de crescimento sincicial, células com alto grau nuclear e proeminente infiltrado linfoide. Cerca de $26 \%$ dos casos originam-se em pacientes jovens e, em relação a outros carcinoma de mama de alto grau nuclear, os carcinoma com características medulares tendem a apresentar melhor prognóstico, possivelmente devido ao proeminente infiltrado linfoide associado ${ }^{15}$. Outro tipo histológico de carcinoma de mama associado a prognóstico relativamente favorável é o carcinoma mucinoso, que se caracteriza por grupamentos de células uniformes flutuando em matriz mucinosa extracelular. Um raro tipo especial de carcinoma de mama a se destacar é o carcinoma secretório, cuja média de idade à apresentação é de 25 anos. Caracteriza-se por células neoplásicas arranjadas em arquitetura sólida, microcística e tubular, com produção de material secretor intra e extracelular. O carcinoma secretório apresenta prognóstico favorável. Os carcinomas de mama podem, ainda, ser classificados como carcinomas de tipo misto, em que $10 \%$ a 49\% do tumor é constituído de carcinoma de tipo não especial e o restante, de tipo especial de carcinoma invasivo ${ }^{14,16}$.

Atualmente, três biomarcadores são rotineiramente avaliados na abordagem de pacientes com câncer de mama: RE, Receptor de Progesterona (RP) e HER2. RE e RP são importantes fatores preditivos para a resposta à terapia endócrina, como o tamoxifeno ${ }^{16}$. De acordo com as recomendações da Sociedade Americana de Oncologia 
Clínica (ASCO) e do Colégio Americano de Patologistas (CAP), são considerados positivos para RE e/ou RP os carcinomas de mama em que ao menos $1 \%$ das células neoplásicas apresentam expressão nuclear ${ }^{17}$.

O gene HER2, localizado no cromossomo 17, codifica um receptor de fator de crescimento localizado na superfície de células epiteliais normais da mama. A amplificação desse gene é intimamente relacionada ao aumento da expressão da proteína correspondente. HER2 é importante fator prognóstico e também um fator preditivo à resposta à terapia com agentes anti-HER2, como o trastuzumab (Herceptin) 14. Assim, a análise de superexpressão da proteína HER2 através de imuno-histoquímica e, em casos duvidosos, a avaliação da amplificação do gene $H E R 2$ através de Hibridização In Situ Fluorescente (FISH), é atualmente prática rotineira na avaliação dos carcinomas de mama, seguindo-se as mais recentes recomendações da ASCO/CAP 18

Carcinoma de mama é neoplasia heterogênea, com achados morfológicos, comportamento clínico e resposta a regimes terapêuticos variáveis. Alguns investigadores têm levantado a hipótese de que essa heterogeneidade pode estar relacionada à origem celular ou à via de diferenciação das células tumorais. A mama normal contém duas camadas celulares: a camada de células luminais ou interna e a de células mioepiteliais ou basal-externa. Pela análise do perfil de expressão gênica, utilizando a metodologia de DNA microarray, Sorlie et al categorizaram 5 grupos diferentes de carcinoma de mama (luminal A, luminal B, HER2, tipo basal e tipo mama normal) e demonstraram pior prognóstico no tipo basal ${ }^{19,20}$. A designação "tipo basal" se deve ao perfil de expressão gênica desses tumores, que é semelhante ao das células basais da mama, provavelmente precursoras das células epiteliais glandulares e das 
células mioepiteliais. Em análise de mais de 300 tumores para avaliação da expressão de perfil gênico e correlação com seguimento clínico, dados de 3 estudos distintos e independentes demonstraram que carcinomas de mama do tipo basal compreendem $19 \%$ desses tumores e apresentam estreita associação com pior prognóstico avaliado pela sobrevida livre de doença ${ }^{20-22}$.

Estudos subsequentes que se propuseram a avaliar o perfil imuno-histoquímico do subtipo basal revelaram que esses tumores são tipicamente negativos para RE, RP e para o produto proteico do HER2 (triplo-negativos) ${ }^{23}$. No entanto, há evidências sugerindo que o grupo de carcinomas de mama com fenótipo triplo-negativo é substancialmente mais heterogêneo que o sub-grupo do tipo basal. Estudos retrospectivos revelam que carcinomas triplo-negativos que expressam marcadores de tipo basal (citoceratina 5/6, EGFR) apresentam comportamento clínico mais agressivo que carcinomas triplo-negativos que não expressam tais marcadores, justificando subanálise sistemática dos carcinomas triplo-negativos com marcadores de tipo basal ${ }^{23,24}$. Além do perfil imuno-histoquímico distinto, o fenótipo basal tem sido relacionado a mutação do BRCAl e apontado como mais frequente no grupo de mulheres na prémenopausa, o que sinaliza uma provável maior frequência em pacientes jovens ${ }^{25,26}$.

\subsection{Genética do câncer de mama}

A frequência de mutação em $B R C A$ na população geral é de $0,2 \%$. Em comparação, o risco de mutação em $B R C A$ em mulheres com câncer de mama em qualquer idade é de $5 \%$ e, em mulheres de até 35 anos com câncer de mama, de $10 \%{ }^{27}$. 
Em estudo com mulheres com câncer de mama com idade igual ou inferior a 30 anos, observou-se que mutação em $B R C A l$ foi detectada em apenas $10 \%$ dos casos, em BRCA2 em 8\% e em TP53 em 4\%. Contudo, a taxa de mutações em BRCA1, BRCA2 ou TP53 detectadas em casos de câncer de mama familial foi de quase 50\%, demonstrando a importância de acurada demonstração de uma história familiar. Nos casos sem história familiar, apenas $6 \%$ possuíam mutações nesses genes ${ }^{28}$. Em outro estudo realizado no Brasil com 54 pacientes com idade menor ou igual a 35 anos, nos casos negativos para receptores hormonais e com história familiar positiva, a presença de mutações em BRCA1, BRCA2 e/ou p53 foi encontrada em $83 \%$ dos casos (em comparação a $22 \%$ em casos sem histórico familiar) ${ }^{29}$.

\subsection{Câncer de mama em mulheres jovens: prognóstico}

Em pacientes com idade inferior a 45 anos, quanto menor for a idade no momento do diagnóstico de câncer de mama, pior o prognóstico. Esse padrão é independente de estadio, extensão da doença ao diagnóstico e do tipo histológico ${ }^{30}$. Em análise retrospectiva de 885 pacientes pré-menopáusicas, com 804 mulheres com idade superior a 35 anos e 81 apresentando até 35 anos, observou-se que idade $\leq 35$ anos foi fator prognóstico independente, em análise multivariada, de menor sobrevida geral e livre de recorrência. Esse pior prognóstico era independente do tamanho, tipo histológico, grau histológico, status de receptores hormonais e linfonodos e tipos de terapia ${ }^{31}$. Em outro estudo com 315 pacientes com câncer de mama mais jovens que 35 anos e 2.655 com idade igual ou superior a 35 anos, Cancello et al demonstraram que o 
grupo mais jovem apresentava maior prevalência de tipo ductal, menor prevalência de carcinomas lobulares, maior prevalência de tumores grau III histológico, uma tendência a apresentar linfonodos comprometidos, maior frequência de invasão angiolinfática, maior porcentagem de tumores negativos para RE e RP, maior índice de proliferação celular, número maior de tumores com superexpressão de HER2, menos tumores com classificação luminal A e mais tumores triplo-negativos para RE, RP e HER2 ${ }^{32}$. Han et al, após análise multivariada ajustando os resultados para tamanho, status de linfonodos e receptores hormonais, encontraram que as diferenças significativas para pior sobrevida, em relação ao grupo de pacientes entre 40 e 50 anos, apareciam apenas naquelas pacientes $<35$ anos. Isso levou aqueles autores a concluírem que 35 anos seria um cut-off razoável para definir mulheres jovens com câncer de mama. Importante destacar que, para essas pacientes abaixo dos 35 anos, o risco de óbito aumentava em 5\% para cada ano de redução na idade e que as diferenças na sobrevida eram maiores ainda no grupo entre 26 e 29 anos ${ }^{33}$.

Essas diferenças de prognóstico podem estar relacionadas a diferenças na biologia de câncer de mama em mulheres jovens. Anders et al identificaram 367 conjuntos de genes diferencialmente expressos em tumores de mulheres jovens $(\leq 45$ anos), enquanto que tumores em mulheres mais velhas ( $\geq 65$ anos) não apresentaram conjuntos gênicos comuns ${ }^{34}$. Entretanto, alguns anos depois esses mesmos autores realizaram novas análises com os mesmos dados, ajustando para variáveis potencialmente confusas não incluídas previamente (subtipo molecular, status de RE, grau e status nodal) e encontraram apenas 1 diferença de gene entre tumores de mama nos 2 grupos etários. Eles sugerem que as diferenças biológicas entre os tumores dos 2 grupos etários são fortemente influenciadas por genes associados aos subtipos 
moleculares e grau histológico, ambos altamente correlacionados a idade. Eles concluíram, portanto, que idade apenas não era indicativa de complexidade biológica além do subtipo e grau histológicos. Eles reconhecem, contudo, que esse estudo poderia não ser fielmente representativo de tumores originando-se em mulheres ainda mais jovens $(<35 \text { anos })^{35}$.

Em contraponto, Azim et al, em análise mais ampla, encontraram 16 genes significativamente relacionados à idade após ajuste para subtipo de câncer, tamanho, status axilar e grau histológico. Eles propõem, portanto, que o câncer de mama originando-se em mulheres jovens seria de fato uma entidade biologicamente distinta, caracterizada por vias de sinalização oncogênica específicas ${ }^{36}$.

\subsection{Câncer de mama em mulheres muito jovens ( $\leq 25$ anos de idade)}

Estudos de câncer de mama em mulheres muito jovens ( $\leq 25$ anos) são escassos, dificultando a estimativa de taxas de incidência ${ }^{37}$. Dados do SEER coletados entre 2006 e 2010 indicam que a taxa de incidência do câncer de mama ajustada para idade em mulheres brancas é de 0,2/100.000 entre 15-19 anos de idade. Na faixa etária de 20-24 anos, essa incidência é de 1,5/100.000 em mulheres brancas e de 1,9/100.000 em mulheres negras ${ }^{4}$. De acordo com dados do Comitê de Registro de Câncer do Japão, referentes a 490 instituições, apenas 107 casos de câncer de mama ocorreram em mulheres com idade inferior a 25 anos entre 2004 e 2008, correspondendo a apenas $0,1 \%$ de todos os casos de câncer de mama ${ }^{38}$. Na Inglaterra, a proporção em 2011 foi 
semelhante, com registro de 39 casos em mulheres na mesma faixa etária, correspondendo a $0,09 \%$ do total de casos de câncer de mama ${ }^{39}$.

Embora haja considerável número de estudos sobre câncer de mama em mulheres de até 35 anos, há escassa literatura em mulheres ainda mais jovens, com até 25 anos. Conforme salientado, há uma tendência de aumento na incidência de câncer de mama em mulheres jovens em vários países, indicando crescente importância epidemiológica dessa doença nesse grupo etário. Assim, é necessário entender melhor a biologia do câncer de mama em mulheres muito jovens. Enquanto alguns estudos focam na análise dos genes envolvidos no câncer de mama em mulheres jovens, poucos avaliam as características clinicopatológicas do câncer de mama em mulheres muito jovens. 
2. Objetivos 
O objetivo do presente estudo foi investigar as características clínico-patológicas do câncer de mama em 149 pacientes brasileiras muito jovens, com até 25 anos de idade ao diagnóstico, comparando com dados da literatura em pacientes jovens com câncer de mama. Os principais pontos avaliados foram:

1. Frequência de câncer de mama em mulheres brasileiras muito jovens $(\leq 25$ anos);

2. Características clínicas das pacientes: idade mediana, história de gestação, história familiar;

3. Características histopatológicas dos tumores: tamanho, tipo histológico e grau histológico;

4. Características imuno-histoquímicas: expressão de receptores hormonais, superexpressão de HER2 e classificação molecular;

5. Dados de tratamento: tipo de cirurgia, realização e esquemas de quimioterapia, realização de radioterapia;

6. Informações de seguimento: desenvolvimento de metástases, recidivas e sobrevida. 
3. Materiais e Métodos 


\subsection{Considerações éticas}

Este estudo foi aprovado pelo Comitê Científico do Departamento de Patologia da Faculdade de Medicina da Universidade de São Paulo e pelo Comitê de Ética para Projetos de Pesquisa do Hospital das Clínicas da Faculdade de Medicina da Universidade de São Paulo (CAPPesq; número de protocolo: 236/11), seguindo as diretrizes da Resolução 196/96 do Conselho Nacional de Saúde (vide anexo 1).

\subsection{Seleção de casos}

Entre 2003 e 2012, 149 amostras de tumores de pacientes com 25 anos ou menos de idade com diagnóstico de câncer de mama foram analisados dos arquivos do Laboratório Bacchi/Consultoria em Patologia, um laboratório de referência em anatomia patológica localizado na cidade de Botucatu, SP, Brasil. Esse laboratório avalia mais de 6.000 casos de câncer por ano, geralmente recebidos para estudo de marcadores preditivos e prognósticos.

Esses casos originaram-se das seguintes regiões geográficas do Brasil: Sudeste (72 casos; 48,3\%), Sul (31 casos; 20,8\%), Nordeste (25 casos; 16,8\%), Norte (13 casos; $8,7 \%)$ and Centro-Oeste (8 casos; $5,4 \%)$.

Dados de seguimento e tratamento foram obtidos através do envio de questionários para os médicos das pacientes (vide modelo de carta em apêndice 1) e de revisão dos relatórios anatomopatológicos originais. Informações de sobrevida foram obtidas em 47 casos, com seguimento mediano de 39 meses (6-131 meses). 


\subsection{A valiação morfológica}

Todas as amostras foram revisadas e classificadas de acordo com o tipo histológico, grau histológico segundo Elston e Ellis ${ }^{40}$ (tabela 1) e a presença de componente de carcinoma in situ.

Tabela 1. Critérios para avaliação do grau histológico em câncer de mama

\begin{tabular}{lc}
\hline Formação Tubular & Escore \\
\hline$>75 \%$ & 1 \\
$10-75 \%$ & 2 \\
$<10 \%$ & 3 \\
\hline Pleomorfismo Nuclear & Escore \\
\hline Células pequenas e regulares & 1 \\
Moderado aumento e variabilidade em tamanho & 2 \\
\hline Variação acentuada & 3 \\
\hline Contagem de Figuras de Mitose & Escore \\
\hline Vide descrição do microscópio $*$ & $1-3$ \\
\hline
\end{tabular}

* Foi utilizado microscópio Olympus Modelo BX51, sendo a contagem realizada com aumento de 400x (10x da ocular e 40x da objetiva) e obedecendo ao seguinte critério: 1 ponto (0-5 figuras de mitose); 2 pontos (6-10 figuras de mitose) e 3 pontos (>10 figuras de mitose). De acordo com essa análise, a graduação histológica foi divida em 3 subgrupos: Grau I: escores 3-5; Grau II: escores 6-7 e Grau III: escores 8-9.

O diagnóstico final em todos os casos foi realizado através da análise de cortes histológicos completos dos blocos originais de parafina corados em hematoxilina-eosina 
e através da interpretação de imuno-histoquímica em cortes de tissue microarray (TMA) e/ou nos cortes histológicos do bloco nativo de parafina.

\subsection{Construção de blocos de TMA e análise imuno-histoquímica}

A partir dos casos de carcinoma invasivo de mama levantados dos arquivos do Laboratório Bacchi/Consultoria em Patologia, foram construídos 03 blocos de parafina do tipo array de tecido (TMA), utilizando-se um "arrayer" de tecido biológico produzido pela Beecher Instruments (Sun Prairie, EUA) para análise de 66 casos.

Através da técnica de TMA, é possível a extração de material de vários blocos originais de parafina e inclusão de vários casos em um único bloco. Assim, os casos ficam representados por cilindros com diâmetro de 2,0 mm, espaçados a uma distância de 3,0 mm. Cada caso foi representado por 1 cilindro de tecido obtido a partir dos blocos de parafina doadores (blocos originais de parafina contendo a neoplasia), com diâmetro de 2,0 mm. Os cilindros de todos os casos foram distribuídos em blocos receptores, de acordo com mapa de TMA para identificação dos casos (figura 1). 


\begin{tabular}{|c|c|c|c|c|c|c|c|c|c|c|c|c|c|c|c|c|c|c|c|c|}
\hline \multicolumn{21}{|c|}{ Mapa para Tissue microarray (TMA) } \\
\hline \multicolumn{21}{|l|}{ Deecriçào: } \\
\hline \multicolumn{21}{|c|}{ Denaidade: } \\
\hline $\begin{array}{l}\text { Linha }(x) \cdot \\
\sim \text { Coluna }(y)\end{array}$ & $\begin{array}{c}A \\
(1,00)\end{array}$ & \begin{tabular}{|c|} 
B \\
$(2,00)$
\end{tabular} & \begin{tabular}{c|c|}
$\mathrm{C}$ \\
$(3,00)$
\end{tabular} & \begin{tabular}{|c|c|c|c|c} 
\\
$(4,00)$
\end{tabular} & \begin{tabular}{c|c|}
$E$ \\
$(5,00)$
\end{tabular} & \begin{tabular}{c|c|}
$F$ \\
$(6,00)$
\end{tabular} & \begin{tabular}{|c|}
$G$ \\
$(7.00)$
\end{tabular} & \begin{tabular}{|c|}
$H$ \\
$(8,00)$
\end{tabular} & $\left.\begin{array}{c|c|} \\
(9,00)\end{array}\right)$ & $\begin{array}{c}J \\
(10,00)\end{array}$ & \begin{tabular}{|c|}
$K$ \\
$(11,00)$
\end{tabular} & $\begin{array}{c}\mathrm{L} \\
(12,00)\end{array}$ & \begin{tabular}{|c|}
$M$ \\
$(13,00)$
\end{tabular} & \begin{tabular}{c|c}
$N$ \\
$(14,00)$
\end{tabular} & \begin{tabular}{c|c}
0 \\
$(15,00)$
\end{tabular} & \begin{tabular}{|c|}
$P$ \\
$(16,00)$
\end{tabular} & $\begin{array}{c}Q \\
(17,00)\end{array}$ & $\begin{array}{c}R \\
(18,00)\end{array}$ & \begin{tabular}{c|}
$S$ \\
$(19,00)$
\end{tabular} & $\begin{array}{c}\mathrm{T} \\
(20,00)\end{array}$ \\
\hline $01(1,00)$ & Figaso & & & & & & ש & 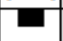 & ש & & - & & 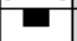 & ש & & ש & & & E & \\
\hline $02(2,00)$ & & & & E & & & 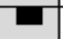 & u & ש & & L & & & 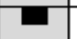 & & 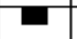 & & & & \\
\hline $03 \quad(3,00)$ & & & & & & & & & w & & & & & 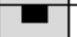 & & L & & & & \\
\hline $04(4,00)$ & & & & & & & & & 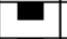 & & & & & & & & & & & \\
\hline $05 \quad(5,00)$ & & & & & & & & & & & & & & 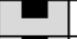 & & 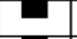 & & & & \\
\hline $06 \quad(6,00)$ & & & & & & & & & 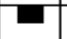 & & 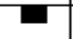 & & & $\mathbf{E}$ & & 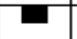 & & & & \\
\hline $07(7.00)$ & & & & & & & - & & - & & 다 & - & & E & & L & & & & \\
\hline $08 \quad(8,00)$ & & & & & & & & & 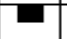 & & & & & & & & & & & \\
\hline $09 \quad(9,00)$ & & & & & & & 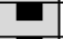 & & E & & 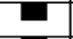 & & & $\square$ & & 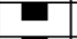 & & & & \\
\hline $10(10,00)$ & & & & & & & & & E & & & & & 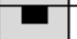 & & & & & & \\
\hline $11(11,00)$ & & & & & & & - & & $\square$ & & & 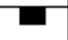 & & ש & & 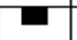 & & & & \\
\hline $12(12,00)$ & & & & & & & & & 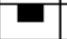 & & & & & & & & & & & \\
\hline $13(13,00)$ & & & & & & & & & $\square$ & & & & & & & & & & & \\
\hline $14(14,00)$ & & & & & & & & & 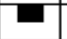 & & & & & & & & & & & \\
\hline $15(15,00)$ & & & & & & & & & $\mathbf{E}$ & & & 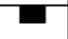 & & E & & & E & & & \\
\hline $16(16,00)$ & & & & & & & & & $\square$ & & & E & & E & & & & & & \\
\hline $17(17.00)$ & & & & & & & & & & & & & & & & & & & & \\
\hline $18(18.00)$ & & & & & & & & & & & $\square$ & - & L & E & & ש & & & & \\
\hline $19(19,00)$ & & & & & & & & & & & & 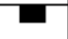 & & E & & E & & & & L \\
\hline $20(20,00)$ & w & G & E & $\boldsymbol{E}$ & $\mathbf{E}$ & $\square$ & & E & $\mathbf{E}$ & & & $\boldsymbol{E}$ & E & & & & & & & \\
\hline
\end{tabular}

Figura 1. Mapa de TMA para identificação dos casos para análise dos resultados de imuno-histoquímica.

Foram realizadas reações de imuno-histoquímica em cortes histológicos de TMA ou dos blocos originais de parafina para RE, RP, HER2, Ki-67, epidermal growth factor receptor (EGFR) e citoceratina 5/6 (CK5/6). As fontes e diluições desses anticorpos e métodos de recuperação antigênica estão descritos na Tabela 2. Foi utilizado sistema de detecção Envision ${ }^{T M}$ mouse ou rabbit (Dako, Carpinteria, CA, USA). Foi considerada marcação imuno-histoquímica positiva quando havia localização nuclear para RE, RP e Ki-67, localização citoplasmática para CK5/6 e marcação de membrana para EGFR. Para avaliação da superexpressão de HER2, amostras foram consideradas positivas se marcassem escore $3+$ de acordo com o consenso da American Society of Clinical Oncology (ASCO) e do College of American Pathologists (CAP). Para casos com imuno-histoquímica escore 2+ (duvidoso) para HER2, as amostras 
foram posteriormente avaliadas utilizando Hibridização in situ fluorescente (FISH) e apenas foram consideradas positivas se a relação sinal HER2:CEP17 fosse $\geq 2.0{ }^{18}$. Aproximação da classificação molecular das amostras utilizando o painel de anticorpos mencionado acima foi realizada de acordo com a classificação modificada 12th St. Gallen Subtype Classification ${ }^{41}$, descrita na Tabela 3.

Tabela 2. Detalhes da análise imuno-histoquímica.

\begin{tabular}{ll|l|l}
\hline Antígeno & Clone/Fonte & Diluição & $\begin{array}{l}\text { Método de Recuperação } \\
\text { Antigênica }\end{array}$ \\
\hline $\begin{array}{l}\text { Receptor de estrógeno } \\
\text { (RE) }\end{array}$ & R; SP1/Thermo Scientific & $1: 500$ & Panela de pressão, 9 min \\
$\begin{array}{l}\text { Receptor de progesterone } \\
\text { (RP) }\end{array}$ & $\begin{array}{l}\text { M; PgR636/Thermo } \\
\text { Scientific }\end{array}$ & $1: 1000$ & Panela de pressão, 9 min \\
\hline HER2 & R; SP3/Thermo Scientific & $1: 100$ & Microondas, 15 min \\
\hline $\begin{array}{l}\text { Ki-67 } \\
\text { Epidermal growth factor } \\
\text { receptor (EGFR) }\end{array}$ & M; MIB1/Dako & $1: 600$ & Panela de pressão, 8 min \\
\hline \begin{tabular}{l} 
Citoceratina 5/6 (CK5/6) \\
\hline
\end{tabular} & M; D5/16B4/Dako & $1: 200$ & $0.1 \%$ Pronase, TA, 15 min \\
\hline
\end{tabular}

Panela de pressão: Tampão com citrato ( $\mathrm{pH}$ 6) (Tender Cooker, Nordic Wave, USA). Microondas: Tampão com citrato ( $\mathrm{pH}$ 6), 15 min (Electrolux, 900 W); R: rabbit monoclonal antibody; M: mouse monoclonal antibody; TA: Temperatura Ambiente; Thermo Scientific: Fremont, CA, EUA; Dako, Carpinteria, CA, USA; Zymed: São Francisco, CA, EUA. 
Tabela 3. Critérios utilizados para a classificação molecular aproximada de acordo com o painel imuno-histoquímico.

\begin{tabular}{lcccc}
\hline \multirow{2}{*}{$\begin{array}{l}\text { Subtipo } \\
\text { Molecular }\end{array}$} & \multicolumn{4}{c}{ Perfil Imuno-histoquímico } \\
\cline { 2 - 5 } & RE e/ou RP & HER2 & Ki-67 & CK5/6 e/ou EGFR \\
\hline Luminal A & + & - & $<14 \%$ & $+/-$ \\
Luminal B/HER2- & + & - & $\geq 14 \%$ & $+/-$ \\
HER2 & - & + & Qualquer & $+/-$ \\
Luminal B/HER2+ & + & + & Qualquer & $+/-$ \\
Basal-like & - & - & Qualquer & + \\
Triplo negativo & - & - & Qualquer & - \\
\hline
\end{tabular}

Abreviações: RE, receptor de estrógeno; RP, receptor de progesterona; CK, citoceratina; EGFR, epidermal growth factor receptor. Modificado de 12th St Gallen subtype classification $^{41}$ 


\subsection{Análise estatística}

As associações entre as variáveis foram testadas com base na estatística quiquadrado de Pearson calculado a partir da função de máxima verossimilhança. A comparação do tamanho mediano dos tumores por classificação molecular foi feita com base na técnica ANOVA. O método de Bonferroni foi aplicado para identificar que classes diferiam das demais. Tábuas de vida foram calculadas para obtenção das curvas de sobrevida das pacientes segundo a classificação molecular. As curvas de sobrevida foram comparadas por meio da metodologia de Kaplan \& Meier, usando um teste de Breslow para analisar as diferenças significativas entre as curvas dos grupos. O nível de significância adotado para os testes foi de 5\%. Todos os níveis descritivos foram calculados e apresentados no texto. 
4. Resultados 


\subsection{Características clínicas e patológicas}

De um total de 39.210 casos de câncer de mama diagnosticados em nossa instituição entre 2003 e 2012, foram identificados 149 pacientes com idade igual ou inferior a 25 anos, correspondendo a $0,4 \%$ de todos os casos. Nas pacientes desse grupo etário, a idade mediana foi de 24 anos (7-25 anos). A idade mediana de todos os casos de câncer de mama nesse mesmo período foi de 54 anos. Deve-se enfatizar, contudo, que essa elevada proporção de câncer de mama em pacientes muito jovens pode estar relacionada a um viés de seleção, pois este laboratório serve de centro de referência para serviços de patologia, consultas de segunda opinião e estudos imuno-histoquímicos para instituições privadas, públicas e acadêmicas de todas as regiões geográficas do Brasil. Por outro lado, a amostra de pacientes neste estudo é muito representativa de todas as regiões geográficas brasileiras e inclui casos do distrito federal e mais 23 dos 26 estados brasileiros em 58 diferentes cidades.

Na Tabela 4 encontram-se descritas as principais características clinicopatológicas dos casos de câncer de mama desta coorte. História de gestação foi obtida em apenas 21 pacientes. Dez pacientes desenvolveram câncer de mama após terem tido gestação e 11 pacientes não referiam história de gravidez. O seguinte número de gestações estava presente: um paciente - 03 gestações, quatro pacientes - 02 gestações, duas pacientes - 01 gestação e em três pacientes não foi possível obter o número de gestações. Nenhuma paciente estava grávida no momento do diagnóstico de câncer. História familiar foi obtida para 19 pacientes. Apenas 02 pacientes relatavam história de câncer de mama em parentes de primeiro grau. Outras 02 pacientes referiam história de câncer de mama em outros membros da família (prima e tia-avó). 
A distribuição de casos com componentes in situ e invasivo foi a seguinte: $8,7 \%$ (13/149) dos casos apresentaram-se como doença apenas in situ [(11 carcinomas ductais in situ (CDIS) e 2 carcinomas lobulares in situ (CLIS)] e 91,3\% (136/149) eram carcinomas invasivos. Cento e vinte e cinco de todos os carcinomas invasivos eram do tipo ductal [91,9\% (125/136) de todos os carcinomas invasivos]. Sessenta e dois casos [45,6\% (62/136) de todos os carcinomas invasivos] apresentavam grau III histológico. Informações sobre tamanho tumoral foram obtidas em 68 carcinomas invasivos e encontrou-se um tamanho tumoral mediano de 2,7 cm $(0,3-11,0 \mathrm{~cm})$.

\subsection{Características imuno-histoquímicas e subtipos moleculares}

Classificação molecular aproximada foi completada em 96 carcinomas invasivos, com os seguintes resultados: Luminal A: 8,3\% (8/96), Luminal B/HER2-: 33,3\% (32/96), HER2+: 11,5\% (11/96), Luminal B/HER2+: 19,8\% (19/96), Basal-like: 11,5\% (11/96) e Triplo Negativo: 15,6\% (15/96). Receptor de estrógeno foi positivo em 59,6\% (62/104) dos casos e superexpressão de HER2 (escore 3+ e/ou FISH com relação $\geq 2.0)$ foi observada em $32,8 \%$ (43/131) dos casos de carcinomas invasivos. 


\subsection{Dados de tratamento e seguimento}

Dados sobre procedimento cirúrgico estavam disponíveis em 46 casos de carcinomas invasivos. Mastectomia total foi o procedimento cirúrgico mais comumente realizado $(65,2 \%$; 30/46). Informações sobre a realização de quimioterapia foram coletadas de 47 pacientes. Quarenta e quatro dessas pacientes receberam quimioterapia $(93,6 \% ; 44 / 47)$. Os esquemas de quimioterapia mais frequentes foram taxanos associados a antraciclinas $(56,4 \% ; 22 / 39)$, baseados em antraciclinas $(12,8 \% ; 5 / 39)$ [incluindo FAC (fluorouracil, doxorrubicina/adriamicina, ciclofosfamida; 3 pacientes), FEC (fluorouracil, epirrubicina, ciclofosfamida; 1 paciente) e 4AC (doxorrubicina/adriamicina and ciclofosfamida; 1 paciente)], baseados em taxano $(10,3 \% ; 4 / 39)$ e baseados em CMF [ciclofosfamida, metotrexato and fluorouracil $(5,1 \%$; 2/39)]. Informações sobre quimioterapia neoadjuvante foram obtidas em 32 casos. Nessas pacientes, quimioterapia neoadjuvante foi administrada em 50,0\% (16/32). Nos tumores HER2-positivos, informações sobre realização de terapia anti-HER2 foram obtidas em 15 casos, sendo realizada em 73,3\% desses casos (11/15). Trinta e oito pacientes receberam radioterapia $(84,4 \%$; $38 / 45$ mulheres com informações disponíveis).

Dados de seguimento revelaram que 38 pacientes desenvolveram metástases para linfonodos axilares $(62,3 \% ; 38 / 61$ carcinomas invasivos) e $22(52,4 \% ; 22 / 42$ carcinomas invasivos) desenvolveram metástases à distância. Os sítios de metástases mais comuns foram ossos $(23,8 \% ; 10 / 42)$, cérebro $(16,7 \% ; 7 / 42)$, fígado $(16,7 \% ; 7 / 42)$ e pulmões $(9,5 \% ; 4 / 42)$. Dezesseis pacientes apresentaram óbito relacionado ao tumor (34.0\%; 16/47), com um seguimento mediano de 39 meses (6-131 meses). 
Tabela 4. Características clinico-patológicas do câncer de mama em mulheres muito jovens ( $\leq 25$ anos)

\begin{tabular}{|c|c|}
\hline Variável & $\mathrm{N}(\%)$ \\
\hline \multicolumn{2}{|l|}{ História de gestação $(\mathrm{N}=21)$} \\
\hline Gestação antes do diagnóstico de câncer & $10(47,6)$ \\
\hline História negativa para gestação & $11(52,4)$ \\
\hline \multicolumn{2}{|l|}{ História Familiar de Câncer de Mamar (N=19) } \\
\hline Câncer de mama em mãe ou irmã & $2(10,5)$ \\
\hline Câncer de mama em outros membros familiares & $2(10,5)$ \\
\hline Negativa & $15(79,0)$ \\
\hline \multicolumn{2}{|l|}{ Subtipos histológicos $(\mathrm{N}=149)$} \\
\hline Carcinoma ductal in situ* & $11(7,4)$ \\
\hline Carcinoma lobular in situ* & $2(1,3)$ \\
\hline Carcinoma ductal invasivo & $125(83,9)$ \\
\hline Carcinoma invasivo com características medulares & $4(2,7)$ \\
\hline Outros subtipos de carcinoma invasivo $* *$ & $7(4,7)$ \\
\hline \multicolumn{2}{|l|}{ Grau Histológico $(\mathrm{N}=136)$} \\
\hline Grau I & $15(11,0)$ \\
\hline Grau II & $59(43,4)$ \\
\hline Grau III & $62(45,6)$ \\
\hline \multicolumn{2}{|l|}{ Tamanho do tumor $(\mathrm{N}=68)$} \\
\hline$\leq 2 \mathrm{~cm}$ & $21(30,9)$ \\
\hline$>2 \mathrm{~cm} \mathrm{e} \leq 5 \mathrm{~cm}$ & $30(44,1)$ \\
\hline$>5 \mathrm{~cm}$ & $17(25,0)$ \\
\hline
\end{tabular}




\begin{tabular}{|c|c|}
\hline Classificação Molecular (N=96) & \\
\hline Luminal A & $8(8,3)$ \\
\hline Luminal B/HER2- & $32(33,3)$ \\
\hline HER2 & $11(11,5)$ \\
\hline Luminal B/HER2+ & $19(19,8)$ \\
\hline Basal-like & $11(11,5)$ \\
\hline Triplo negativo & $15(15,6)$ \\
\hline Receptor de estrógeno $(\mathrm{N}=104)$ & \\
\hline Positivo & $62(59,6)$ \\
\hline Negativo & $42(40,4)$ \\
\hline HER2 $(\mathrm{N}=131)^{* * *}$ & \\
\hline Positivo & $43(32,8)$ \\
\hline Negativo & $88(67,2)$ \\
\hline Procedimento Cirúrgico $* * * *(\mathrm{~N}=46)$ & \\
\hline Mastectomia total & $30(65,2)$ \\
\hline Tratamento cirúrgico conservador & $13(28,3)$ \\
\hline Procedimento cirúrgico não realizado & $3(6,5)$ \\
\hline Quimioterapia (N=47) & \\
\hline Sim & $44(93,6)$ \\
\hline Não & $3(6,4)$ \\
\hline Terapia neoadjuvante $(\mathrm{N}=32)$ & \\
\hline Sim & $16(50,0)$ \\
\hline Não (apenas terapia adjuvante) & $16(50,0)$ \\
\hline
\end{tabular}


Esquema de quimioterapia $(\mathrm{N}=39)$

Taxano associado a antraciclinas

$22(56,4)$

Baseado em antraciclinas

Baseado em taxano

Baseado em CMF

$2(5,1)$

Outros

$6(15,4)$

Terapia anti-HER2 $(\mathrm{N}=15)$

Sim

$11(73,3)$

Não

$4(26,7)$

Radioterapia ( $\mathrm{N}=45)$

Sim

$38(84,4)$

Não

$7(15,6)$

Status de linfonodos $(\mathrm{N}=61)$

Ausência de metástases

$23(37,7)$

Presença de metástases

$38(62,3)$

Metástase à distância $(\mathrm{N}=42)$

Ausente

$20(47,6)$

Presente

$22(52,4)$

Ossos

$10(23,8)$

Cérebro

$7(16,7)$

Fígado

$7(16,7)$

Pulmão

$4(9,5)$

Outros*****

$3(7,1)$ 
Dados de seguimento $(\mathrm{N}=47)$

Vivo sem tumor

$23(48,9)$

Vivo com recorrência local

Vivo com metástase à distância

$6(12,8)$

Óbito relacionado ao tumor

$16(34,0)$

*Ausência de carcinoma infiltrante; **Outros subtipos de carcinomas invasivos incluem apócrino, carcinoma ductal in situ com microinvasão, lobular, metaplásico, mucinoso, misto mucinoso e lobular e carcinoma secretório (um caso para cada um desses subtipos); ***Por imuno-histoquímica ou FISH; ****Mastectomia total: remoção de todo o tecido mamário, geralmente incluindo o mamilo e aréola; Tratamento cirúrgico conservador: inclui "mastectomia parcial", "segmentectomia", and "quadrantectomia"; *****Outros inclui linfonodos não regionais ( 2 casos) e ignorado (1 caso).

Tamanho tumoral foi significativamente maior para tumores associados com os grupos de classificação HER2 e Triplo Negativos ( $p<0,001$; tabela 5). Observou-se também associação significativa entre classificação molecular e grau histológico ( $p<0,001$; tabela 6). Entretanto, não se observou associação significativa entre classificação molecular e metástases para linfonodos axilares, metástases à distância e/ou óbito relacionado ao tumor. Por outro lado, sobrevida geral diferiu significativamente entre os grupos de classificação molecular. Análise estatística utilizando teste de Breslow para analisar as diferenças significantes entre os grupos revelou que as curvas de sobrevida dos grupos HER2 e Basal-like tiveram expectativa de vida geral de $<24$ meses (Breslow $=22,16$, p $<0,001$; tabela 7 e figura 2). 
Tabela 5. Relação entre tamanho tumoral e grupos moleculares

\begin{tabular}{lccccccc}
\hline \multicolumn{1}{c}{$\begin{array}{c}\text { Classificação } \\
\text { Molecular }\end{array}$} & N & Média & $\begin{array}{c}\text { Desvio } \\
\text { Padrão }\end{array}$ & LI & LS & Mínimo & Máximo \\
\hline Luminal A & 5 & 2,38 & 2,01 & $-0,11$ & 4,87 & 0,8 & 5,80 \\
Luminal B/HER2- & 11 & 2,05 & 0,70 & 1,59 & 2,52 & 0,7 & 3,00 \\
HER2 & 5 & 7,34 & 2,49 & 4,25 & 10,42 & 4,00 & 10,00 \\
Luminal B/HER2+ & 11 & 2,45 & 1,35 & 1,54 & 3,35 & 0,9 & 5,20 \\
Basal-like & 5 & 2,78 & 1,71 & 0,65 & 4,91 & 0,3 & 5,00 \\
Triplo Negativo & 9 & 4,91 & 2,73 & 2,82 & 7,01 & 1,40 & 10,00 \\
\hline Total & 46 & 3,40 & 2,45 & 2,67 & 4,12 & 0,3 & 10 \\
\hline
\end{tabular}

Método de Bonferroni indicou diferenças significantes entre os tamanhos tumorais médios dos grupos HER2 e Triplo Negativos em relação aos outros grupos $(\mathrm{F}=8,006$, $\mathrm{p}<0,001)$. 
Tabela 6. Relação entre grau histológico e grupos moleculares

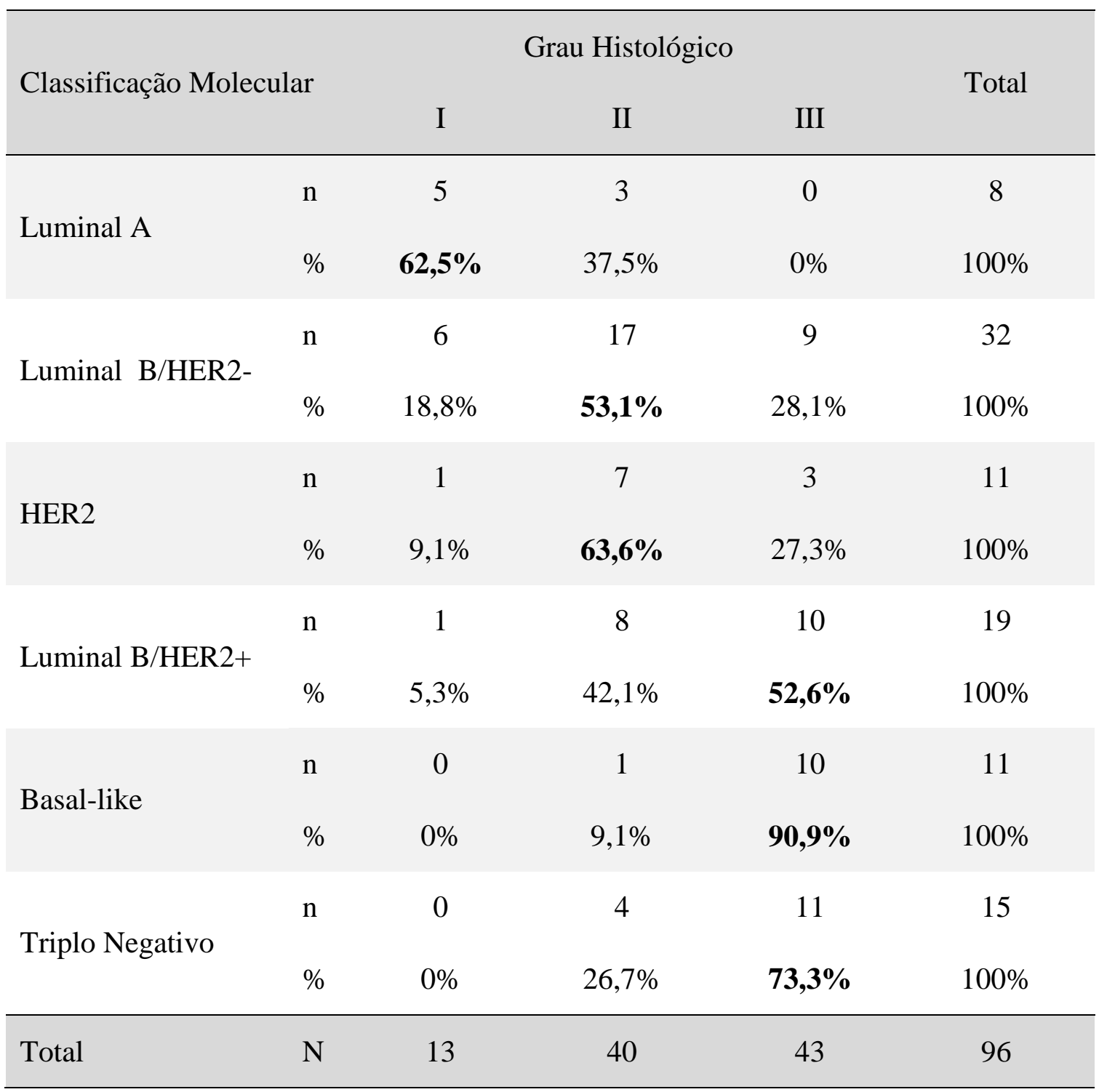

Observou-se associação significativa entre classificação molecular e grau histológico $\left(\chi^{2}=40.496, p<0,001\right)$. 
Tabela 7. Sobrevida geral de acordo com os grupos moleculares

\begin{tabular}{lcc} 
Classificação Molecular & Tempo de Sobrevida Geral (meses) & IC 95\% \\
\hline Luminal A & Não Estimável & - \\
Luminal B/HER2- & 99 & {$[71---127]$} \\
HER2 & 20 & {$[18---22]$} \\
Luminal B/HER2+ & 78 & {$[71---84]$} \\
Basal-like & 22 & {$[16---28]$} \\
Triplo Negativo & Não Estimável
\end{tabular}

Tempo de sobrevida geral diferiu significativamente entre os grupos (vide disjunção nos intervalos de confiança para os grupos HER2 e Basal-like). Tempo de sobrevida geral não pôde ser estimada para os grupos Luminal A e Triplo Negativo porque $>50 \%$ das pacientes permaneceram vivos durante o período de seguimento. 


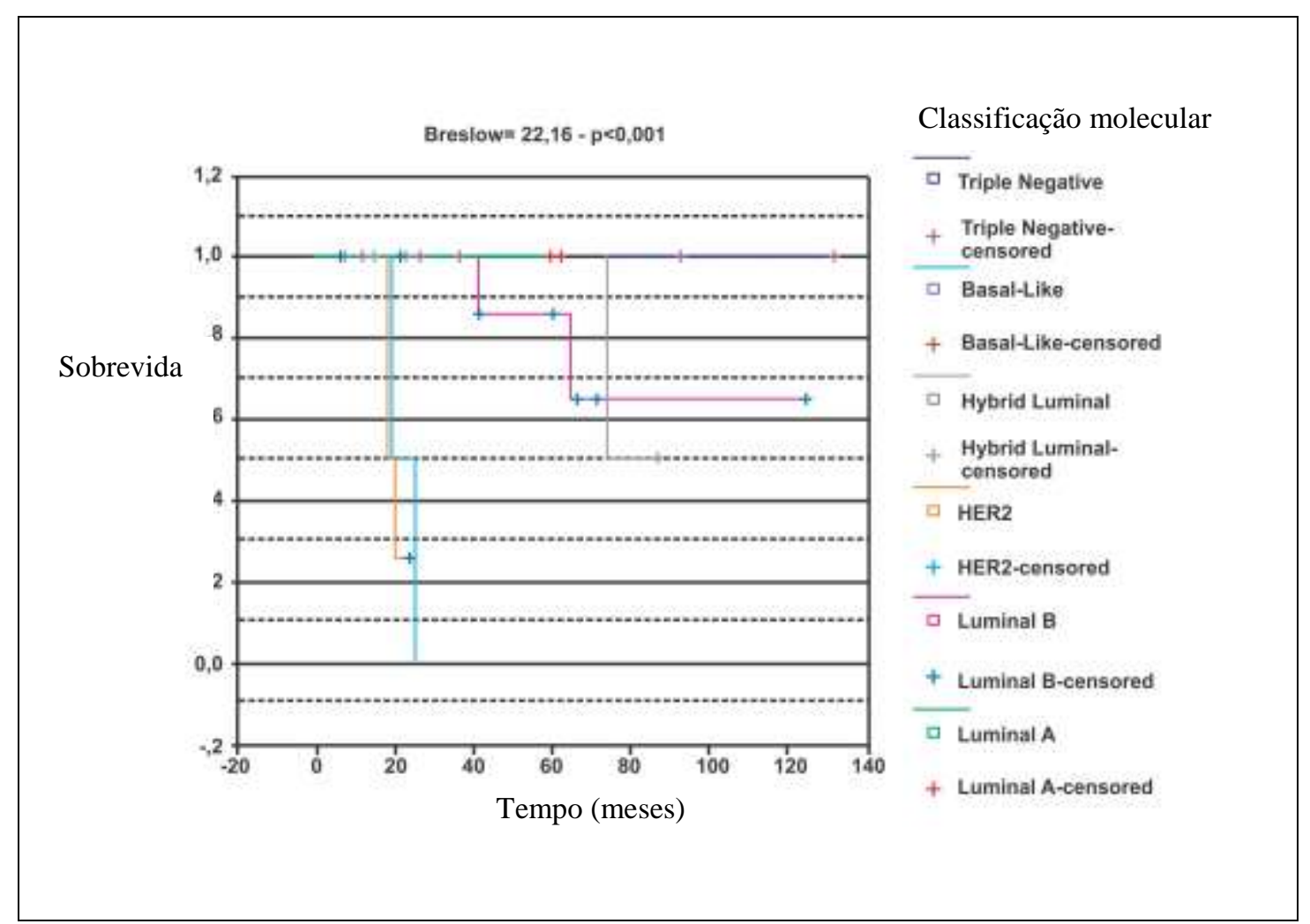

Figura 2. Sobrevida geral das pacientes de acordo com os grupos moleculares 
5. Discussão 
Poucos estudos na literatura têm avaliado o câncer de mama em mulheres muito jovens ( $\leq 25$ anos). Nesses poucos estudos, o número de casos é em geral pequeno para conclusões relevantes sobre os achados clínicos, patológicos e imuno-histoquímicos 37,42-47. De maneira resumida, são as seguintes as poucas publicações na literatura sobre o assunto: Simmons et al., selecionaram 12 pacientes $<25$ anos com diagnóstico de câncer de mama entre 1935 e 2005 em Olmsted County, MN, EUA ${ }^{37}$. Os autores encontraram incidência de câncer de mama ajustada para a idade de 3,2 por milhão para essa faixa etária. Aceto et al. relataram apenas 5 pacientes argentinas até 25 anos de idade com câncer de mama ${ }^{42}$. Khotari et al. avaliaram 15 casos de mulheres com câncer de mama diagnosticado nesta faixa etária no Hospital Guy, Londres, Inglaterra ${ }^{43}$. Paillocher et al. descreveram 13 pacientes <25 anos diagnosticadas entre 1977 e 2005 no Serviço de Ginecologia e Obstetrícia, França ${ }^{44}$. Cancello et al. encontraram 22 pacientes com menos de 25 anos de idade de um total de 497 casos consecutivos de câncer de mama em mulheres com menos de 35 anos operadas no renomado Instituto Europeu de Oncologia, Milão, Itália ${ }^{45}$. Alipour et al selecionaram 50 pacientes diagnosticadas com carcinoma de mama com até 25 anos de idade, de um total de 5.265 casos de câncer de mama diagnosticados entre 1979 e 2012 em Teerã, Iran ${ }^{47}$. Como há indícios de que a idade possa representar um importante papel no comportamento biológico do câncer de mama, decidimos estudar as características clinicopatológicas e imuno-histoquímicas em um número relativamente grande de pacientes muito jovens (até 25 anos de idade) com câncer de mama.

Em relação às características patológicas dos tumores encontrados em pacientes muito jovens, em nosso estudo, o tamanho mediano dos tumores foi de 2,7 cm (0,3-11,0 $\mathrm{cm}$ ) e $69,1 \%$ dos tumores mediam mais que $2 \mathrm{~cm}$. Esses resultados são similares aos 
obtidos em outros estudos do mesmo grupo etário, com tamanhos medianos de 2,0 cm (variando entre 1,0 e $13,0 \mathrm{~cm}){ }^{43} ; 4,0 \mathrm{~cm}(0,7-10,0 \mathrm{~cm}){ }^{37} ; 2,8 \mathrm{~cm}^{44} ; 2,5 \mathrm{~cm}(2,3-4,5$ $\mathrm{cm})^{42}$ and $5,7 \mathrm{~cm}^{47}$. Em outros estudos envolvendo mulheres mais jovens que 35 anos de idade com câncer de mama, a frequência de pacientes com tumores medindo $>2,0 \mathrm{~cm}$ varia entre $47,9 \%$ e $84,3 \%{ }^{32,48-51}$. Na Coréia do Sul, Ahn et al. encontraram que $65,9 \%$ (940/1.427) das pacientes <35 anos de idade tinham tumores $>2,0 \mathrm{~cm}$ em comparação a $60,1 \%(5.021 / 8.359)$ das pacientes com idade entre 35 e 50 anos ${ }^{52}$. Acredita-se que uma importante razão para o desenvolvimento de tumores maiores em pacientes jovens é a ausência de programas de triagem nessa população. Detecção precoce poderia reduzir o tamanho dos tumores ao diagnóstico, que por sua vez poderia levar a redução da mortalidade em mulheres jovens ${ }^{53}$. O Ministério da Saúde/INCA recomenda que exame clínico da mama seja realizado em mulheres acima de 40 anos de idade e que mamografias sejam realizadas em mulheres com mais de 50 anos. Até mesmo para mulheres pertencentes a grupos de alto risco para câncer de mama, a recomendação é de iniciar triagem em mulheres a partir dos 35 anos de idade ${ }^{54}$.

Sobre os tipos e graus histológicos, encontramos que a vasta maioria dos nossos casos eram do tipo carcinoma ductal invasivo [91,9\% (125/136)] sendo o grau III o mais frequente $[45,6 \%(62 / 136)]$. Apenas um carcinoma invasivo era do tipo lobular $(0,7 \% ; 1 / 136)$. Nossos resultados são diferentes quando comparados aos dados obtidos para a população geral com câncer de mama, que revela uma frequência de carcinoma ductal invasivo entre $56 \%$ e $80 \%$ dos casos ${ }^{55-57}$ e de carcinoma lobular invasivo entre 5 e $15 \%{ }^{14}$. Essa elevada frequência do tipo ductal e raridade do tipo lobular em mulheres jovens também tem sido observada em outros estudos. Cancello et al. observaram em sua série que 89,8\% (283/315) dos casos de câncer de mama em mulheres <35 anos 
eram do tipo ductal [versus 79,7\% (2115/2655) dos casos em pacientes $\geq 35$ anos $(\mathrm{p}<0,0001)]$. Apenas 2,2\% dos casos nas pacientes jovens eram do tipo lobular (versus 9,3\% em mulheres mais velhas) ${ }^{32}$. Bacchi et al., em sua série de 120 mulheres com câncer de mama $\leq 35$ anos, observaram que 97,5\% dos casos eram do tipo ductal (em comparação a $86,9 \%$ mulheres $\geq 60$ anos) e $2,5 \%$ eram do tipo lobular (em comparação a $9,8 \%$ no grupo de mulheres mais velhas) ${ }^{58}$. Rapiti et al. encontraram resultados semelhantes, com 89\% (73/82) dos casos em mulheres $\leq 35$ anos apresentando carcinomas do tipo ductal ${ }^{59}$. É sabido que existe uma associação entre idade jovem e alto grau histológico 32,49,50,59,60. Cancello et al., estudando pacientes <35 anos, encontraram que mulheres muito jovens $(<25$ anos) têm frequência significativamente maior de tumores grau III histológico (81.8\%) se comparadas a pacientes de 25 a 29 anos $(66,7 \%)$ e de 30 a 34 anos $(56,5 \%){ }^{45}$. Paluch-Shimon et al. observaram que $57 \%$ (35/61) das pacientes $\leq 35$ anos apresentavam tumores grau III histológico [versus 33\% (31/94) em mulheres entre 37 - 44 anos) ${ }^{49}$. Colleoni et al., avaliando 134 pacientes diagnosticadas com câncer de mama $<35$ anos, identificaram que 61,9\% eram grau III (em relação a 37,4\% em mulheres entre $35-50$ anos) ${ }^{60}$. Segundo dados da literatura, uma base genética pode responder pela prevalência de tumores de alto grau em mulheres jovens ou muito jovens. Mutações germline em BRCA1, BRCA2 e TP53 representam importantes fatores associados a início precoce de câncer de mama e levam a uma frequência aumentada de tumores de alto grau ${ }^{29}$.

Em nosso estudo, 8,7\% das pacientes apresentaram apenas carcinomas não invasivos (11 CDIS e 2 CLIS). Resultados similares foram obtidos por Rosen et al. (8\% dos tumores - 10 CDIS e 2 CLIS) ${ }^{61}$ e Kothari et al. $(13 \%){ }^{43}$. Em contraste, estima-se que nos EUA, 60.290 novos casos de carcinoma in situ de mama (20,6\% de todos os 
carcinomas de mama) serão diagnosticados na população geral em $2015^{1}$. Carcinomas in situ não são diagnosticados comumente em mulheres jovens e, nos EUA, apenas $3 \%$ dos CDIS são diagnosticados em pacientes abaixo dos 40 anos de idade ${ }^{62}$. Essa diferença está relacionada à não triagem mamográfica com biópsia de lesões mamograficamente suspeitas nessa faixa etária ${ }^{63}$.

Receptor de estrógeno foi expresso em 59,6\% (62/104) dos nossos casos. Positividade para RE é observada em menor frequência nas mulheres muito jovens quando comparada com mulheres mais velhas. Kothari et al, analisando pacientes $\leq 25$ anos e comparando com pacientes mais velhas, observaram expressão de RE em 8 de 13 pacientes com carcinoma invasivo (62\%) versus $68 \%$ em pacientes entre 46 e 55 anos e $75 \%$ em pacientes entre 56 e 65 anos de idade ${ }^{43}$. Por outro lado, Cancello et al encontraram distribuição semelhante na expressão de RE em subgrupos etários de mulheres jovens. No subgrupo de mulheres $<25$ anos, foi observada expressão de RE em 18/22 pacientes $(81,8 \%)$, no de mulheres entre $25-29$ anos, observou-se expressão de $\mathrm{RE}$ em $82 / 123$ pacientes $(66,7 \%)$ e no subgrupo de mulheres entre 30 e 34 anos, houve expressão de RE em 271/352 (77,0\%) ${ }^{45}$.

Encontramos uma frequência muito elevada de superexpressão de HER2 em carcinomas invasivos $(32,8 \%$; 43/131). Na população geral com câncer de mama, superexpressão de HER2 é observada em $15 \%$ a $20 \%$ das pacientes ${ }^{18}$. A maioria dos estudos demonstra menor frequência de superexpressão de HER2 em mulheres mais velhas quando comparadas com pacientes mais jovens $5,29,32,52,58,60,64$. Por outro lado, Colleoni et al não observaram diferenças significativas na superexpressão de HER2 entre pacientes jovens (<35 anos) e menos jovens (35-50 anos): 39,7\% versus $37,4 \%$ $(\mathrm{p}=0,741)^{60}$. Cancello et al. encontraram que a superexpressão de HER2 é maior em 
pacientes jovens em relação a pacientes mais velhas [21\% (66/315) em $<35$ anos versus $14,5 \%(385 / 2655)$ em $\geq 35$ anos; $p=0,003){ }^{32}$. Entretanto, quando os mesmos autores compararam 3 subgrupos diferentes de mulheres jovens, não foram observadas diferenças significantes na superexpressão de HER2: <25 anos, 25-29 anos e 30-34 anos). Uma possível razão para esses achados é o pequeno número de pacientes $<25$ anos (apenas 22 mulheres) desse estudo ${ }^{45}$. Esses dados sugerem que o gene $H E R 2$ pode desempenhar importante papel em considerável número de casos de câncer de mama em mulheres jovens.

Cancello et al. investigaram o prognóstico de 315 pacientes jovens (abaixo dos 35 anos) em comparação com 2.655 pacientes mais velhas pre-menopáusicas (com idade entre 35 e 50 anos) utilizando uma classificação imuno-histoquímica ${ }^{32}$. Menor número de tumores identificados como Luminal A foram encontrados no grupo de pacientes $<35$ anos de idade $(9,2 \%$ versus $21,2 \%)$, além de maior número de tumores Triplo Negativos $(16,2 \%$ versus $7,5 \%)$, quando comparados com pacientes mais velhas. Em comparação, nossos resultados mostraram uma frequência similar de casos Luminal A $(8,3 \% ; 8 / 96)$, mas uma maior proporção de casos negativos para RE, RP e HER2 (triplo negativos); 27,1\% (26/96). Collins et al. encontraram proporção maior de casos Luminal A $(29,8 \%)$ em pacientes $\leq 30$ anos mas uma proporção semelhante de casos Triplo Negativos $(23,4 \%){ }^{65}$. Nosso grupo já relatou previamente uma maior prevalência de casos Luminal A [22,5\% (48/213)] e Triplo Negativos [34,7\% (74/213)] em mulheres jovens $\leq 35$ anos de idade ${ }^{58}$. Na presente série, também demonstramos em curvas de sobrevida que os grupos de classificação molecular HER2 e Basal-like tiveram curso clínico pior que o grupo Luminal A, com expectativa de sobrevida geral de $<24$ meses. Achados semelhantes foram previamente descritos por outros estudos 
envolvendo todos os grupos etários ${ }^{66,67}$. García Fernandez et al, avaliando 1.167 pacientes operadas para 1.191 carcinomas, observaram que pacientes $<50$ anos tinham incidência significativamente maior de tumores ER+/RP+/HER2- e de Triplo Negativos. Os grupos HER2 e Triplo Negativo destacaram-se por sua pior sobrevida livre de neoplasia, maior taxa de metástases à distância e menor sobrevida geral em cinco anos ${ }^{66}$.

Tratamento cirúrgico conservador (TCC) para câncer de mama em mulheres jovens ainda é controverso. Por um lado, não se observa risco aumentado de óbito entre mulheres que recebem TCC quando comparadas com mulheres submetidas a mastectomia radical independente da idade ao diagnóstico e idade jovem ao diagnóstico aparentemente não precisa ser uma contraindicação para TCC ${ }^{68,69}$. Por outro lado, mulheres $\leq 35$ anos de idade submetidas ao TCC estão em maior risco de recorrência local que mulheres mais velhas ${ }^{70-72}$. Kroman et al, investigando uma amostra de 9.285 mulheres pré-menopáusicas ( $<50$ anos ao diagnóstico de carcinoma de mama) observaram que $77,2 \%$ foram tratadas com mastectomia total e $22,8 \%$ com TCC. Não houve aumento no risco de óbito entre mulheres que receberam TCC em comparação às mulheres submetidas a mastectomia total, independente da idade, apesar do maior risco de recorrência local em mulheres jovens $(<35$ anos) em comparação às pacientes entre 45-49 anos ${ }^{68}$. No $13^{\circ}$ St Gallen International Breast Cancer Conference, foi recomendado que em mulheres jovens ( $<35$ anos), cirurgia conservadora deveria ser realizada com cautela, pois pode aumentar o risco de recorrência ${ }^{73}$. No presente estudo, o procedimento cirúrgico inicial mais comum foi mastectomia total $(65,2 \%$; $30 / 46)$, seguida de TCC $(28,3 \% ; 13 / 46)$. Três casos $(6,5 \% ; 3 / 46)$ eram irressecáveis. Han et al. realizaram estudo incluindo 351 mulheres $<30$ anos de idade com câncer de mama e 
encontraram resultados semelhantes com $64.1 \%$ (221/345) das mulheres $<30$ anos de idade sendo submetidas a mastectomia total. Os autores desse estudo destacaram que a proporção de pacientes submetidas a TCC foi maior no grupo mais jovem $(35,9 \%$ em $<30$ anos) que no grupo de pacientes mais velhas $(24,8 \%$ em entre 40 e 50 anos de idade) ${ }^{33}$.

Em nosso estudo, 34,0\% das pacientes com seguimento disponível apresentaram óbito relacionado do tumor (16/47), com seguimento mediano de 39 meses (6-131 meses). No Brasil, o INCA estima em $80 \%$ a sobrevida em 5 anos de pacientes com câncer de mama ${ }^{3}$. Idade jovem é preditor independente de óbito em análise multivariada ${ }^{31,48,50}$. Em uma série com 346 pacientes $<35$ anos com câncer de mama, Livi et al. encontraram resultados semelhantes aos nossos, com $62 \%$ das pacientes vivas após 6,8 anos de seguimento mediano. Eles também observaram que pacientes <30 anos tiveram pior prognóstico que pacientes com idade entre 30-35 anos ${ }^{48}$. Dubsky et al. compararam retrospectivamente 804 pacientes $>35$ anos de idade com 81 mulheres $\leq 35$ anos e encontraram um risco relativo de morte de 2,2 para o grupo mais jovem ${ }^{31}$. Fredholm et al, observando retrospectivamente 471 mulheres com idade entre 20-34 anos à época do diagnóstico de câncer de mama (realizado entre 1992 e 2005), encontraram que $26 \%$ foram a óbito até o final de 2006. Após análise multivariada, mulheres nesse grupo etário com doença em estadios I, IIa e IIb apresentaram sobrevida relativa pior que mulheres mais velhas (entre 50 e 69 anos) ${ }^{50}$. 
6. Conclusões 
Os resultados obtidos neste estudo levaram às seguintes conclusões:

1. A frequência de câncer de mama em mulheres brasileiras muito jovens ( $\leq 25$ anos) correspondeu a $0,4 \%$ de todos os casos de câncer de mama no período estudado;

2. As pacientes deste estudo apresentaram idade mediana de 24 anos. Das 21 pacientes com história gestacional disponível, 10 desenvolveram câncer de mama após terem tido gestação. De 19 pacientes com história familiar disponível, 02 relatavam história de câncer de mama em parentes de primeiro grau e outras 02 pacientes referiam história de câncer de mama em outros membros familiares.

3. O tamanho mediano dos tumores foi de $2,7 \mathrm{~cm}$, com $69,1 \%$ dos tumores medindo mais que $2 \mathrm{~cm}$. Carcinoma ductal invasivo foi o tipo histológico mais prevalente $(91,9 \%$ de todos os carcinomas invasivos) e o grau histológico mais frequente foi grau III $(45,6 \%)$.

4. Receptor de estrógeno foi positivo em $59,6 \%$ e superexpressão de HER2 foi observada em 32,8\% dos casos de carcinomas invasivos. Classificação molecular aproximada apresentou a seguinte predomínio dos subtipos Luminal B/HER2-: 33,3\%, Luminal B/HER2+: 19,8\% e Triplo Negativo: 15,6\%.

5. Dos procedimentos cirúrgicos, a mastectomia total foi o procedimento cirúrgico mais comumente realizado $(65,2 \%)$. 93,6\% das pacientes receberam quimioterapia e o esquema de quimioterapia mais frequente foi Taxanos associados a Antraciclinas (56,4\%). 84,4\% receberam radioterapia.

6. Metástase linfonodal foi observada em 62,3\% (linfonodos axilares); Mais da metade das pacientes com informações sobre doença metastática apresentaram 
metástase à distância $(52,4 \%)$. 34,0\% apresentaram óbito relacionado ao tumor, com um seguimento mediano de 39 meses (6-131 meses). As curvas de sobrevida dos grupos HER2 e Basal-like revelaram pior curso clinico, com expectativa de vida geral de $<24$ meses $($ Breslow $=22,16, \mathrm{p}<0,001)$. 
Referências 
1. Siegel RL, Miller KD, Jemal A. Cancer statistics, 2015. CA Cancer J Clin. Jan-Feb 2015;65(1):5-29.

2. Ferlay J, Soerjomataram I, Ervik M, et al. GLOBOCAN 2012 v1.0, Cancer Incidence and Mortality Worldwide: IARC CancerBase No. 11 [Internet]. GLOBOCAN 2012 v1.0 http://globocan.iarc.fr. Accessed 03/27/2014, 2013.

3. Estimativa 2014 - Incidência de Câncer no Brasil. Rio de Janeiro, 2011: Instituto Nacional de Câncer José Alencar Gomes da Silva/ Ministério da Saúde.

4. Howlader N, Noone A, Krapcho M, Garshell J, Neyman N. SEER Cancer Statistics Review, 1975-2010, National Cancer Institute. Bethesda, MD. Bethesda, MD.2013.

5. Bacchi LM, Corpa M, Bacchi CE, Carvalho FM. Pathological and molecular characterization of breast carcinomas of young women. Rev Bras Mastol. AprilJune 2009;19(2):42-46.

6. Johnson RH, Chien FL, Bleyer A. Incidence of breast cancer with distant involvement among women in the United States, 1976 to 2009. JAMA. Feb 27 2013;309(8):800-805.

7. Bouchardy C, Fioretta G, Verkooijen HM, et al. Recent increase of breast cancer incidence among women under the age of forty. $\mathrm{Br} J$ Cancer. Jun 4 2007;96(11):1743-1746. 
8. Pollan M, Pastor-Barriuso R, Ardanaz E, et al. Recent changes in breast cancer incidence in Spain, 1980-2004. J Natl Cancer Inst. Nov 18 2009;101(22):15841591.

9. Mirra AP, Latorre MRDO. Incidência de Câncer no Município de São Paulo. Brasil: 1997-1998. Instituto Nacional de Câncer. Brasília: Ministério da Saúde; 2001.

10. Ortega Jacome GP, Koifman RJ, Rego Monteiro GT, Koifman S. Environmental exposure and breast cancer among young women in Rio de Janeiro, Brazil. $J$ Toxicol Environ Health A. 2010;73(13-14):858-865.

11. Anderson WF, Matsuno RK, Sherman ME, et al. Estimating age-specific breast cancer risks: a descriptive tool to identify age interactions. Cancer Causes Control. May 2007;18(4):439-447.

12. Cleary MP, Maihle NJ. The role of body mass index in the relative risk of developing premenopausal versus postmenopausal breast cancer. Proc Soc Exp Biol Med. Oct 1997;216(1):28-43.

13. Joslyn SA, Foote ML, Nasseri K, Coughlin SS, Howe HL. Racial and ethnic disparities in breast cancer rates by age: NAACCR Breast Cancer Project. Breast Cancer Res Treat. Jul 2005;92(2):97-105.

14. Lakhani SR, Cancer IAfRo. WHO Classification of Tumours of the Breast: International Agency for Research on Cancer; 2012. 
15. Rakha EA, Aleskandarany M, El-Sayed ME, et al. The prognostic significance of inflammation and medullary histological type in invasive carcinoma of the breast. Eur J Cancer. Jul 2009;45(10):1780-1787.

16. Schnitt SJ, Collins LC. Biopsy Interpretation of the Breast: Wolters Kluwer Health; 2012.

17. Hammond ME, Hayes DF, Dowsett M, et al. American Society of Clinical Oncology/College Of American Pathologists guideline recommendations for immunohistochemical testing of estrogen and progesterone receptors in breast cancer. J Clin Oncol. Jun 1 2010;28(16):2784-2795.

18. Wolff AC, Hammond ME, Hicks DG, et al. Recommendations for human epidermal growth factor receptor 2 testing in breast cancer: American Society of Clinical Oncology/College of American Pathologists clinical practice guideline update. J Clin Oncol. Nov 1 2013;31(31):3997-4013.

19. Sorlie T, Perou CM, Tibshirani R, et al. Gene expression patterns of breast carcinomas distinguish tumor subclasses with clinical implications. Proc Natl Acad Sci U S A. Sep 11 2001;98(19):10869-10874.

20. Sorlie T, Tibshirani R, Parker $J$, et al. Repeated observation of breast tumor subtypes in independent gene expression data sets. Proc Natl Acad Sci U S A. Jul 8 2003;100(14):8418-8423. 
21. van 't Veer LJ, Dai H, van de Vijver MJ, et al. Gene expression profiling predicts clinical outcome of breast cancer. Nature. Jan 31 2002;415(6871):530-536.

22. Sotiriou C, Neo SY, McShane LM, et al. Breast cancer classification and prognosis based on gene expression profiles from a population-based study. Proc Natl Acad Sci U S A. Sep 2 2003;100(18):10393-10398.

23. Nielsen TO, Hsu FD, Jensen $K$, et al. Immunohistochemical and clinical characterization of the basal-like subtype of invasive breast carcinoma. Clin Cancer Res. Aug 15 2004;10(16):5367-5374.

24. Livasy CA, Karaca G, Nanda R, et al. Phenotypic evaluation of the basal-like subtype of invasive breast carcinoma. Mod Pathol. Feb 2006;19(2):264-271.

25. Foulkes WD, Stefansson IM, Chappuis PO, et al. Germline BRCA1 mutations and a basal epithelial phenotype in breast cancer. $J$ Natl Cancer Inst. Oct 1 2003;95(19):1482-1485.

26. Carey LA, Perou CM, Livasy CA, et al. Race, breast cancer subtypes, and survival in the Carolina Breast Cancer Study. JAMA. Jun 7 2006;295(21):2492-2502.

27. Evans JP, Skrzynia C, Susswein L, Harlan M. Genetics and the young woman with breast cancer. Breast Dis. 2005;23:17-29. 
28. Lalloo F, Varley J, Moran A, et al. BRCA1, BRCA2 and TP53 mutations in very early-onset breast cancer with associated risks to relatives. Eur J Cancer. May 2006;42(8):1143-1150.

29. Carraro DM, Koike Folgueira MA, Garcia Lisboa BC, et al. Comprehensive analysis of BRCA1, BRCA2 and TP53 germline mutation and tumor characterization: a portrait of early-onset breast cancer in Brazil. PLoS One. 2013;8(3):e57581.

30. Bleyer A, Barr R, Hayes-Lattin B, Thomas D, Ellis C, Anderson B. The distinctive biology of cancer in adolescents and young adults. Nat Rev Cancer. Apr 2008;8(4):288-298

31. Dubsky PC, Gnant MF, Taucher S, et al. Young age as an independent adverse prognostic factor in premenopausal patients with breast cancer. Clin Breast Cancer. 2002;3(1):65-72.

32. Cancello G, Maisonneuve P, Rotmensz N, et al. Prognosis and adjuvant treatment effects in selected breast cancer subtypes of very young women $(<35$ years $)$ with operable breast cancer. Ann Oncol. Oct 2010;21(10):1974-1981.

33. Han W, Kang SY. Relationship between age at diagnosis and outcome of premenopausal breast cancer: age less than 35 years is a reasonable cut-off for defining young age-onset breast cancer. Breast Cancer Res Treat. 2010;119(1):193200. 
34. Anders CK, Hsu DS, Broadwater G, et al. Young age at diagnosis correlates with worse prognosis and defines a subset of breast cancers with shared patterns of gene expression. J Clin Oncol. Jul 10 2008;26(20):3324-3330.

35. Anders CK, Fan C, Parker JS, et al. Breast carcinomas arising at a young age: unique biology or a surrogate for aggressive intrinsic subtypes?: J Clin Oncol. 2011 Jan 1;29(1):e18-20. doi: 10.1200/JCO.2010.28.9199. Epub 2010 Nov 29.

36. Azim HA, Jr., Michiels S, Bedard PL, et al. Elucidating prognosis and biology of breast cancer arising in young women using gene expression profiling. Clin Cancer Res. Mar 1 2012;18(5):1341-1351.

37. Simmons PS, Jayasinghe YL, Wold LE, Melton LJ, 3rd. Breast carcinoma in young women. Obstet Gynecol. Sep 2011;118(3):529-536.

38. Kataoka A, Tokunaga E, Masuda N, Shien $T$, Kawabata K, Miyashita M. Clinicopathological features of young patients ( $<35$ years of age) with breast cancer in a Japanese Breast Cancer Society supported study. Breast Cancer. Apr 162013.

39. Cancer Registration Statistics, England, 2011. The Office for National Statistics. The Office for National Statistics

40. Elston CW, Ellis IO. Pathological prognostic factors in breast cancer. I. The value of histological grade in breast cancer: experience from a large study with long-term follow-up. Histopathology. Sep 2002;41(3A):154-161. 
41. Goldhirsch A, Wood WC, Coates AS, Gelber RD, Thurlimann B, Senn HJ. Strategies for subtypes--dealing with the diversity of breast cancer: highlights of the St. Gallen International Expert Consensus on the Primary Therapy of Early Breast Cancer 2011. Ann Oncol. Aug 2011;22(8):1736-1747.

42. Aceto GM, Solano AR, Neuman MI, et al. High-risk human papilloma virus infection, tumor pathophenotypes, and BRCA1/2 and TP53 status in juvenile breast cancer. Breast Cancer Res Treat. Aug 2010;122(3):671-683.

43. Kothari AS, Beechey-Newman N, D'Arrigo C, et al. Breast carcinoma in women age 25 years or less. Cancer. Feb 1 2002;94(3):606-614.

44. Paillocher N, Lacourtoisie SA, Fondrinier E, et al. [Infiltrating breast cancer in women younger than 25 years: 13 cases]. Presse Med. Nov 2006;35(11 Pt 1):16181624.

45. Cancello G, Maisonneuve P, Mazza M, et al. Pathological features and survival outcomes of very young patients with early breast cancer: how much is "very young"? Breast. Dec 2013;22(6):1046-1051.

46. Alipour S, Omranipour R, Jahanzad I, Bagheri K. Very young breast cancer in a referral center in Tehran, Iran; review of 55 cases aged 25 or less throughout 33 years. Asian Pac J Cancer Prev. 2014;14(11):6529-6532. 
47. Alipour S, Omranipour R, Jahanzad I, Bagheri K. Very young breast cancer in a referral center in Tehran, Iran; review of 55 cases aged 25 or less throughout 33 years. Asian Pac J Cancer Prev. 2013;14(11):6529-6532.

48. Livi L, Meattini I, Saieva C, et al. The impact of young age on breast cancer outcome. Eur J Surg Oncol. Jul 2010;36(7):639-645.

49. Paluch-Shimon S, Wolf I, Sadetzki S, et al. Association between very young age and adverse characteristics of breast cancer at presentation amongst Israeli women. Am J Clin Oncol. Jun 2011;34(3):219-222.

50. Fredholm H, Eaker S, Frisell J, Holmberg L, Fredriksson I, Lindman H. Breast cancer in young women: poor survival despite intensive treatment. PLoS One. 2009;4(11):e7695.

51. El Saghir NS, Seoud M, Khalil MK, et al. Effects of young age at presentation on survival in breast cancer. BMC Cancer. 2006;6:194.

52. Ahn SH, Son BH, Kim SW, et al. Poor outcome of hormone receptor-positive breast cancer at very young age is due to tamoxifen resistance: nationwide survival data in Korea--a report from the Korean Breast Cancer Society. J Clin Oncol. Jun 10 2007;25(17):2360-2368.

53. Narod SA. Age of diagnosis, tumor size, and survival after breast cancer: implications for mammographic screening. Breast Cancer Res Treat. Jul 2011;128(1):259-266. 
54. Controle do Cancer de Mama - Documento de Consenso: Ministério da Saúde; Rio de Janeiro, 2004.

55. Rakha EA, Putti TC, Abd El-Rehim DM, et al. Morphological and immunophenotypic analysis of breast carcinomas with basal and myoepithelial differentiation. J Pathol. Mar 2006;208(4):495-506.

56. Louwman MW, Vriezen $M$, van Beek MW, et al. Uncommon breast tumors in perspective: incidence, treatment and survival in the Netherlands. Int J Cancer. Jul $12007 ; 121(1): 127-135$.

57. Weigelt B, Geyer FC, Reis-Filho JS. Histological types of breast cancer: how special are they? Mol Oncol. Jun 2010;4(3):192-208.

58. Bacchi LM, Corpa M, Santos PP, Bacchi CE, Carvalho FM. Estrogen receptorpositive breast carcinomas in younger women are different from those of older women: a pathological and immunohistochemical study. Breast. Apr 2010;19(2):137-141.

59. Rapiti E, Fioretta G, Verkooijen HM, et al. Survival of young and older breast cancer patients in Geneva from 1990 to 2001. Eur J Cancer. Jul 2005;41(10):14461452.

60. Colleoni M, Rotmensz N, Robertson C, et al. Very young women (<35 years) with operable breast cancer: features of disease at presentation. Ann Oncol. Feb 2002;13(2):273-279. 
61. Rosen PP, Lesser ML, Kinne DW, Beattie EJ. Breast carcinoma in women 35 years of age or younger. Ann Surg. Feb 1984;199(2):133-142.

62. VandenBussche CJ, Elwood H, Cimino-Mathews A, Bittar Z, Illei PB, Warzecha HN. Clinicopathologic features of ductal carcinoma in situ in young women with an emphasis on molecular subtype. Hum Pathol. Nov 2013;44(11):2487-2493.

63. Li CI, Daling JR, Malone KE. Age-specific incidence rates of in situ breast carcinomas by histologic type, 1980 to 2001. Cancer Epidemiol Biomarkers Prev. Apr 2005;14(4):1008-1011.

64. Walker RA, Lees E, Webb MB, Dearing SJ. Breast carcinomas occurring in young women (< 35 years) are different. Br J Cancer. Dec 1996;74(11):1796-1800.

65. Collins LC, Marotti JD, Gelber S, et al. Pathologic features and molecular phenotype by patient age in a large cohort of young women with breast cancer. Breast Cancer Res Treat. 2012;131(3):1061-1066.

66. Garcia Fernandez A, Gimenez N, Fraile M, et al. Survival and clinicopathological characteristics of breast cancer patient according to different tumour subtypes as determined by hormone receptor and Her2 immunohistochemistry. a single institution survey spanning 1998 to 2010. Breast. Jun 2012;21(3):366-373.

67. O'Brien KM, Cole SR, Tse CK, et al. Intrinsic breast tumor subtypes, race, and long-term survival in the Carolina Breast Cancer Study. Clin Cancer Res. Dec 15 2010;16(24):6100-6110. 
68. Kroman N, Holtveg $\mathrm{H}$, Wohlfahrt $\mathrm{J}$, et al. Effect of breast-conserving therapy versus radical mastectomy on prognosis for young women with breast carcinoma. Cancer. Feb 15 2004;100(4):688-693.

69. Zhou P, Recht A. Young age and outcome for women with early-stage invasive breast carcinoma. Cancer. Sep 15 2004;101(6):1264-1274.

70. Kim SH, Simkovich-Heerdt A, Tran KN, Maclean B, Borgen PI. Women 35 years of age or younger have higher locoregional relapse rates after undergoing breast conservation therapy. J Am Coll Surg. Jul 1998;187(1):1-8.

71. Voogd AC, Nielsen M, Peterse JL, et al. Differences in risk factors for local and distant recurrence after breast-conserving therapy or mastectomy for stage I and II breast cancer: pooled results of two large European randomized trials. J Clin Oncol. Mar 15 2001;19(6):1688-1697.

72. Arriagada R, Le MG, Guinebretiere JM, Dunant A, Rochard F, Tursz T. Late local recurrences in a randomised trial comparing conservative treatment with total mastectomy in early breast cancer patients. Ann Oncol. Nov 2003;14(11):16171622.

73. Curigliano G, Criscitiello C, Andre F, Colleoni M, Di Leo A. Highlights from the 13th St Gallen International Breast Cancer Conference 2013. Access to innovation for patients with breast cancer: how to speed it up? Ecancermedicalscience. 2013;7:299. 
Apêndices 
Apêndice 1 - Ficha para coleta de dados anatomoclínicos.

Prezado colega,

$\mathrm{CB} X X X X X / X X$ Sua referência:

Estamos desenvolvendo um estudo sobre carcinoma de mama em pacientes jovens (até 25 anos). Apreciariamos muito seu apoio na obtenção de dados clínicos da paciente abaixo:

Paciente:

ANATOMOPATOLÓGICO:

Lateralidade: ()Direita ()Esquerda ()Bilateral ()Extra-numerária ()Ignorado

Localização: ()QSL ()QIL ( )QSM ( )QIM ( ) JQS ( )JQI ( ) JQM

( ) JQL ( )Retroareolar ( ) Central ( )Ignorado

()Outro:

Tamanho:

Retirada de Infonodos: ()Não ( )LN sentinela ( )LN axilares ( )Ignorado ()Outros

Status axilar: ( )Ausência de metástases ( )Presença de metástases

Metástases à distância: ()Ausente () Óssea ( )Linfonodos não regionais

( )Ignorado

TNM clinico:

()Pleura () Hepática () Ignorado () Outra

CLINICA:

Situação atual: ()Vivo livre de neoplasia ( ) Vivo com recidiva local

()Vivo com metástases à distância ()óbito relacionado ao tumor

( ) Óbito não relacionado ao tumor ( )Ignorado ( ) Outro

História de Gestação: ( ) Gestação prévia ao diagnóstico ( ) Gestação durante o diagnóstico

( ) Gestação após o diagnóstico

( ) História de gestaçăo (não se sabe quando) ( ) Ignorado

História Familiar: ( ) Câncer de mama em parente de $1^{\circ} \mathrm{grau}$

( ) Cáncer năo-mamário em parente de $1^{\circ}$ grau

( ) Ausência de história de cáncer em parente de $1^{\circ} \mathrm{grau}$

( ) Ignorado

\section{TRATAMENTO:}

Procedimento: () Excisão* sem localizaçăo por fio guia

() Excisăo* com localização por fio guia

() Mastectomia total (incluindo mamilo e pele)

() Outro

"Excisão inclui "mastectomia parcial", "segmentectomia" e "quadrantectomia"

Uso de trastuzumab/Herceptin? ( ) sim ( ) não ( ) Ignorado

Terapia Neoadjuvante? ( ) sim ( ) não ( ) Ignorado

Quimioterapia? () sim ( ) não ( ) Ignorado

Número de ciclos:

Esquemas usados:

Radioterapia? ( ) sim ( ) não ( ) Ignorado

Agradecemos desde já sua colaboraçẫo. Estas informaçōes podem ser repassadas pelo fax (14) 3112-5920 ou pelos e-mais dedeusmoura@gmail.com ou bacchi@conspat.com.br

Cordialmente,

Dr. Rafael de Deus Moura

Dr. Carlos E. Bacchi 
Apêndice 2 - Planilha com dados anatomoclínicos das pacientes.

\begin{tabular}{|c|c|c|c|c|c|c|c|}
\hline Paciente & Data do diagnóstico & $\begin{array}{l}\text { data da amostra } \\
\text { analisada }\end{array}$ & Idade & Cidade & $\mathrm{UF}$ & História gestacional & História familiar para câncer de mama \\
\hline 1 & ND & 2012 & 24 & Araguaína & TO & ND & ND \\
\hline 2 & $02 / 09 / 11$ & 2011 & 21 & Teresina & PI & ND & Ausente \\
\hline 3 & $30 / 08 / 11$ & 2011 & 25 & Brasília & $\mathrm{DF}$ & ND & ND \\
\hline 4 & 08/04/11 & 2011 & 25 & Teresina & PI & Ausência de gestação & Ausente \\
\hline 5 & ND & 2011 & 25 & Belem & PA & ND & ND \\
\hline 6 & ND & 2011 & 24 & Belo Horizonte & MG & ND & ND \\
\hline 7 & ND & 2011 & 25 & Vitória & $\mathrm{ES}$ & ND & ND \\
\hline 8 & ND & 2011 & 23 & Maceió & $\mathrm{AL}$ & ND & ND \\
\hline 9 & ND & 2011 & 25 & Londrina & PR & ND & ND \\
\hline 10 & 07/06/11 & 2011 & 23 & Patos de Minas & MG & ND & ND \\
\hline 11 & 02/06/11 & 2011 & 25 & $\begin{array}{l}\text { Balneário } \\
\text { Camboriú }\end{array}$ & $\mathrm{SC}$ & ND & ND \\
\hline 12 & ND & 2011 & 24 & Criciúma & $\mathrm{SC}$ & ND & ND \\
\hline 13 & $19 / 04 / 11$ & 2011 & 22 & Londrina & PR & ND & ND \\
\hline 14 & ND & 2011 & 24 & Maringá & PR & ND & ND \\
\hline 15 & $23 / 02 / 11$ & 2011 & 24 & Mococa & SP & Gestação prévia (G2P2A0) & Ausente \\
\hline 16 & ND & 2011 & 25 & Varginha & MG & ND & ND \\
\hline 17 & $05 / 02 / 11$ & 2011 & 22 & São Paulo & SP & Ausência de gestação & Câncer de mama em mãe \\
\hline 18 & ND & 2011 & 25 & Recife & $\mathrm{PE}$ & ND & ND \\
\hline
\end{tabular}




\begin{tabular}{|c|c|c|c|c|c|c|c|}
\hline 19 & ND & 2011 & 24 & Jundiaí & SP & $\begin{array}{l}\text { Gestação prévia }(2 \mathrm{x}) \\
\text { Gestação após o diagnóstico } \\
(2 \mathrm{x}), 1 \text { Aborto }\end{array}$ & Câncer de mama em mãe \\
\hline 20 & ND & 2010 & 20 & Maringá & $\mathrm{PR}$ & ND & ND \\
\hline 21 & ND & 2010 & 24 & Goiânia & GO & ND & ND \\
\hline 22 & $26 / 10 / 10$ & 2010 & 24 & São Paulo & SP & Gestação prévia & Ausente \\
\hline 23 & ND & 2010 & 25 & Curitiba & PR & ND & ND \\
\hline 24 & $01 / 09 / 10$ & 2010 & 23 & Sorocaba & SP & Ausência de gestação & Ausente \\
\hline 25 & ND & 2010 & 25 & Vila Velha & ES & ND & ND \\
\hline 26 & ND & 2010 & 24 & Araguaína & TO & Ausência de gestação & Ausente \\
\hline 27 & ND & 2010 & 25 & Araguaína & TO & ND & ND \\
\hline 28 & ND & 2010 & 24 & Porto Alegre & $\mathrm{RS}$ & ND & ND \\
\hline 29 & ND & 2010 & 25 & Belo Horizonte & MG & ND & ND \\
\hline 30 & ND & 2010 & 25 & Curitiba & PR & ND & ND \\
\hline 31 & $25 / 05 / 10$ & 2010 & 23 & Montes Claros & MG & Ausência de gestação & Ausente \\
\hline 32 & ND & 2010 & 23 & Franca & $\mathrm{SP}$ & ND & ND \\
\hline 33 & ND & 2010 & 20 & Natal & $\mathrm{RN}$ & ND & ND \\
\hline 34 & $02 / 03 / 10$ & 2010 & 20 & Uberaba & MG & ND & ND \\
\hline 35 & ND & 2009 & 24 & Maringá & PR & ND & ND \\
\hline 36 & $25 / 02 / 10$ & 2010 & 20 & Fortaleza & $\mathrm{CE}$ & ND & ND \\
\hline 37 & ND & 2009 & 24 & $\begin{array}{l}\text { Balneário } \\
\text { Camboriú }\end{array}$ & $\mathrm{SC}$ & ND & ND \\
\hline 38 & ND & 2009 & 22 & $\begin{array}{l}\text { São José do Rio } \\
\text { Preto }\end{array}$ & SP & ND & ND \\
\hline 39 & 29/01/09 & 2009 & 24 & Teresina & PI & Gestação prévia (G1P1) & Câncer de mama em prima \\
\hline
\end{tabular}




\begin{tabular}{|c|c|c|c|c|c|c|c|}
\hline 40 & ND & 2009 & 25 & Campinas & SP & ND & ND \\
\hline 41 & ND & 2009 & 21 & Belo Horizonte & MG & ND & ND \\
\hline 42 & ND & 2009 & 25 & Franca & SP & ND & ND \\
\hline 43 & ND & 2009 & 25 & Vitória & ES & ND & ND \\
\hline 44 & $22 / 07 / 09$ & 2009 & 22 & Teresina & PI & Ausência de gestação & Ausente \\
\hline 45 & ND & 2009 & 21 & Brasilia & $\mathrm{DF}$ & ND & ND \\
\hline 46 & $29 / 07 / 09$ & 2009 & 17 & Limeira & SP & ND & ND \\
\hline 47 & ND & 2009 & 20 & Franca & SP & ND & ND \\
\hline 48 & 06/07/09 & 2009 & 21 & São Carlos & SP & ND & ND \\
\hline 49 & ND & 2009 & 25 & Niterói & RJ & ND & ND \\
\hline 50 & ND & 2009 & 24 & Salvador & $\mathrm{BA}$ & ND & ND \\
\hline 51 & $22 / 06 / 09$ & 2009 & 25 & São Luís & MA & ND & ND \\
\hline 52 & $15 / 04 / 09$ & 2009 & 23 & São Paulo & SP & ND & ND \\
\hline 53 & ND & 2009 & 24 & Maringá & PR & ND & ND \\
\hline 54 & ND & 2009 & 25 & Brasília & $\mathrm{DF}$ & ND & ND \\
\hline 55 & 07/01/09 & 2009 & 20 & Barretos & SP & Ausência de gestação & Câncer de mama em tia-avó \\
\hline 56 & $\mathrm{ND}$ & 2009 & 25 & Tubarão & $\mathrm{SC}$ & ND & $\mathrm{ND}$ \\
\hline 57 & $12 / 01 / 09$ & 2009 & 24 & Maceió & AL & ND & ND \\
\hline 58 & 08/10/08 & 2008 & 23 & São Paulo & SP & Ausência de gestação & Ausente \\
\hline 59 & $11 / 08 / 08$ & 2008 & 22 & Santa Maria & $\mathrm{RS}$ & ND & ND \\
\hline 60 & $19 / 02 / 08$ & 2008 & 25 & Criciúma & $\mathrm{SC}$ & ND & ND \\
\hline 61 & ND & 2008 & 24 & Londrina & PR & ND & ND \\
\hline
\end{tabular}




\begin{tabular}{|c|c|c|c|c|c|c|c|}
\hline 62 & ND & 2008 & 25 & Araguaína & TO & ND & ND \\
\hline 63 & 08/11/01 & 2008 & 22 & Varginha & MG & ND & ND \\
\hline 64 & $29 / 05 / 08$ & 2008 & 24 & Piracicaba & SP & ND & ND \\
\hline 65 & ND & 2008 & 18 & $\begin{array}{l}\text { São José do Rio } \\
\text { Preto }\end{array}$ & SP & ND & ND \\
\hline 66 & $12 / 03 / 08$ & 2008 & 25 & Ribeirão Preto & SP & ND & ND \\
\hline 67 & ND & 2008 & 25 & Sorocaba & SP & ND & ND \\
\hline 68 & ND & 2008 & 25 & Franca & SP & ND & ND \\
\hline 69 & ND & 2008 & 25 & Manaus & $\mathrm{AM}$ & ND & ND \\
\hline 70 & ND & 2008 & 25 & Criciúma & $\mathrm{SC}$ & ND & ND \\
\hline 71 & ND & 2008 & 25 & Sorocaba & SP & ND & $\mathrm{ND}$ \\
\hline 72 & $17 / 12 / 07$ & 2007 & 23 & Santos & SP & ND & ND \\
\hline 73 & $15 / 10 / 07$ & 2007 & 25 & Teresina & PI & $\begin{array}{l}\text { Gestação prévia ( } 3 \\
\text { gestações) }\end{array}$ & Ausente \\
\hline 74 & ND & 2007 & 22 & Aracaju & SE & ND & ND \\
\hline 75 & ND & 2007 & 24 & Maceió & $\mathrm{AL}$ & ND & ND \\
\hline 76 & ND & 2007 & 21 & Maringa & PR & ND & ND \\
\hline 77 & $\mathrm{ND}$ & 2007 & 24 & Goiânia & GO & ND & ND \\
\hline 78 & ND & 2007 & 25 & Blumenau & $\mathrm{SC}$ & ND & ND \\
\hline 79 & $\mathrm{ND}$ & 2007 & 24 & Porto Alegre & $\mathrm{RS}$ & ND & ND \\
\hline 80 & 07/04/07 & 2007 & 23 & Teresina & PI & ND & ND \\
\hline 81 & ND & 2006 & 25 & Bauru & SP & ND & ND \\
\hline 82 & ND & 2007 & 25 & Blumenau & $\mathrm{SC}$ & ND & ND \\
\hline
\end{tabular}




\begin{tabular}{|c|c|c|c|c|c|c|c|}
\hline 83 & $19 / 06 / 07$ & 2007 & 24 & Criciúma & $\mathrm{SC}$ & Gestação prévia & Ausente \\
\hline 84 & ND & 2007 & 21 & São Carlos & SP & ND & ND \\
\hline 85 & ND & 2007 & 24 & Lajeado & SP & ND & ND \\
\hline 86 & $24 / 01 / 07$ & 2007 & 24 & Teresina & PI & $\begin{array}{l}\text { Gestação prévia, Gestação } \\
\text { após o diagnóstico } \\
\text { (G2P1A1) }\end{array}$ & ND \\
\hline 87 & ND & 2007 & 20 & $\begin{array}{l}\text { São José dos } \\
\text { Campos }\end{array}$ & SP & ND & ND \\
\hline 88 & $\mathrm{ND}$ & 2007 & 23 & Ciuabá & MT & ND & $\mathrm{ND}$ \\
\hline 89 & ND & 2007 & 21 & Jundiaí & SP & ND & ND \\
\hline 90 & $\mathrm{ND}$ & 2007 & 19 & Goiania & $\mathrm{GO}$ & ND & ND \\
\hline 91 & $24 / 10 / 06$ & 2007 & 25 & Teresina & PI & Gestação prévia (G2P1A1) & ND \\
\hline 92 & ND & 2007 & 25 & Maringá & PR & ND & ND \\
\hline 93 & ND & 2007 & 24 & Sorocaba & SP & ND & ND \\
\hline 94 & $28 / 12 / 06$ & 2006 & 25 & Itu & SP & ND & ND \\
\hline 95 & ND & 2006 & 21 & Manaus & $\mathrm{AM}$ & ND & ND \\
\hline 96 & ND & 2006 & 18 & Limeira & SP & ND & ND \\
\hline 97 & ND & 2006 & 23 & Maringá & PR & ND & ND \\
\hline 98 & 01/09/06 & 2006 & 23 & Três Pontas & MG & ND & ND \\
\hline 99 & $25 / 08 / 06$ & 2006 & 25 & Uberaba & MG & ND & $\mathrm{ND}$ \\
\hline 100 & $\mathrm{ND}$ & 2006 & 24 & Vitória & $\mathrm{ES}$ & ND & $\mathrm{ND}$ \\
\hline 101 & $\mathrm{ND}$ & 2006 & 24 & São Luís & MA & ND & ND \\
\hline 102 & ND & 2006 & 22 & Rio de Janeiro & RJ & ND & ND \\
\hline 103 & ND & 2006 & 21 & Manaus & $\mathrm{AM}$ & ND & ND \\
\hline
\end{tabular}




\begin{tabular}{|c|c|c|c|c|c|c|c|}
\hline 104 & ND & 2006 & 23 & Araçatuba & SP & ND & ND \\
\hline 105 & $12 / 12 / 05$ & 2006 & 24 & Teresina & PI & ND & ND \\
\hline 106 & ND & 2006 & 24 & Vitória & ES & ND & ND \\
\hline 107 & ND & 2006 & 25 & Belém & PA & ND & ND \\
\hline 108 & ND & 2006 & 21 & Joinville & $\mathrm{SC}$ & ND & ND \\
\hline 109 & ND & 2006 & 24 & João Pessoa & PB & ND & ND \\
\hline 110 & ND & 2006 & 25 & São Carlos & SP & ND & ND \\
\hline 111 & ND & 2006 & 25 & Belo Horizonte & MG & ND & ND \\
\hline 112 & 02/01/06 & 2006 & 25 & Pouso Alegre & MG & ND & $\mathrm{ND}$ \\
\hline 113 & ND & 2005 & 25 & Americana & SP & ND & ND \\
\hline 114 & ND & 2005 & 24 & Maringa & PR & ND & $\mathrm{ND}$ \\
\hline 115 & ND & 2005 & 23 & Bauru & SP & ND & ND \\
\hline 116 & ND & 2005 & 25 & Belém & PA & ND & ND \\
\hline 117 & $26 / 09 / 05$ & 2005 & 7 & Pouso Alegre & MG & ND & ND \\
\hline 118 & $01 / 12 / 02$ & 2005 & 24 & São Paulo & SP & Ausência de gestação & Ausente \\
\hline 119 & ND & 2005 & 23 & Sorocaba & SP & ND & ND \\
\hline 120 & $\mathrm{ND}$ & 2005 & 24 & São Luís & MA & ND & $\mathrm{ND}$ \\
\hline 121 & 02/06/05 & 2005 & 25 & Salvador & MA & Ausência de gestação & ND \\
\hline 122 & ND & 2005 & 23 & Vitória & $\mathrm{ES}$ & ND & ND \\
\hline 123 & ND & 2005 & 25 & Maringá & PR & ND & ND \\
\hline 124 & ND & 2005 & 24 & $\begin{array}{l}\text { São Jose dos } \\
\text { Campos }\end{array}$ & SP & ND & ND \\
\hline
\end{tabular}




\begin{tabular}{|c|c|c|c|c|c|c|c|}
\hline 125 & $\mathrm{ND}$ & 2005 & 25 & Salvador & $\mathrm{BA}$ & ND & ND \\
\hline 126 & ND & 2005 & 25 & Vitória & ES & ND & ND \\
\hline 127 & $05 / 05 / 05$ & 2005 & 23 & Rio de Janeiro & RJ & Gestação prévia (G2P2) & Ausente \\
\hline 128 & ND & 2005 & 23 & São Paulo & SP & ND & ND \\
\hline 129 & $24 / 03 / 05$ & 2005 & 25 & São Paulo & SP & Ausência de gestação & Ausente \\
\hline 130 & ND & 2005 & 23 & Aracaju & SE & ND & ND \\
\hline 131 & ND & 2005 & 24 & Blumenau & $\mathrm{SC}$ & ND & ND \\
\hline 132 & ND & 2005 & 20 & Fortaleza & $\mathrm{CE}$ & ND & ND \\
\hline 133 & ND & 2005 & 23 & Fortaleza & $\mathrm{CE}$ & ND & ND \\
\hline 134 & ND & 2005 & 25 & Vitória & ES & ND & ND \\
\hline 135 & $\mathrm{ND}$ & 2004 & 22 & São Luís & MA & ND & $\mathrm{ND}$ \\
\hline 136 & ND & 2004 & 22 & Blumenau & $\mathrm{SC}$ & ND & ND \\
\hline 137 & $06 / 12 / 04$ & 2004 & 19 & Londrina & PR & ND & ND \\
\hline 138 & $\mathrm{ND}$ & 2004 & 18 & Rio de Janeiro & $\mathrm{RJ}$ & ND & ND \\
\hline 139 & ND & 2004 & 25 & Florianópolis & $\mathrm{SC}$ & ND & ND \\
\hline 140 & $25 / 08 / 11$ & 2011 & 25 & São Paulo & SP & ND & ND \\
\hline 141 & ND & 2011 & 25 & São Paulo & SP & ND & ND \\
\hline 142 & $\mathrm{ND}$ & 2011 & 25 & Taubaté & SP & ND & $\mathrm{ND}$ \\
\hline 143 & ND & 2011 & 16 & São Paulo & SP & ND & ND \\
\hline 144 & $\mathrm{ND}$ & 2011 & 25 & São Paulo & SP & ND & $\mathrm{ND}$ \\
\hline 145 & ND & 2011 & 24 & São Paulo & $\mathrm{SP}$ & ND & $\mathrm{ND}$ \\
\hline 146 & ND & 2011 & 16 & São Paulo & SP & ND & ND \\
\hline
\end{tabular}




\begin{tabular}{llllllll}
\hline 147 & $20 / 05 / 10$ & 2010 & 25 & Porto Alegre & RS & ND & ND \\
148 & ND & 2010 & 25 & Cascavel & PR & ND & ND \\
149 & $23 / 04 / 07$ & 2007 & 24 & São Paulo & SP & Gestação prévia & Ausente \\
\hline
\end{tabular}




\begin{tabular}{|c|c|c|c|c|c|c|c|c|}
\hline Paciente & Subtipo histológico & Grau histológico (Nottingham) & Lateralidade & Tamanho $(\mathrm{cm})$ & $\mathrm{RE}$ & $\mathrm{RP}$ & HER2 (escore) & HER2 \\
\hline 1 & Carcinoma ductal invasivo SOE & 3 & Direita & ND & $\mathrm{N}$ & $\mathrm{N}$ & 1 & $\mathrm{~N}$ \\
\hline 2 & Carcinoma ductal invasivo SOE & 2 & Esquerda & 1,2 & $\mathrm{P}$ & $P$ & 3 & $P$ \\
\hline 3 & Carcinoma ductal invasivo SOE & 2 & Direita & 3,7 & ND & ND & 2 & $P$ \\
\hline 4 & Carcinoma medular invasivo & 3 & Direita & 2,4 & $\mathrm{~N}$ & $\mathrm{~N}$ & 0 & $\mathrm{~N}$ \\
\hline 5 & Carcinoma ductal invasivo SOE & 1 & Esquerda & 0,9 & $P$ & $P$ & 3 & $P$ \\
\hline 6 & Carcinoma ductal invasivo SOE & 3 & Esquerda & 5,0 & $\mathrm{~N}$ & $\mathrm{~N}$ & 0 & $\mathrm{~N}$ \\
\hline 7 & Carcinoma ductal invasivo SOE & 2 & ND & ND & $\mathrm{P}$ & $P$ & 0 & $\mathrm{~N}$ \\
\hline 8 & Carcinoma ductal invasivo SOE & 2 & ND & ND & $\mathrm{P}$ & $P$ & 3 & $P$ \\
\hline 9 & Carcinoma ductal invasivo SOE & 2 & ND & ND & $\mathrm{P}$ & $\mathrm{N}$ & 3 & $P$ \\
\hline 10 & Carcinoma ductal invasivo SOE & 3 & Esquerda & 7,2 & $\mathrm{~N}$ & $\mathrm{~N}$ & 3 & $P$ \\
\hline 11 & Carcinoma ductal invasivo SOE & 3 & Direita & 10,0 & $\mathrm{~N}$ & $\mathrm{~N}$ & 2 & $\mathrm{~N}$ \\
\hline 12 & Carcinoma ductal invasivo SOE & 2 & Direita & ND & $\mathrm{N}$ & $\mathrm{N}$ & 3 & $P$ \\
\hline 13 & Carcinoma ductal invasivo SOE & 2 & Esquerda & 1,7 & $\mathrm{P}$ & $\mathrm{N}$ & 3 & $P$ \\
\hline 14 & Carcinoma ductal invasivo SOE & 1 & Esquerda & 6,0 & $\mathrm{~N}$ & $\mathrm{~N}$ & 3 & $P$ \\
\hline 15 & Carcinoma ductal invasivo SOE & 2 & Esquerda & 5,2 & $\mathrm{P}$ & $\mathrm{N}$ & 3 & $P$ \\
\hline 16 & Carcinoma ductal invasivo SOE & 3 & Esquerda & 1,5 & $\mathrm{P}$ & $P$ & 3 & $P$ \\
\hline 17 & Carcinoma ductal invasivo SOE & 3 & Esquerda & 2,5 & ND & ND & 2 & $P$ \\
\hline 18 & Carcinoma ductal invasivo SOE & 2 & Esquerda & 8,0 & ND & ND & 2 & $\mathrm{~N}$ \\
\hline 19 & Carcinoma medular invasivo & 3 & Esquerda & 5,0 & $\mathrm{~N}$ & $\mathrm{~N}$ & 0 & $\mathrm{~N}$ \\
\hline 20 & Carcinoma ductal invasivo SOE & 2 & Esquerda & 0,7 & ND & ND & 2 & $\mathrm{~N}$ \\
\hline 21 & Carcinoma ductal invasivo SOE & 1 & Direita & ND & $\mathrm{P}$ & $P$ & 1 & $\mathrm{~N}$ \\
\hline
\end{tabular}




\begin{tabular}{|c|c|c|c|c|c|c|c|c|}
\hline 22 & Carcinoma ductal invasivo SOE & 3 & Direita & 11,0 & ND & ND & 2 & $\mathrm{~N}$ \\
\hline 23 & Carcinoma ductal invasivo SOE & 2 & ND & ND & $\mathrm{N}$ & $\mathrm{N}$ & 2 & $\mathrm{~N}$ \\
\hline 24 & Carcinoma ductal invasivo SOE & 2 & Direita & 9,5 & $\mathrm{~N}$ & $\mathrm{~N}$ & 3 & $\mathrm{P}$ \\
\hline 25 & Carcinoma ductal invasivo SOE & 3 & ND & ND & $\mathrm{P}$ & $\mathrm{N}$ & 0 & $\mathrm{~N}$ \\
\hline 26 & Carcinoma ductal invasivo SOE & 2 & Esquerda & 7,5 & $\mathrm{P}$ & $\mathrm{P}$ & 0 & $\mathrm{~N}$ \\
\hline 27 & Carcinoma ductal invasivo SOE & 3 & ND & ND & $\mathrm{N}$ & $P$ & 0 & $\mathrm{~N}$ \\
\hline 28 & Carcinoma ductal invasivo SOE & 3 & Direita & 2,5 & $\mathrm{P}$ & $\mathrm{P}$ & 2 & $\mathrm{~N}$ \\
\hline 29 & Carcinoma ductal invasivo SOE & 2 & Esquerda & ND & $P$ & $P$ & 0 & $\mathrm{~N}$ \\
\hline 30 & Carcinoma ductal invasivo SOE & 3 & ND & ND & $\mathrm{P}$ & $\mathrm{P}$ & 2 & $P$ \\
\hline 31 & Carcinoma ductal invasivo SOE & 3 & Direita & 3,0 & $\mathrm{~N}$ & $\mathrm{~N}$ & 1 & $\mathrm{~N}$ \\
\hline 32 & Carcinoma lobular in situ & ND & Esquerda & ND & ND & ND & 1 & ND \\
\hline 33 & Carcinoma lobular invasivo & 2 & Esquerda & ND & ND & ND & 2 & $\mathrm{~N}$ \\
\hline 34 & Carcinoma mucinoso invasivo & 2 & Esquerda & 2,7 & $\mathrm{P}$ & $P$ & 1 & $\mathrm{~N}$ \\
\hline 35 & Carcinoma ductal invasivo SOE & 1 & Esquerda & ND & $\mathrm{P}$ & $\mathrm{P}$ & 2 & ND \\
\hline 36 & Carcinoma ductal invasivo SOE & 2 & Esquerda & ND & $\mathrm{P}$ & $\mathrm{P}$ & 2 & $\mathrm{P}$ \\
\hline 37 & Carcinoma ductal invasivo SOE & 2 & Direita & ND & $\mathrm{P}$ & $P$ & 0 & $\mathrm{~N}$ \\
\hline 38 & Carcinoma ductal invasivo SOE & 3 & ND & ND & ND & ND & 0 & $\mathrm{~N}$ \\
\hline 39 & Carcinoma ductal invasivo SOE & 3 & Direita & 8,0 & $\mathrm{~N}$ & $\mathrm{~N}$ & 0 & $\mathrm{~N}$ \\
\hline 40 & CDIS com microinvasão & 2 & ND & ND & $P$ & $\mathrm{~N}$ & 2 & $\mathrm{~N}$ \\
\hline 41 & Carcinoma ductal invasivo SOE & 2 & Esquerda & ND & ND & ND & 2 & $\mathrm{P}$ \\
\hline 42 & Carcinoma invasivo misto (mucinoso e lobular) & 3 & Direita & ND & ND & ND & 3 & $\mathrm{P}$ \\
\hline 43 & Carcinoma ductal invasivo SOE & 2 & Esquerda & ND & $\mathrm{N}$ & $\mathrm{N}$ & 3 & $P$ \\
\hline
\end{tabular}




\begin{tabular}{|c|c|c|c|c|c|c|c|c|}
\hline 44 & Carcinoma ductal invasivo SOE & 3 & Esquerda & 3,5 & $P$ & $\mathrm{P}$ & 3 & $P$ \\
\hline 45 & Carcinoma ductal invasivo SOE & 2 & Esquerda & ND & ND & ND & 3 & $P$ \\
\hline 46 & Carcinoma lobular in situ & ND & Direita & 1,8 & ND & ND & ND & ND \\
\hline 47 & Carcinoma ductal in situ & ND & Esquerda & 1,5 & ND & ND & ND & ND \\
\hline 48 & Carcinoma ductal invasivo SOE & 2 & Direita & 10,0 & $\mathrm{~N}$ & $\mathrm{~N}$ & 3 & $P$ \\
\hline 49 & Carcinoma ductal invasivo SOE & 2 & ND & ND & ND & ND & 2 & $P$ \\
\hline 50 & Carcinoma ductal in situ & ND & Esquerda & 1,5 & ND & ND & 2 & ND \\
\hline 51 & Carcinoma ductal invasivo SOE & 2 & Direita & 2,4 & $P$ & $\mathrm{P}$ & 1 & $\mathrm{~N}$ \\
\hline 52 & Carcinoma ductal invasivo SOE & 2 & Direita & 0,8 & ND & ND & 2 & $\mathrm{~N}$ \\
\hline 53 & Carcinoma ductal invasivo SOE & 3 & Direita & ND & $\mathrm{N}$ & $\mathrm{N}$ & 0 & $\mathrm{~N}$ \\
\hline 54 & Carcinoma ductal invasivo SOE & 2 & Esquerda & ND & ND & ND & 2 & $\mathrm{~N}$ \\
\hline 55 & Carcinoma ductal invasivo SOE & 2 & Direita & ND & ND & ND & 3 & $P$ \\
\hline 56 & Carcinoma ductal invasivo SOE & 3 & Esquerda & ND & $\mathrm{P}$ & $P$ & 3 & $\mathrm{P}$ \\
\hline 57 & Carcinoma ductal in situ & ND & Esquerda & 1,5 & ND & ND & 3 & ND \\
\hline 58 & Carcinoma ductal invasivo SOE & 3 & Direita & 3,9 & ND & ND & 2 & $\mathrm{~N}$ \\
\hline 59 & Carcinoma ductal invasivo SOE & 3 & Direita & 6,0 & ND & ND & 3 & $\mathrm{P}$ \\
\hline 60 & Carcinoma ductal invasivo SOE & 1 & Esquerda & 0,8 & $P$ & $\mathrm{P}$ & 1 & $\mathrm{~N}$ \\
\hline 61 & Carcinoma ductal invasivo SOE & 2 & ND & ND & $P$ & $P$ & 0 & $\mathrm{~N}$ \\
\hline 62 & Carcinoma ductal invasivo SOE & 3 & ND & ND & $P$ & $\mathrm{~N}$ & 0 & $\mathrm{~N}$ \\
\hline 63 & Carcinoma ductal invasivo SOE & 3 & Esquerda & 5,5 & $\mathrm{~N}$ & $\mathrm{~N}$ & 0 & $\mathrm{~N}$ \\
\hline 64 & Carcinoma ductal invasivo SOE & 2 & ND & ND & $P$ & $P$ & 0 & $\mathrm{~N}$ \\
\hline 65 & Carcinoma ductal in situ & ND & Esquerda & ND & ND & ND & 3 & ND \\
\hline
\end{tabular}




\begin{tabular}{|c|c|c|c|c|c|c|c|c|}
\hline 66 & Carcinoma ductal invasivo SOE & 2 & Direita & 5,8 & $\mathrm{P}$ & $\mathrm{N}$ & 0 & $\mathrm{~N}$ \\
\hline 67 & Carcinoma ductal invasivo SOE & 2 & Esquerda & ND & $\mathrm{P}$ & $P$ & 0 & $\mathrm{~N}$ \\
\hline 68 & Carcinoma ductal invasivo SOE & 2 & Esquerda & ND & ND & ND & 2 & $\mathrm{~N}$ \\
\hline 69 & Carcinoma ductal invasivo SOE & 1 & Direita & ND & $\mathrm{P}$ & $\mathrm{P}$ & 0 & $\mathrm{~N}$ \\
\hline 70 & Carcinoma medular invasivo & 3 & ND & 1,4 & $\mathrm{~N}$ & $\mathrm{~N}$ & 0 & $\mathrm{~N}$ \\
\hline 71 & Carcinoma ductal invasivo SOE & 2 & ND & ND & $\mathrm{P}$ & $P$ & 0 & $\mathrm{~N}$ \\
\hline 72 & Carcinoma ductal invasivo SOE & 3 & Esquerda & 6,2 & ND & ND & 0 & $\mathrm{~N}$ \\
\hline 73 & Carcinoma ductal invasivo SOE & 2 & Direita & 2,4 & $P$ & $\mathrm{~N}$ & 0 & $\mathrm{~N}$ \\
\hline 74 & Carcinoma ductal invasivo SOE & 3 & Direita & ND & $\mathrm{N}$ & $P$ & 0 & $\mathrm{~N}$ \\
\hline 75 & Carcinoma ductal invasivo SOE & 2 & Esquerda & ND & ND & ND & 3 & $\mathrm{P}$ \\
\hline 76 & Carcinoma ductal invasivo SOE & 3 & Direita & ND & $\mathrm{N}$ & $\mathrm{N}$ & 0 & $\mathrm{~N}$ \\
\hline 77 & Carcinoma ductal invasivo SOE & 3 & Esquerda & 2,3 & $\mathrm{~N}$ & $\mathrm{~N}$ & 1 & $\mathrm{~N}$ \\
\hline 78 & Carcinoma ductal in situ & ND & ND & 1,5 & ND & ND & 0 & ND \\
\hline 79 & Carcinoma ductal invasivo SOE & 3 & ND & ND & $\mathrm{P}$ & $P$ & 3 & $\mathrm{P}$ \\
\hline 80 & Carcinoma ductal invasivo SOE & 2 & Esquerda & 3,8 & $\mathrm{P}$ & $P$ & 3 & $\mathrm{P}$ \\
\hline 81 & Carcinoma ductal invasivo SOE & 3 & Esquerda & 6,5 & ND & ND & 3 & $\mathrm{P}$ \\
\hline 82 & Carcinoma ductal invasivo SOE & 2 & Esquerda & 2,0 & $\mathrm{P}$ & $P$ & 1 & $\mathrm{~N}$ \\
\hline 83 & Carcinoma ductal invasivo SOE & 2 & Esquerda & 2,3 & $\mathrm{P}$ & $P$ & 1 & $\mathrm{~N}$ \\
\hline 84 & Carcinoma ductal invasivo SOE & 3 & ND & ND & $\mathrm{P}$ & $P$ & 3 & $P$ \\
\hline 85 & Carcinoma ductal invasivo SOE & 2 & ND & ND & $\mathrm{P}$ & $\mathrm{P}$ & 3 & $P$ \\
\hline 86 & Carcinoma ductal invasivo SOE & 3 & Esquerda & 1,5 & $\mathrm{P}$ & $P$ & 0 & $\mathrm{~N}$ \\
\hline 87 & Carcinoma ductal invasivo SOE & 3 & Esquerda & 3,5 & $\mathrm{P}$ & $\mathrm{N}$ & 2 & $P$ \\
\hline
\end{tabular}




\begin{tabular}{|c|c|c|c|c|c|c|c|c|}
\hline 88 & Carcinoma ductal invasivo SOE & 2 & ND & 2,6 & ND & ND & 3 & $P$ \\
\hline 89 & Carcinoma ductal invasivo SOE & 3 & ND & ND & $\mathrm{P}$ & $P$ & 0 & $\mathrm{~N}$ \\
\hline 90 & Carcinoma apócrino & 2 & Direita & ND & $\mathrm{N}$ & $\mathrm{N}$ & 3 & $\mathrm{P}$ \\
\hline 91 & Carcinoma ductal invasivo SOE & 3 & Esquerda & 1,8 & $\mathrm{~N}$ & $P$ & 3 & $P$ \\
\hline 92 & Carcinoma ductal invasivo SOE & 1 & Esquerda & 1,5 & $\mathrm{P}$ & $\mathrm{N}$ & 1 & $\mathrm{~N}$ \\
\hline 93 & Carcinoma ductal invasivo SOE & 3 & ND & ND & $P$ & $P$ & 1 & $\mathrm{~N}$ \\
\hline 94 & Carcinoma ductal invasivo SOE & 1 & Direita & 3,0 & $\mathrm{P}$ & $P$ & 0 & $\mathrm{~N}$ \\
\hline 95 & Carcinoma ductal invasivo SOE & 3 & Esquerda & 2,7 & $\mathrm{~N}$ & $\mathrm{~N}$ & 0 & $\mathrm{~N}$ \\
\hline 96 & Carcinoma ductal invasivo SOE & 2 & ND & ND & $\mathrm{N}$ & $\mathrm{P}$ & 0 & $\mathrm{~N}$ \\
\hline 97 & Carcinoma ductal invasivo SOE & 3 & Direita & 2,0 & $\mathrm{P}$ & $P$ & 0 & $\mathrm{~N}$ \\
\hline 98 & Carcinoma ductal in situ & ND & ND & ND & ND & ND & 0 & ND \\
\hline 99 & Carcinoma ductal invasivo SOE & 2 & Direita & 2,2 & $\mathrm{P}$ & $\mathrm{P}$ & 2 & $P$ \\
\hline 100 & Carcinoma ductal in situ & ND & ND & ND & ND & ND & 0 & ND \\
\hline 101 & Carcinoma ductal invasivo SOE & 3 & Direita & ND & $\mathrm{N}$ & $\mathrm{N}$ & 2 & $P$ \\
\hline 102 & Carcinoma ductal invasivo SOE & 3 & Esquerda & 1,6 & $\mathrm{P}$ & $\mathrm{P}$ & 3 & $P$ \\
\hline 103 & Carcinoma ductal invasivo SOE & 2 & ND & ND & $\mathrm{N}$ & $\mathrm{N}$ & 0 & $\mathrm{~N}$ \\
\hline 104 & Carcinoma ductal invasivo SOE & 1 & Esquerda & ND & $\mathrm{P}$ & $\mathrm{P}$ & 0 & $\mathrm{~N}$ \\
\hline 105 & Carcinoma ductal invasivo SOE & 3 & Esquerda & 3,5 & $\mathrm{~N}$ & $\mathrm{~N}$ & 0 & $\mathrm{~N}$ \\
\hline 106 & Carcinoma ductal invasivo SOE & 3 & ND & ND & $\mathrm{N}$ & $\mathrm{N}$ & 0 & $\mathrm{~N}$ \\
\hline 107 & Carcinoma ductal invasivo SOE & 3 & Direita & ND & $\mathrm{P}$ & $P$ & 2 & ND \\
\hline 108 & Carcinoma medular invasivo & 3 & Esquerda & ND & $\mathrm{N}$ & $\mathrm{N}$ & 0 & $\mathrm{~N}$ \\
\hline 109 & Carcinoma ductal invasivo SOE & 1 & Esquerda & 1,3 & $\mathrm{P}$ & $\mathrm{P}$ & 0 & $\mathrm{~N}$ \\
\hline
\end{tabular}




\begin{tabular}{|c|c|c|c|c|c|c|c|c|}
\hline 110 & Carcinoma ductal invasivo SOE & 2 & ND & ND & $\mathrm{P}$ & $\mathrm{P}$ & 1 & $\mathrm{~N}$ \\
\hline 111 & Carcinoma ductal invasivo SOE & 3 & ND & 5,0 & ND & ND & 1 & $\mathrm{~N}$ \\
\hline 112 & Carcinoma ductal invasivo SOE & 2 & Direita & 5,0 & $\mathrm{~N}$ & $\mathrm{~N}$ & 1 & $\mathrm{~N}$ \\
\hline 113 & Carcinoma ductal invasivo SOE & 2 & ND & ND & $\mathrm{P}$ & $\mathrm{P}$ & 0 & $\mathrm{~N}$ \\
\hline 114 & Carcinoma ductal invasivo SOE & 2 & ND & ND & $\mathrm{P}$ & $\mathrm{P}$ & 0 & $\mathrm{~N}$ \\
\hline 115 & Carcinoma ductal invasivo SOE & 2 & Direita & 8,0 & ND & ND & 2 & $\mathrm{~N}$ \\
\hline 116 & Carcinoma ductal invasivo SOE & 3 & Esquerda & 6,0 & $\mathrm{P}$ & $P$ & 2 & ND \\
\hline 117 & Carcinoma secretório & 2 & Esquerda & 1,4 & $\mathrm{~N}$ & $\mathrm{~N}$ & 0 & $\mathrm{~N}$ \\
\hline 118 & Carcinoma ductal invasivo SOE & 2 & Direita & 1,1 & $\mathrm{P}$ & $\mathrm{P}$ & 2 & $\mathrm{~N}$ \\
\hline 119 & Carcinoma ductal invasivo SOE & 3 & Direita & ND & $\mathrm{N}$ & $\mathrm{N}$ & 0 & $\mathrm{~N}$ \\
\hline 120 & Carcinoma ductal invasivo SOE & 3 & ND & ND & $\mathrm{N}$ & $\mathrm{N}$ & 0 & $\mathrm{~N}$ \\
\hline 121 & Carcinoma ductal invasivo SOE & 3 & Esquerda & 2,2 & ND & ND & 1 & $\mathrm{~N}$ \\
\hline 122 & Carcinoma ductal invasivo SOE & 2 & ND & ND & $\mathrm{N}$ & $\mathrm{N}$ & 0 & $\mathrm{~N}$ \\
\hline 123 & Carcinoma ductal invasivo SOE & 1 & Direita & 2,5 & $\mathrm{P}$ & $P$ & 0 & $\mathrm{~N}$ \\
\hline 124 & Carcinoma ductal invasivo SOE & 3 & Esquerda & 1,7 & ND & ND & 2 & $\mathrm{~N}$ \\
\hline 125 & Carcinoma ductal invasivo SOE & 3 & Direita & ND & ND & ND & 1 & $\mathrm{~N}$ \\
\hline 126 & Carcinoma ductal invasivo SOE & 2 & ND & ND & $\mathrm{P}$ & $\mathrm{P}$ & 0 & $\mathrm{~N}$ \\
\hline 127 & Carcinoma ductal invasivo SOE & 3 & Direita & 3,2 & ND & ND & 2 & $\mathrm{~N}$ \\
\hline 128 & Carcinoma ductal invasivo SOE & 3 & Esquerda & ND & ND & ND & 0 & $\mathrm{~N}$ \\
\hline 129 & Carcinoma ductal invasivo SOE & 3 & Esquerda & 2,5 & ND & ND & 2 & $\mathrm{~N}$ \\
\hline 130 & Carcinoma ductal in situ & ND & ND & ND & ND & ND & 3 & ND \\
\hline 131 & Carcinoma ductal invasivo SOE & 2 & Esquerda & ND & $\mathrm{N}$ & $\mathrm{N}$ & 3 & $P$ \\
\hline
\end{tabular}




\begin{tabular}{|c|c|c|c|c|c|c|c|c|}
\hline 132 & Carcinoma ductal in situ & ND & ND & ND & ND & ND & 0 & ND \\
\hline 133 & Carcinoma metaplásico & 3 & ND & ND & $\mathrm{N}$ & $\mathrm{N}$ & 0 & $\mathrm{~N}$ \\
\hline 134 & Carcinoma ductal invasivo SOE & 3 & ND & ND & $\mathrm{P}$ & $\mathrm{P}$ & 3 & $P$ \\
\hline 135 & Carcinoma ductal invasivo SOE & 1 & Esquerda & ND & $P$ & $\mathrm{P}$ & 0 & $\mathrm{~N}$ \\
\hline 136 & Carcinoma ductal invasivo SOE & 1 & Direita & ND & $P$ & $P$ & 0 & $\mathrm{~N}$ \\
\hline 137 & Carcinoma ductal invasivo SOE & 3 & Direita & 4,0 & $\mathrm{~N}$ & $\mathrm{~N}$ & 3 & $P$ \\
\hline 138 & Carcinoma ductal invasivo SOE & 1 & Esquerda & 1,8 & ND & ND & 0 & $\mathrm{~N}$ \\
\hline 139 & Carcinoma ductal invasivo SOE & 2 & ND & ND & ND & ND & 3 & $P$ \\
\hline 140 & Carcinoma ductal invasivo SOE & 1 & Esquerda & 0,7 & $\mathrm{~N}$ & $\mathrm{P}$ & 0 & $\mathrm{~N}$ \\
\hline 141 & Carcinoma ductal invasivo SOE & 2 & Direita & ND & $\mathrm{P}$ & $P$ & 0 & $\mathrm{~N}$ \\
\hline 142 & Carcinoma ductal invasivo SOE & 3 & Esquerda & 0,3 & $\mathrm{~N}$ & $\mathrm{~N}$ & 0 & $\mathrm{~N}$ \\
\hline 143 & Carcinoma ductal in situ & ND & Esquerda & ND & ND & ND & 3 & ND \\
\hline 144 & Carcinoma ductal invasivo SOE & 2 & Esquerda & ND & $\mathrm{P}$ & $P$ & 2 & ND \\
\hline 145 & Carcinoma ductal invasivo SOE & 2 & ND & ND & $\mathrm{P}$ & $\mathrm{P}$ & 1 & $\mathrm{~N}$ \\
\hline 146 & Carcinoma ductal in situ & ND & Esquerda & ND & ND & ND & 0 & ND \\
\hline 147 & Carcinoma ductal invasivo SOE & 3 & Esquerda & 4,0 & $\mathrm{~N}$ & $\mathrm{~N}$ & 0 & $\mathrm{~N}$ \\
\hline 148 & Carcinoma ductal invasivo SOE & 3 & Esquerda & ND & $\mathrm{N}$ & $\mathrm{N}$ & ND & ND \\
\hline 149 & Carcinoma ductal invasivo SOE & 3 & Esquerda & 3,0 & ND & ND & 2 & $\mathrm{P}$ \\
\hline
\end{tabular}




\begin{tabular}{|c|c|c|c|c|c|c|c|c|}
\hline Paciente & Ki-67 (\%) & EGFR & CK5/6 & Classificação molecular & Status axilar & $\begin{array}{l}\text { Metástases à } \\
\text { distância }\end{array}$ & $\begin{array}{l}\text { Localização da } \\
\text { metástase }\end{array}$ & Procedimento \\
\hline 1 & 90 & $\mathrm{P}$ & $\mathrm{P}$ & Basal-Like & ND & ND & ND & ND \\
\hline 2 & 20 & $\mathrm{P}$ & $\mathrm{P}$ & Luminal B/HER2 & $\mathrm{N}$ & $\mathrm{N}$ & Ausente & $\begin{array}{l}\text { Nodulectomia e posteriormente } \\
\text { quadrantescomia, por margem } \\
\text { positiva }\end{array}$ \\
\hline 3 & ND & ND & ND & ND & $\mathrm{N}$ & $\mathrm{N}$ & Ausente & Mastectomia total \\
\hline 4 & 90 & $\mathrm{~N}$ & $\mathrm{P}$ & Basal-Like & $\mathrm{P}$ & $P$ & Cérebro & Mastectomia total \\
\hline 5 & 15 & $\mathrm{P}$ & $\mathrm{N}$ & Luminal B/HER2 & $\mathrm{N}$ & ND & ND & ND \\
\hline 6 & ND & ND & ND & Triplo Negativo & ND & ND & ND & ND \\
\hline 7 & 20 & $\mathrm{P}$ & $\mathrm{P}$ & Luminal B & ND & ND & ND & ND \\
\hline 8 & 50 & ND & ND & Luminal B/HER2 & ND & ND & ND & ND \\
\hline 9 & 30 & $\mathrm{P}$ & $\mathrm{P}$ & Luminal B/HER2 & ND & ND & ND & ND \\
\hline 10 & 20 & $\mathrm{P}$ & $\mathrm{P}$ & HER2 & $\mathrm{N}$ & $\mathrm{N}$ & Ausente & Mastectomia total \\
\hline 11 & 90 & ND & ND & Triplo Negativo & $\mathrm{P}$ & ND & ND & Mastectomia total \\
\hline 12 & 30 & ND & ND & HER2 & ND & $\mathrm{P}$ & Óssea, Fígado & ND \\
\hline 13 & 50 & $\mathrm{P}$ & $\mathrm{P}$ & Luminal B/HER2 & ND & $\mathrm{P}$ & Fígado & $\begin{array}{l}\text { Mastectomia total + hepatectomia } \\
\text { parcial }\end{array}$ \\
\hline 14 & 40 & $\mathrm{P}$ & $\mathrm{P}$ & HER2 & $\mathrm{P}$ & ND & ND & ND \\
\hline 15 & 30 & $\mathrm{P}$ & $\mathrm{P}$ & Luminal B/HER2 & $\mathrm{P}$ & $P$ & Óssea, Cérebro & Ausência de cirurgia \\
\hline 16 & ND & ND & ND & Luminal B/HER2 & $\mathrm{P}$ & ND & ND & ND \\
\hline 17 & ND & ND & ND & ND & $\mathrm{P}$ & $\mathrm{N}$ & Ausente & Adenomastectomia \\
\hline 18 & ND & ND & ND & ND & $P$ & ND & ND & ND \\
\hline 19 & ND & $\mathrm{N}$ & $\mathrm{N}$ & Triplo Negativo & $P$ & ND & ND & ND \\
\hline
\end{tabular}




\begin{tabular}{|c|c|c|c|c|c|c|c|c|}
\hline 20 & ND & ND & ND & ND & ND & ND & ND & ND \\
\hline 21 & 20 & $\mathrm{P}$ & $P$ & Luminal B & ND & ND & ND & ND \\
\hline 22 & ND & ND & ND & ND & $P$ & $\mathrm{P}$ & Cérebro & Mastectomia total \\
\hline 23 & 30 & ND & $\mathrm{N}$ & Triplo Negativo & ND & ND & ND & ND \\
\hline 24 & 40 & $\mathrm{P}$ & $P$ & HER2 & $P$ & $\mathrm{P}$ & Cérebro & Mastectomia total \\
\hline 25 & 80 & $\mathrm{~N}$ & $P$ & Luminal B & ND & ND & ND & ND \\
\hline 26 & 20 & ND & ND & Luminal B & $\mathrm{N}$ & $\mathrm{N}$ & Ausente & Mastectomia total \\
\hline 27 & 60 & ND & ND & Luminal B & ND & ND & ND & ND \\
\hline 28 & 60 & ND & ND & Luminal B & $\mathrm{N}$ & ND & ND & Mastectomia total \\
\hline 29 & ND & ND & ND & ND & $P$ & $P$ & ND & Excisão local \\
\hline 30 & 30 & ND & ND & Luminal B/HER2 & ND & ND & ND & ND \\
\hline 31 & ND & $\mathrm{N}$ & $\mathrm{N}$ & Triplo Negativo & $\mathrm{N}$ & $\mathrm{P}$ & Pulmão & Mastectomia total \\
\hline 32 & 5 & $\mathrm{P}$ & $P$ & ND & ND & ND & ND & ND \\
\hline 33 & ND & ND & ND & ND & ND & ND & ND & ND \\
\hline 34 & 60 & ND & ND & Luminal B & $\mathrm{N}$ & $\mathrm{N}$ & Ausente & Mastectomia total \\
\hline 35 & 10 & ND & ND & ND & ND & ND & ND & ND \\
\hline 36 & ND & ND & ND & Luminal B/HER2 & $\mathrm{N}$ & $\mathrm{N}$ & Ausente & Mastectomia total \\
\hline 37 & 50 & ND & ND & Luminal B & ND & ND & ND & ND \\
\hline 38 & ND & ND & ND & ND & ND & ND & ND & ND \\
\hline 39 & 30 & $\mathrm{~N}$ & $\mathrm{~N}$ & Triplo Negativo & $P$ & $\mathrm{~N}$ & Ausente & Mastectomia total \\
\hline 40 & ND & ND & ND & ND & ND & ND & ND & ND \\
\hline 41 & ND & ND & ND & ND & ND & ND & ND & ND \\
\hline
\end{tabular}




\begin{tabular}{|c|c|c|c|c|c|c|c|c|}
\hline 42 & ND & ND & ND & ND & ND & ND & ND & ND \\
\hline 43 & 25 & $\mathrm{~N}$ & $\mathrm{~N}$ & HER2 & ND & ND & ND & ND \\
\hline 44 & 25 & $\mathrm{P}$ & $\mathrm{P}$ & Luminal B/HER2 & ND & ND & ND & Nodulectomia \\
\hline 45 & ND & ND & ND & ND & ND & ND & ND & ND \\
\hline 46 & ND & ND & ND & ND & ND & ND & ND & Nodulectomia \\
\hline 47 & ND & ND & ND & ND & ND & ND & ND & ND \\
\hline 48 & 60 & $\mathrm{P}$ & $\mathrm{P}$ & HER2 & $P$ & $\mathrm{P}$ & Óssea, Fígado & Ausência de cirurgia \\
\hline 49 & ND & ND & ND & ND & ND & ND & ND & ND \\
\hline 50 & ND & ND & ND & ND & ND & ND & ND & ND \\
\hline 51 & 20 & $\mathrm{P}$ & $\mathrm{P}$ & Luminal B & $P$ & $\mathrm{~N}$ & Ausente & Excisão local \\
\hline 52 & ND & ND & ND & ND & $N$ & $\mathrm{P}$ & ND & Excisão local \\
\hline 53 & 90 & $\mathrm{~N}$ & $\mathrm{P}$ & Basal-Like & ND & ND & ND & ND \\
\hline 54 & ND & ND & ND & ND & ND & ND & ND & ND \\
\hline 55 & ND & ND & ND & ND & $\mathrm{N}$ & $\mathrm{N}$ & Ausente & Excisão local \\
\hline 56 & 35 & $\mathrm{P}$ & $\mathrm{P}$ & Luminal B/HER2 & ND & ND & ND & ND \\
\hline 57 & 10 & $\mathrm{P}$ & $\mathrm{P}$ & ND & ND & ND & ND & Quadrantectomia \\
\hline 58 & ND & ND & ND & ND & $N$ & $\mathrm{~N}$ & Ausente & ND \\
\hline 59 & ND & ND & ND & ND & $\mathrm{P}$ & $\mathrm{P}$ & Óssea, Pulmão & Mastectomia total \\
\hline 60 & 5 & $\mathrm{P}$ & $\mathrm{P}$ & Luminal A & $\mathrm{N}$ & ND & ND & Quadrantectomia \\
\hline 61 & 25 & $\mathrm{P}$ & $\mathrm{P}$ & Luminal B & ND & ND & ND & ND \\
\hline 62 & 85 & ND & ND & Luminal B & ND & ND & ND & ND \\
\hline 63 & 65 & ND & ND & Triplo Negativo & $P$ & $\mathrm{~N}$ & Ausente & Mastectomia total \\
\hline
\end{tabular}




\begin{tabular}{|c|c|c|c|c|c|c|c|c|}
\hline 64 & 20 & $\mathrm{P}$ & $\mathrm{P}$ & Luminal B & ND & $\mathrm{N}$ & Ausente & Quadrantectomia \\
\hline 65 & ND & ND & ND & ND & ND & ND & ND & ND \\
\hline 66 & 10 & $P$ & $\mathrm{P}$ & Luminal A & $P$ & $\mathrm{~N}$ & Ausente & Quadrantectomia \\
\hline 67 & 35 & $\mathrm{P}$ & $\mathrm{P}$ & Luminal B & ND & ND & ND & ND \\
\hline 68 & ND & ND & ND & ND & ND & ND & ND & ND \\
\hline 69 & 25 & $P$ & $P$ & Luminal B & ND & ND & ND & ND \\
\hline 70 & 70 & $\mathrm{~N}$ & $P$ & Basal-Like & ND & ND & ND & ND \\
\hline 71 & 5 & ND & ND & Luminal A & ND & ND & ND & ND \\
\hline 72 & ND & ND & ND & ND & $P$ & ND & ND & ND \\
\hline 73 & 40 & $P$ & $P$ & Luminal B & $P$ & $P$ & Fígado & Mastectomia total \\
\hline 74 & 35 & $P$ & $\mathrm{P}$ & Luminal B & $\mathrm{P}$ & ND & ND & ND \\
\hline 75 & ND & ND & ND & ND & $\mathrm{P}$ & ND & ND & ND \\
\hline 76 & 90 & $\mathrm{~N}$ & $\mathrm{P}$ & Basal-Like & ND & ND & ND & ND \\
\hline 77 & ND & ND & ND & Triplo Negativo & $P$ & $\mathrm{P}$ & Pulmão & Mastectomia total \\
\hline 78 & 30 & ND & ND & ND & ND & ND & ND & ND \\
\hline 79 & 15 & $P$ & $P$ & Luminal B/HER2 & ND & ND & ND & ND \\
\hline 80 & 15 & $P$ & $P$ & Luminal B/HER2 & $P$ & $P$ & Óssea & Mastectomia total \\
\hline 81 & ND & ND & ND & ND & $P$ & ND & ND & ND \\
\hline 82 & 25 & ND & ND & Luminal B & ND & $P$ & Fígado & Quadrantectomia \\
\hline 83 & 15 & $\mathrm{P}$ & $\mathrm{P}$ & Luminal B & $\mathrm{P}$ & ND & ND & Quadrantectomia \\
\hline 84 & 60 & $P$ & $\mathrm{P}$ & HER2 & ND & ND & ND & ND \\
\hline 85 & 20 & $P$ & $P$ & HER2 & ND & ND & ND & ND \\
\hline
\end{tabular}




\begin{tabular}{|c|c|c|c|c|c|c|c|c|}
\hline 86 & 30 & $P$ & $\mathrm{P}$ & Luminal B & $P$ & $\mathrm{~N}$ & Ausente & Mastectomia total \\
\hline 87 & 60 & $P$ & $\mathrm{P}$ & Luminal B/HER2 & $\mathrm{N}$ & ND & ND & ND \\
\hline 88 & ND & ND & ND & ND & ND & ND & ND & ND \\
\hline 89 & 50 & ND & ND & Luminal B & ND & ND & ND & ND \\
\hline 90 & 10 & $P$ & $\mathrm{P}$ & HER2 & ND & ND & ND & ND \\
\hline 91 & 20 & $\mathrm{P}$ & $\mathrm{P}$ & Luminal B/HER2 & $\mathrm{P}$ & $\mathrm{P}$ & Óssea & Mastectomia total \\
\hline 92 & 5 & $P$ & $P$ & Luminal A & ND & ND & ND & ND \\
\hline 93 & 25 & $P$ & $P$ & Luminal B & ND & ND & ND & ND \\
\hline 94 & 15 & ND & ND & Luminal B & $\mathrm{P}$ & $P$ & $\begin{array}{l}\text { Óssea, Linfonodos não } \\
\text { regionais, Fígado, } \\
\text { Cérebro }\end{array}$ & Mastectomia total \\
\hline 95 & 20 & $\mathrm{~N}$ & $P$ & Basal-Like & $\mathrm{P}$ & ND & ND & ND \\
\hline 96 & 20 & $\mathrm{P}$ & $\mathrm{P}$ & Luminal B & ND & ND & ND & ND \\
\hline 97 & 80 & ND & ND & Luminal B & ND & ND & ND & ND \\
\hline 98 & 5 & $P$ & $P$ & ND & ND & ND & ND & ND \\
\hline 99 & 10 & $P$ & $P$ & Luminal B/HER2 & $\mathrm{N}$ & $\mathrm{N}$ & Ausente & Excisão local \\
\hline 100 & 10 & $P$ & $P$ & ND & ND & ND & ND & ND \\
\hline 101 & 75 & ND & ND & Luminal B/HER2 & ND & ND & ND & ND \\
\hline 102 & 20 & $\mathrm{P}$ & $P$ & Luminal B/HER2 & $\mathrm{N}$ & ND & ND & ND \\
\hline 103 & 45 & ND & ND & Triplo Negativo & $\mathrm{P}$ & ND & ND & ND \\
\hline 104 & 45 & ND & ND & Luminal B & ND & ND & ND & ND \\
\hline 105 & 20 & $\mathrm{~N}$ & $\mathrm{P}$ & Basal-Like & $\mathrm{N}$ & ND & ND & Mastectomia total \\
\hline 106 & 90 & ND & ND & Triplo Negativo & ND & ND & ND & ND \\
\hline
\end{tabular}




\begin{tabular}{|c|c|c|c|c|c|c|c|c|}
\hline 107 & 40 & ND & ND & ND & ND & ND & ND & ND \\
\hline 108 & ND & $\mathrm{P}$ & $\mathrm{P}$ & Basal-Like & ND & ND & ND & ND \\
\hline 109 & 5 & $P$ & $\mathrm{~N}$ & Luminal A & ND & ND & ND & ND \\
\hline 110 & 25 & $P$ & $P$ & Luminal B & ND & ND & ND & ND \\
\hline 111 & ND & ND & ND & ND & $P$ & ND & ND & ND \\
\hline 112 & ND & $\mathrm{P}$ & $\mathrm{N}$ & Basal-Like & $P$ & ND & ND & ND \\
\hline 113 & 10 & $\mathrm{P}$ & $\mathrm{P}$ & Luminal A & ND & ND & ND & ND \\
\hline 114 & 20 & $\mathrm{P}$ & $P$ & Luminal B & ND & ND & ND & ND \\
\hline 115 & ND & ND & ND & ND & ND & ND & ND & ND \\
\hline 116 & 40 & ND & ND & ND & $\mathrm{P}$ & ND & ND & ND \\
\hline 117 & 20 & ND & ND & Triplo Negativo & $\mathrm{N}$ & $N$ & Ausente & Mastectomia total \\
\hline 118 & 40 & ND & ND & Luminal B & $\mathrm{N}$ & $\mathrm{P}$ & Pulmão & Mastectomia total \\
\hline 119 & 70 & $\mathrm{~N}$ & $P$ & Basal-Like & ND & ND & ND & ND \\
\hline 120 & 80 & $\mathrm{~N}$ & $\mathrm{~N}$ & Triplo Negativo & ND & ND & ND & ND \\
\hline 121 & ND & ND & ND & ND & $P$ & $\mathrm{P}$ & Óssea & Mastectomia total \\
\hline 122 & 40 & $\mathrm{~N}$ & $\mathrm{~N}$ & Triplo Negativo & ND & ND & ND & ND \\
\hline 123 & 5 & $\mathrm{P}$ & $\mathrm{P}$ & Luminal A & $\mathrm{N}$ & ND & ND & ND \\
\hline 124 & ND & ND & ND & ND & ND & ND & ND & ND \\
\hline 125 & ND & ND & ND & ND & ND & ND & ND & ND \\
\hline 126 & 50 & ND & ND & Luminal B & ND & ND & ND & ND \\
\hline 127 & ND & ND & ND & ND & $\mathrm{N}$ & $\mathrm{N}$ & Ausente & Mastectomia total \\
\hline 128 & ND & ND & ND & ND & ND & ND & ND & ND \\
\hline
\end{tabular}




\begin{tabular}{|c|c|c|c|c|c|c|c|c|}
\hline 129 & ND & ND & ND & ND & $P$ & $P$ & Óssea & Mastectomia total \\
\hline 130 & 20 & $N$ & $\mathrm{P}$ & ND & ND & ND & ND & ND \\
\hline 131 & 50 & ND & ND & HER2 & ND & ND & ND & ND \\
\hline 132 & ND & ND & ND & ND & ND & ND & ND & ND \\
\hline 133 & 20 & $\mathrm{~N}$ & $\mathrm{~N}$ & Triplo Negativo & ND & ND & ND & ND \\
\hline 134 & 30 & $\mathrm{P}$ & $\mathrm{P}$ & Luminal B/HER2 & ND & ND & ND & ND \\
\hline 135 & 30 & ND & ND & Luminal B & ND & ND & ND & ND \\
\hline 136 & 5 & $\mathrm{P}$ & $\mathrm{P}$ & Luminal A & ND & ND & ND & ND \\
\hline 137 & 15 & $\mathrm{P}$ & $\mathrm{P}$ & HER2 & $\mathrm{P}$ & $\mathrm{N}$ & Ausente & Excisão local \\
\hline 138 & ND & ND & ND & ND & $\mathrm{N}$ & ND & ND & ND \\
\hline 139 & ND & ND & ND & ND & ND & ND & ND & ND \\
\hline 140 & 30 & ND & ND & Luminal B & $\mathrm{N}$ & $\mathrm{N}$ & Ausente & $\begin{array}{l}\text { Nodulectomia (com margem } \\
\text { comprometida) e posterior } \\
\text { mastectomia total }\end{array}$ \\
\hline 141 & 60 & ND & ND & Luminal B & ND & ND & ND & ND \\
\hline 142 & 15 & $P$ & $\mathrm{P}$ & Basal-Like & $\mathrm{P}$ & ND & ND & ND \\
\hline 143 & ND & ND & ND & ND & ND & ND & ND & ND \\
\hline 144 & 10 & ND & ND & ND & ND & ND & ND & ND \\
\hline 145 & ND & ND & ND & ND & ND & ND & ND & ND \\
\hline 146 & 5 & ND & ND & ND & ND & ND & ND & ND \\
\hline 147 & 50 & ND & ND & Triplo Negativo & $P$ & $P$ & $\begin{array}{l}\text { Óssea, Linfonodos não } \\
\text { regionais, Cérebro }\end{array}$ & ND \\
\hline 148 & ND & ND & ND & ND & ND & ND & ND & ND \\
\hline 149 & ND & ND & ND & ND & ND & $P$ & Fígado, Cérebro & Ausência de cirurgia \\
\hline
\end{tabular}




\begin{tabular}{|c|c|c|c|}
\hline Paciente & Retirada de Linfonodos & Quimioterapia & Esquema \\
\hline 1 & ND & ND & ND \\
\hline 2 & Sentinela & Sim & ACTH e Tamoxifeno. \\
\hline 3 & Axilares & Sim & 8 ciclos: AC (4) + Docetaxel (4) / Herceptin por 1 ano \\
\hline 4 & Axilares & Sim & 4 ciclos - AC - neoadjuvante. TAXOL - adjuvante. \\
\hline 5 & Sentinela & ND & ND \\
\hline 6 & ND & ND & ND \\
\hline 7 & ND & ND & ND \\
\hline 8 & ND & ND & ND \\
\hline 9 & ND & ND & ND \\
\hline 10 & Axilares & Sim & QT convencional (6 ciclos) + Herceptin \\
\hline 11 & Axilares & Sim & 6x FEC pré-cirurgia (excelente resposta clínica) e 3x TAC \\
\hline 12 & ND & ND & ND \\
\hline 13 & NÃO & Sim & 6 ciclos de FAC. Herceptin. Tamoxifeno. \\
\hline 14 & Axilares & ND & ND \\
\hline 15 & Não & Sim & Paclitaxel semanal ( 1 ciclo), Docetaxel ( 1 ciclo), FAC ( 2 ciclos) \\
\hline 16 & Axilares & ND & ND \\
\hline 17 & Axilares & Sim & 6 ciclos: Taxotere + Carboplatina + Herceptin \\
\hline 18 & Axilares & ND & ND \\
\hline 19 & Axilares & ND & ND \\
\hline 20 & ND & ND & ND \\
\hline 21 & ND & ND & ND \\
\hline
\end{tabular}




\begin{tabular}{|c|c|c|c|}
\hline 22 & Axilares & Sim & 8 ciclos: $4 A C+4 T$ \\
\hline 23 & ND & ND & ND \\
\hline 24 & Axilares & Sim & 8 ciclos de Paclitaxel (semanais) sem regressaõ do tumor. Quimio adjuvante (pós-op): Herceptin. \\
\hline 25 & ND & ND & ND \\
\hline 26 & Axilares & Sim & 4 ciclos de $A C+4$ ciclos de docetaxel \\
\hline 27 & ND & ND & ND \\
\hline 28 & Axilares & ND & ND \\
\hline 29 & Axilares & Sim & 6 ciclos de FAC adjuvante, Capecitabina 6 ciclos palitaiva. Tamoxifeno, Taxol, ooferectomia e anastrozol \\
\hline 30 & ND & ND & ND \\
\hline 31 & Axilares & Sim & 4 ciclos de Doxorrubicina e Ciclofosfamida seguido de 12 semanas de Taxol \\
\hline 32 & ND & ND & ND \\
\hline 33 & ND & ND & ND \\
\hline 34 & Sentinela & Sim & 1o e 2o: ciclos A 60mg/m3 - 85mg; C 600mg/m3 - 850 mg. 3o e 4o: ciclos A - 75mg; C - 750 mg. \\
\hline 35 & ND & ND & ND \\
\hline 36 & Sentinela & Sim & 8 ciclos (esquema não disponível) \\
\hline 37 & ND & ND & ND \\
\hline 38 & ND & ND & ND \\
\hline 39 & Axilares & Sim & 3 ciclos - AC - neoadjuvante. Taxol - adjuvante. TNM (desde de outubro de 2009). \\
\hline 40 & ND & ND & ND \\
\hline 41 & ND & ND & ND \\
\hline 42 & ND & ND & ND \\
\hline 43 & ND & ND & ND \\
\hline
\end{tabular}




\begin{tabular}{|c|c|c|c|}
\hline 44 & ND & Não & ND \\
\hline 45 & ND & ND & ND \\
\hline 46 & Não & ND & ND \\
\hline 47 & ND & ND & ND \\
\hline 48 & Axilares & Sim & 8x FAC + bifosfonato + Herceptin $4 x$ Paclitaxel/CTX + Bifosfonato + Herceptin $2 x$ CMF + bifosfonato \\
\hline 49 & ND & ND & ND \\
\hline 50 & Sentinela & ND & ND \\
\hline 51 & Axilares & Sim & 16 ciclos. Esquemas usados: 04 ciclos de Adriamicina e Ciclofosfamida, 12 de Taxol semanal. \\
\hline 52 & Sentinela & Sim & 4 ciclos de Taxotere (docetaxel) e ciclofosfamida \\
\hline 53 & ND & ND & ND \\
\hline 54 & ND & ND & ND \\
\hline 55 & Sentinela & Sim & $\begin{array}{l}8 \text { ciclos }(4 x A C+4 x T) \text { seguido de } 18 \text { ciclos Herceptin. AC (doxorrubicina mais ciclofosfamida) seguido de } \\
\text { Paclitaxel, mais Herceptin } 18 \text { ciclos }\end{array}$ \\
\hline 56 & ND & ND & ND \\
\hline 57 & Sentinela & SimSim & 18 ciclos (aplicações mensais) de Herceptin \\
\hline 58 & Sentinela & Sim & 6 ciclos: 1 AC + 3 Docetaxel + 2 FEC 90. Endocrinoterapia: em uso atual de Tamoxifeno. \\
\hline 59 & Axilares & Sim & Inúmeros ciclos de AC, Herceptin + Hormonioterapia (Tam + Z), Taxotere/Carboplatina/Herceptin. \\
\hline 60 & $\begin{array}{l}\text { Sentinela e } \\
\text { parassentinela }\end{array}$ & Não & fez só hormonioterapia: 5 zoladex (analogo lhrh) + Tamoxifeno + zometa (pela osteopenia) \\
\hline 61 & ND & ND & ND \\
\hline 62 & ND & ND & ND \\
\hline 63 & Axilares & $\operatorname{Sim}$ & 8 ciclos de CMF \\
\hline 64 & Axilares & Sim & ND \\
\hline
\end{tabular}




\begin{tabular}{|c|c|c|c|}
\hline 65 & ND & ND & ND \\
\hline 66 & Axilares & Sim & 8 ciclos neoadjuvantes ( $4 \mathrm{EC}+4 \mathrm{~T}$ ) \\
\hline 67 & ND & ND & ND \\
\hline 68 & ND & ND & ND \\
\hline 69 & ND & ND & ND \\
\hline 70 & ND & ND & ND \\
\hline 71 & ND & ND & ND \\
\hline 72 & Axilares & ND & ND \\
\hline 73 & Axilares & Sim & $\begin{array}{l}4 \text { ciclos ACT (21/01/2008 a 03/04/2008). TAXOL (05/05/2008 a 24/09/2009). Arimedex (21/12/2009 a } \\
15 / 12 / 2010) . \text { Navelbine (pós-cirurgia; 16/02/2011) }\end{array}$ \\
\hline 74 & Axilares & ND & ND \\
\hline 75 & Axilares & ND & ND \\
\hline 76 & ND & ND & ND \\
\hline 77 & Axilares & ND & ND \\
\hline 78 & ND & ND & ND \\
\hline 79 & ND & ND & ND \\
\hline 80 & Axilares & Sim & $\begin{array}{l}8 \text { ciclos (AC + TAXOL). AC neoadjuvante (julho a agosto/2007). TAXOL adjuvante (setembro/2007 a } \\
\text { maio/2008). Navelbine (maio/2008). Pamidronato.(junho/2008). Xeloda (outubro a dezembro/2008). Gemzar } \\
\text { (janeiro/2009). }\end{array}$ \\
\hline 81 & Axilares & ND & ND \\
\hline 82 & ND & ND & ND \\
\hline 83 & Axilares & Sim & 4 ciclos AC +4 ciclos Taxol. Tamoxifeno de 08/2007 até 2012 . Ooforectomia bilateral em 10/2007. \\
\hline 84 & ND & ND & ND \\
\hline 85 & ND & ND & ND \\
\hline
\end{tabular}




\begin{tabular}{|c|c|c|c|}
\hline 86 & Axilares & Sim & $\begin{array}{l}4 \text { ciclos - AC - neoadjuvante. } 4 \text { ciclos TAXOL - adjuvante (até novembro 2007). TMX adjuvante (desde janeiro } \\
\text { de 2008). }\end{array}$ \\
\hline 87 & Axilares & ND & ND \\
\hline 88 & ND & ND & ND \\
\hline 89 & ND & ND & ND \\
\hline 90 & ND & ND & ND \\
\hline 91 & Axilares & Sim & $\begin{array}{l}\text { Mastectomia em 24/11/2006. TAMOXIFENO - março de } 2008 \text { a dezembro de 2011. Arimedex (16/12/2011). } \\
\text { Taxol e Gemzar (12/03/2012). Xelodia (26/07/2012). }\end{array}$ \\
\hline 92 & ND & ND & ND \\
\hline 93 & ND & ND & ND \\
\hline 94 & Axilares & Sim & $\begin{array}{l}4 \text { cliclos de Doxorrubicina e Docetaxel. } 6 \text { ciclos de Navelbine, adriamicina +RT. Zolatex 3,6-08/11/2007 a } \\
07 / 2012 \text {. }\end{array}$ \\
\hline 95 & Axilares & ND & ND \\
\hline 96 & ND & ND & ND \\
\hline 97 & ND & ND & ND \\
\hline 98 & ND & ND & ND \\
\hline 99 & Sentinela & Sim & 6 ciclos: FEC (convenio não autorizou taxano). Herceptin 12 Aplicações. \\
\hline 100 & ND & ND & ND \\
\hline 101 & ND & ND & ND \\
\hline 102 & Sentinela & ND & ND \\
\hline 103 & Axilares & ND & ND \\
\hline 104 & ND & ND & ND \\
\hline 105 & Axilares & Sim & $\begin{array}{l}3 \text { ciclos (realizado com o diagnóstico da biópsia de mama no período de 20/12/2005 a 02/02/2006). } 2 \text { ciclos } \\
\text { (realizado com o diagnóstico na mastectomia no período de 27/04/2006 a 24/05/2006). FAC - Finalidade } \\
\text { adjuvante. }\end{array}$ \\
\hline
\end{tabular}




\begin{tabular}{|c|c|c|c|}
\hline 106 & ND & ND & ND \\
\hline 107 & ND & ND & ND \\
\hline 108 & ND & ND & ND \\
\hline 109 & ND & ND & ND \\
\hline 110 & ND & ND & ND \\
\hline 111 & ND & ND & ND \\
\hline 112 & Axilares & Sim & 6 FAC / 8CMF /USOU TAMOXIFENO \\
\hline 113 & ND & ND & ND \\
\hline 114 & ND & ND & ND \\
\hline 115 & ND & ND & ND \\
\hline 116 & Axilares & ND & ND \\
\hline 117 & Sentinela & Não & - \\
\hline 118 & Sentinela & Sim & $\begin{array}{l}6 \text { ciclos de adriblastina + ciclofosfamida. 1a recidiva (junho/2008): local ( } 6 \text { ciclos de TC). Segunda recidiva: } \\
\text { março/2011: local + sistêmica (pulmão): paclitaxel semanal } 6 \text { meses, atualmente hormonioterapia. }\end{array}$ \\
\hline 119 & ND & ND & ND \\
\hline 120 & ND & ND & ND \\
\hline 121 & Axilares & Sim & $\begin{array}{l}\text { AT por } 08 \text { ciclos (02/06/05 a 07/11/05); Tamoxifeno (11/05/05 a 10/06/06); Zoladex (19/09/06 a 07/03/07) } \\
\text { Femara (setembro/2006 a março/2007); Zometa (10/01/06 a 11/10/07); Gemzar e Cisplatina (09/03/07 a } \\
\text { 18/09/07); Faslodex (11/10/07); Xeloda (23/10/07). }\end{array}$ \\
\hline 122 & ND & ND & ND \\
\hline 123 & Sentinela & ND & ND \\
\hline 124 & ND & ND & ND \\
\hline 125 & ND & ND & ND \\
\hline 126 & ND & ND & ND \\
\hline
\end{tabular}




\begin{tabular}{|c|c|c|c|}
\hline 127 & Axilares & Sim & $\begin{array}{l}6 \text { ciclos adriamicina e taxotere, mastectomia direita em 21/01/2011, resposta patológica completa. } \\
\text { Aromasin Vo adjuvante de } 10 / 2005 \text { até 10/2010. }\end{array}$ \\
\hline 128 & ND & ND & ND \\
\hline 129 & Axilares & Sim & 6 ciclos adjuvante // 9 1a linha // 7 2a linha. Esquemas: FAC, Taxotene, NUB + Gemzar. \\
\hline 130 & ND & ND & ND \\
\hline 131 & ND & ND & ND \\
\hline 132 & ND & ND & ND \\
\hline 133 & ND & ND & ND \\
\hline 134 & ND & ND & ND \\
\hline 135 & ND & ND & ND \\
\hline 136 & ND & ND & ND \\
\hline 137 & Axilares & Sim & FAC (6 ciclos) \\
\hline 138 & ND & ND & ND \\
\hline 139 & ND & ND & ND \\
\hline 140 & Sentinela & Sim & CMF (6 ciclos). \\
\hline 141 & ND & ND & ND \\
\hline 142 & Axilares & Sim & ND \\
\hline 143 & ND & ND & ND \\
\hline 144 & ND & ND & ND \\
\hline 145 & ND & ND & ND \\
\hline 146 & ND & ND & ND \\
\hline 147 & Axilares & Sim & $4 A C+4 T$ \\
\hline
\end{tabular}




\begin{tabular}{|c|c|c|c|c|c|c|}
\hline Paciente & QT Neoadjuvante & Herceptin & Tempo em remissão (meses) & Radioterapia & Dados de seguimento & Tempo de seguimento (meses) \\
\hline 1 & ND & - & ND & ND & ND & ND \\
\hline 2 & Não & Sim & 26 & Sim & Vivo sem tumor & 14 \\
\hline 3 & ND & Sim & 17 & Sim & Vivo sem tumor & 19 \\
\hline 4 & Sim & - & ND & Sim & Óbito relacionado ao tumor & 19 \\
\hline 5 & ND & ND & ND & ND & ND & ND \\
\hline 6 & ND & - & ND & ND & ND & ND \\
\hline 7 & ND & - & ND & ND & ND & ND \\
\hline 8 & ND & ND & ND & ND & ND & ND \\
\hline 9 & ND & ND & ND & ND & ND & ND \\
\hline 10 & ND & Sim & 24 & Sim & Vivo sem tumor & 24 \\
\hline 11 & Sim & - & 11 & Sim & Vivo com recorrência local & ND \\
\hline 12 & ND & ND & ND & ND & ND & ND \\
\hline 13 & ND & Sim & ND & Sim & Vivo sem tumor & 22 \\
\hline 14 & ND & ND & ND & ND & ND & ND \\
\hline 15 & Não & Não & ND & Sim & Óbito relacionado ao tumor & ND \\
\hline 16 & ND & ND & ND & ND & ND & ND \\
\hline 17 & Não & Sim & 26 & Sim & Vivo sem tumor & 26 \\
\hline 18 & ND & - & ND & ND & ND & ND \\
\hline 19 & Sim & - & ND & Sim & Vivo sem tumor & ND \\
\hline 20 & ND & - & ND & ND & ND & ND \\
\hline 21 & ND & - & ND & ND & ND & ND \\
\hline
\end{tabular}




\begin{tabular}{|c|c|c|c|c|c|c|}
\hline 22 & Sim & - & 12 & Sim & Vivo com metástase à distância & 12 \\
\hline 23 & ND & - & ND & ND & ND & ND \\
\hline 24 & Sim & Sim & Sem remissão & Sim & Óbito relacionado ao tumor & 20 \\
\hline 25 & ND & - & ND & ND & ND & ND \\
\hline 26 & Sim & - & ND & Sim & Vivo sem tumor & ND \\
\hline 27 & ND & - & ND & ND & ND & ND \\
\hline 28 & ND & - & ND & ND & ND & ND \\
\hline 29 & Não & - & ND & Sim & Vivo com metástase à distância & ND \\
\hline 30 & ND & ND & ND & ND & ND & ND \\
\hline 31 & Não & - & 26 & Sim & Vivo com metástase à distância & 44 \\
\hline 32 & ND & ND & ND & ND & ND & ND \\
\hline 33 & ND & - & ND & ND & ND & ND \\
\hline 34 & ND & - & 6 & Não & Vivo sem tumor & 6 \\
\hline 35 & ND & ND & ND & ND & ND & ND \\
\hline 36 & ND & ND & 7 & Sim & Vivo sem tumor & 7 \\
\hline 37 & ND & - & ND & ND & ND & ND \\
\hline 38 & ND & - & ND & ND & ND & ND \\
\hline 39 & Sim & - & ND & Sim & Vivo sem tumor & 36 \\
\hline 40 & ND & - & ND & ND & ND & ND \\
\hline 41 & ND & ND & ND & ND & ND & ND \\
\hline 42 & ND & ND & ND & ND & ND & ND \\
\hline 43 & ND & ND & ND & ND & ND & ND \\
\hline
\end{tabular}




\begin{tabular}{|c|c|c|c|c|c|c|}
\hline 44 & Não & ND & ND & ND & ND & ND \\
\hline 45 & ND & ND & ND & ND & ND & ND \\
\hline 46 & ND & ND & ND & ND & ND & ND \\
\hline 47 & ND & ND & ND & ND & ND & ND \\
\hline 48 & Sim & Sim & Sem remissão & Não & Óbito relacionado ao tumor & 18 \\
\hline 49 & ND & ND & ND & ND & ND & ND \\
\hline 50 & ND & ND & ND & ND & ND & ND \\
\hline 51 & Não & - & ND & Sim & Vivo sem tumor & 41 \\
\hline 52 & ND & - & 42 & Sim & Vivo com metástase à distância & 51 \\
\hline 53 & ND & - & ND & ND & ND & ND \\
\hline 54 & ND & - & ND & ND & ND & ND \\
\hline 55 & Não & Sim & 52 meses & Sim & Vivo sem tumor & 52 \\
\hline 56 & ND & ND & ND & ND & ND & ND \\
\hline 57 & ND & ND & ND & ND & ND & ND \\
\hline 58 & Não & - & ND & Sim & Vivo sem tumor & 56 \\
\hline 59 & $\operatorname{Sim}$ & Sim & 13 & Sim & Óbito relacionado ao tumor & 12 \\
\hline 60 & Não & - & ND & Sim & Vivo sem tumor & 61 \\
\hline 61 & ND & - & ND & ND & ND & ND \\
\hline 62 & ND & - & ND & ND & ND & ND \\
\hline 63 & ND & - & 132 & Sim & Vivo sem tumor & 131 \\
\hline 64 & ND & - & ND & Sim & Vivo sem tumor & 60 \\
\hline 65 & ND & ND & ND & ND & ND & ND \\
\hline
\end{tabular}




\begin{tabular}{|c|c|c|c|c|c|c|}
\hline 66 & Sim & - & 52 & Sim & Vivo sem tumor & 59 \\
\hline 67 & ND & - & ND & ND & ND & ND \\
\hline 68 & ND & - & ND & ND & ND & ND \\
\hline 69 & ND & - & ND & ND & ND & ND \\
\hline 70 & ND & - & ND & ND & ND & ND \\
\hline 71 & ND & - & ND & ND & ND & ND \\
\hline 72 & ND & - & ND & ND & Óbito relacionado ao tumor & ND \\
\hline 73 & Não & - & ND & Sim & Óbito relacionado ao tumor & 41 \\
\hline 74 & ND & - & ND & ND & ND & ND \\
\hline 75 & ND & ND & ND & ND & ND & ND \\
\hline 76 & ND & - & ND & ND & ND & ND \\
\hline 77 & Não & - & ND & ND & ND & ND \\
\hline 78 & ND & ND & ND & ND & ND & ND \\
\hline 79 & ND & ND & ND & ND & ND & ND \\
\hline 80 & Sim & Não & ND & Sim & Vivo com metástase à distância & 21 \\
\hline 81 & ND & ND & ND & ND & ND & ND \\
\hline 82 & ND & - & ND & ND & Óbito relacionado ao tumor & ND \\
\hline 83 & Não & - & ND & Sim & Vivo sem tumor & 66 \\
\hline 84 & ND & ND & ND & ND & ND & ND \\
\hline 85 & ND & ND & ND & ND & ND & ND \\
\hline 86 & Sim & - & ND & Sim & Vivo com recorrência local & 71 \\
\hline 87 & ND & ND & ND & ND & ND & ND \\
\hline
\end{tabular}




\begin{tabular}{|c|c|c|c|c|c|c|}
\hline 88 & ND & ND & ND & ND & ND & ND \\
\hline 89 & ND & - & ND & ND & ND & ND \\
\hline 90 & ND & ND & ND & ND & ND & ND \\
\hline 91 & Não & Não & ND & Sim & Óbito relacionado ao tumor & 73 \\
\hline 92 & ND & - & ND & ND & ND & ND \\
\hline 93 & ND & - & ND & ND & ND & ND \\
\hline 94 & ND & - & 24 & Sim & Óbito relacionado ao tumor & 64 \\
\hline 95 & ND & - & ND & ND & ND & ND \\
\hline 96 & ND & - & ND & ND & ND & ND \\
\hline 97 & ND & - & ND & ND & ND & ND \\
\hline 98 & ND & ND & ND & ND & ND & ND \\
\hline 99 & ND & Sim & ND & Sim & Vivo sem tumor & 82 \\
\hline 100 & ND & ND & ND & ND & ND & ND \\
\hline 101 & ND & ND & ND & ND & ND & ND \\
\hline 102 & ND & ND & ND & ND & ND & ND \\
\hline 103 & ND & - & ND & ND & ND & ND \\
\hline 104 & ND & - & ND & ND & ND & ND \\
\hline 105 & Sim & - & ND & Não & ND & ND \\
\hline 106 & ND & - & ND & ND & ND & ND \\
\hline 107 & ND & ND & ND & ND & ND & ND \\
\hline 108 & ND & - & ND & ND & ND & ND \\
\hline 109 & ND & - & ND & ND & ND & ND \\
\hline
\end{tabular}




\begin{tabular}{|c|c|c|c|c|c|c|}
\hline 110 & ND & - & ND & ND & ND & ND \\
\hline 111 & ND & - & ND & ND & ND & ND \\
\hline 112 & ND & - & 25 & Não & Óbito relacionado ao tumor & 25 \\
\hline 113 & ND & - & ND & ND & ND & ND \\
\hline 114 & ND & - & ND & ND & ND & ND \\
\hline 115 & ND & - & ND & ND & ND & ND \\
\hline 116 & ND & ND & ND & ND & ND & ND \\
\hline 117 & ND & - & ND & Não & Vivo sem tumor & 92 \\
\hline 118 & Não & - & 60 & Sim & Vivo com metástase à distância & 124 \\
\hline 119 & ND & - & ND & ND & ND & ND \\
\hline 120 & ND & - & ND & ND & ND & ND \\
\hline 121 & Sim & - & 13 & Sim & Óbito relacionado ao tumor & 28 \\
\hline 122 & ND & - & ND & ND & ND & ND \\
\hline 123 & ND & - & ND & ND & ND & ND \\
\hline 124 & ND & - & ND & ND & ND & ND \\
\hline 125 & ND & - & ND & ND & ND & ND \\
\hline 126 & ND & - & ND & ND & ND & ND \\
\hline 127 & Sim & - & 36 & Não & Vivo sem tumor & 65 \\
\hline 128 & ND & - & ND & ND & ND & ND \\
\hline 129 & Não & - & ND & Sim & Óbito relacionado ao tumor & ND \\
\hline 130 & ND & ND & ND & ND & ND & ND \\
\hline 131 & ND & ND & ND & ND & ND & ND \\
\hline
\end{tabular}




\begin{tabular}{|c|c|c|c|c|c|c|}
\hline 132 & ND & ND & ND & ND & ND & ND \\
\hline 133 & ND & - & ND & ND & ND & ND \\
\hline 134 & ND & ND & ND & ND & ND & ND \\
\hline 135 & ND & - & ND & ND & ND & ND \\
\hline 136 & ND & - & ND & ND & ND & ND \\
\hline 137 & ND & Não & 18 & Sim & Óbito relacionado ao tumor & ND \\
\hline 138 & ND & - & ND & ND & ND & ND \\
\hline 139 & ND & ND & ND & ND & ND & ND \\
\hline 140 & ND & - & ND & Não & Vivo sem tumor & 21 \\
\hline 141 & ND & - & ND & ND & Vivo sem tumor & ND \\
\hline 142 & ND & - & ND & ND & ND & ND \\
\hline 143 & ND & ND & ND & ND & ND & ND \\
\hline 144 & ND & ND & ND & ND & ND & ND \\
\hline 145 & ND & - & ND & ND & ND & ND \\
\hline 146 & ND & ND & ND & ND & ND & ND \\
\hline 147 & ND & - & ND & Sim & Óbito relacionado ao tumor & ND \\
\hline 148 & ND & ND & ND & ND & ND & ND \\
\hline 149 & Sim & Sim & Sem remissão & Sim & Óbito relacionado ao tumor & 10 \\
\hline
\end{tabular}

ND (Não disponível); N (Negativo); P (Positivo); ACTH (Doxorrubicina, Ciclofosfamida, Taxol e Herceptin); AC (Doxorrubicina e Ciclofosfamida); FEC (fluorouracil, epirrubicina e ciclofosfamida); TAC (Taxol, Doxorrubicina e Ciclofosfamida); FAC (Fluorouracil, Doxorrubicina e Ciclofosfamida); CMF (Ciclofosfamida, Metotrexato and Fluorouracil). 
Apêndice 3 - Artigo Publicado (Breast Cancer in Very Young Woman).

\title{
ARIICIE IN PRESS
}

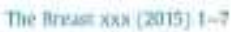

Original article

\section{Breast cancer in very young women: Clinicopathological study of 149 patients $\leq 25$ years old}

\author{
Rafael de Deus Moura ${ }^{\text {ab }}$, Filomena M. Carvalho ${ }^{\mathrm{b}}$, Carlos E. Bacchi a, b, *

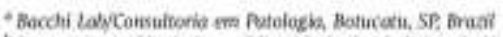

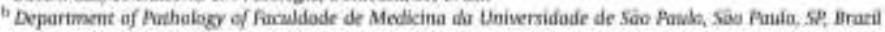

\section{ARTICLE I NFO}

\section{Atticle Mistory:}

Received 12 October 2014

Received in revised form

9 Fobruary 2015

Accepted 8 April 2015

Avarilabie anline $\mathrm{xxx}$

\section{Neyworde:}

bieast canoer

hreast cancer
Very young

Imununohistochemistry

\begin{abstract}
A B STR A C T
Bockeround: Breast cancer in young women bas different dinical and pathologic features and a mom aggressive biological behavior when compared to breast cancers in older women. However, information is limited to the group of very young women ( $\leq 25$ years).

Objectives: The aim of the present study was to investigate the pathological characteristics of breas cancer in 149 frazilian women who were $<25$ years old at the time of breast cancer diagnosis.

Materials and methods: Tumor tamples diagrosed between 2003 and 2009 were analyzed from the archives of the Bacchi Lathoratory.

fiesult: In our series of 149 Brazilian women $\leq 25$ years, $8.7 \%$ presented with in situ disease only, of 136 invasive carcinomas, 9198 were of the ductal type and $45.6 \%$ were of histological gracte III. Overall. estrogen receptar (ER) was positive in $59.6 \%$ cases, and HER2 overexpression was defected in $32.8 \%$. We also found a low prevalence of Luminal A cases and a high prevalence of Triple Negative cases. Statistical analysis showed that HER2 and basal-like groups had a lower owerall survival expectation. follow-up data showed high frequencies of regional tymph node mesastasis, distant metastasis, and tumor related deaths.

Concitsion: The present study represents the largest series of breast cancer arising in women 825 years and establishes the main dinical, pathological, immunohistochemical and follow-19 features of this population.

o 2015 Elsevier Ltd, All rights reserved.
\end{abstract}

\section{Introduction}

Breast cancer is the most frequent cancer in women worldwide and is second in incidence only to skin cancer. Incidence rates are higher in more developed regions of the world in comparison with developing regions, and they vary from 27 per 100,000 women in Middle Africa to 96 per 100,000 women in Western Europe [1], In the United States of America (USA), the incidence rate of breast cancer decreased between 1999 and 2005 (by $2 \%$ per year) and has remained stable from 2005 to 2009 |2|. In contrast, the incidence of metastatic breast cancer in women younger than age 40 bas been increasing in the USA. The increase in metastatic disease in young women was shown to be independent of race and ethnicity but was more pronounced in non-Hispanic white and African-American

\footnotetext{
* Correspoeding author. Reia Leonidas Candoso 739, Botucatu, SP I8602-010, Brazil. Tel: + 551431125000 ; fax +551431125920

patients and in women with estrogen receptor (ER)-positive tu mors. Importantly, no trend for decelerating was obserwed $[3$, in Geneva, Switzerland, breast cancer incidence in women $<40$ years old doubled between 1995 and 2004. Of note, the mean annual increase was much higher in the last three years of the study $|4|$ Similar trend was also observed Spain |S| and Netherland $|6|$.

Approximately $15 \%$ of women diagnosed with breast cancer are in the reproductive age group and, according to the latest National Cancer Institute Surveillance, Epidemiology and End Results (SEER) database, in the USA $1.8 \%$ of all breast cancers occur in women younger than 35 years of age $|2.7|$, Breast cancer is the leading cause of cancer death for women between 20 and 39 years old in the USA $12 \mathrm{l}$. At a young age, breast cancers have a more aggressive biological behavior and have been correlated with larger tumor sizes, less hormone positive tumors, higher grade tumors, more frequent metastases to lymph nodes and inferior survival when compared to breast cancers in older women $18-10)$. The observed difference in prognosis may be related to differences in the biology of breast cancer in younger patients $[11]$. In the group of youni 
patients ( $\leq 35$ years), the risk of death rises by $5 \%$ for every 1-year reduction in age, highlighting the importance of studying breast cancer at an even younger age.

Studies of breast cancer occurring in very young women ( $\leq 25$ years) are scarce, making it difficult to estimate incidence rates [12], Data from the SEER database collected between 2006 and 2010 indicate that the age-adjusted incidence rate of breast cancer in white females is 0.2 in $1.5-19$ year olds and 1.6 per 100,000 persons per year for $20-24$ year olds. With respect to the proportion of breast cancer cases in very young patients when compared to the entire population of breast cancer patients, in Japan and England only $0.09 \%$ of breast cancers diagnosed corresponds to women $<25$ years old $\{14,15\}$

Although there are a considerable number of studies regarding breast cancer in women $\leq 35$ years old, information is limited in younger women ( $\leq 25$ years). The aim of the present study was to investigate the parthological characteristics of breast cancer in 149 Brazilian women who were $\leq 2.5$ years old at the time of breast cancer diagnosis.

\section{Materials and methods}

\section{Study patients}

Between 2003 and 2012, 149 tumor samples from patients 25 years and younger with the diagnosis of breast cancer were analyzed from the archives of the Consultoria em Patologia, a large anatomic pathology reference laboratory located in the city of Botucatu, State of Sao Paulo, Brazi. This laboratory evaluates more than 6000 cases of breast cancer per year, usually received for the study of prognostic and predictive markers. All samples were reviewed and classified according to histological type, histological grading and the presence of an in situ carcinoma component. These cases originated from the following geographic regions of Brazil: Southeast ( 72 cases; $48.3 \%$ ). South (31 cases; $20.8 \%$ ) Northeast (25 cases; $16.8 \%$ ), North (13 cases; $8.7 \%$ ) and CentralWest ( 8 cases; $5.4 \%$ ). Follow-up and treatment data were obtained by sending questionnaires to patients' physicians and from the original pathology reports. Survival data were obtained for 46 cases, with a median follow-up of 39 months (range 6-131). The final diagnosis in all cases was reached through the analysis of whole histological sections from the original paraffin block stained with hematoxylin-eosin and through the interpretation of immunostaining of the tissue microarray sections and/or immunohistochemistry analysis performed on histological sections of the native paraffin block. This study was approved by the Scientific Committee of the Department of Pathology of Faculdade de Medicina da Universidade de Sas Paulo and by the Ethical Committee for Research Projects of the Hospital das Clinicas da Faculdade de Medicina da Universidade de Sao Paulo (CAPPesq; protocol number: 236/11) Because the study was retrospective, informed patient consent was waived; however, all forms of patient identification were protected.

\section{Tissue microarnay (TMA) blocks and immumohistochemistry analysis}

Tissue microarray of 66 cases was constructed as described elsewhere $[16$. Histological sections from the TMA or the original blocks were stained for ER, progesterone receptor (PR), HER2, Ki-6) antigen, epidermal growth factor receptor (EGFR) and cytokeratin 5/6 (CK.5/6). The sources and dilutions of these antibodies and epitope retrieval methods are listed in Table 1. Bound antibodies were detected using Envision ${ }^{\text {TM }}$ mouse or rabbit (Dako, Carpinteria, CA, USA) secondary antibodies after a $45 \mathrm{~min}$ incubation at room temperature, Positive immunohistochemistry staining for the nu. dear localization of ER, PR and $\mathrm{Ki}-67$, cytoplasmic localization of CK.5/6 and membrane-associated staining of ECFR were assessed. For HER2 assessment, samples were considered positive if they scored $3+$ according to the guidelines of the American Society of Clinical Oncology (ASCO) and the College of American Pathologists (CAP). For cases with a $2+$ score for HERZ, each sample was further assayed tasing fluorescence in situ hybridization (FISH) and were only considered positive if the ratio of HER2 signal to CEP17 was $\geq 2.0 \mid 171$. Approximation of the molecular classification of samples using the panel of antibodies mentioned above was performed according to modified 12th St Gallen subtype classification [18], described in Table 2.

\section{Statistical methods}

Association between variables was tested with chi-square statistics calculated using the maximum likelihood ratio. Molecular dass and mean tumor size were compared using an ANOVA table. Bonferroni's method was applied to identify which classes differed from others, Lifespan tables were performed to apply methods to obtain survival curves, Survival curves were estimated by the Kaplan-Meier method, using a Breslow test to analyze the significant differences between the groups' curves. The significance level used in this study was $5 \%$ and all p-values were calculated and presented in the text.

\section{Results}

\section{Cinical and pathological features}

From a total of 39,210 breast cancer cases diagnosed at our Institution between 2003 and 2012, 149 patients age 25 years or younger were selected, corresponding to $0.4 \%$ of all breast cancers. Among patients in this age group, the median age was 24 years (range 7-25). The median age of all breast cancer cases from the total number of cases during the same period of time was 54 years It must be emphasized, however, that this high proportion of breast cancer in very young patients may be related to a selection bias, as this laboratory is a reference center for pathology services, general second opinions and immunohistochemical studies to private public and academic institutions from all Brazilian geographic

Table 1

Details of immenohistochemical analyses.

\begin{tabular}{|c|c|c|c|}
\hline Primary anfibody to & Cone/Source & Dilution & Epitope retrieval method \\
\hline Estrogen receptor (ER) & R; SP1/thermo Scientific & $1: 500$ & Pressute cooker, $9 \mathrm{~min}$ \\
\hline Progesterone receptor (PR) & M: PER636rThermo Scientife & $1: 1000$ & Pressere cooker, $9 \mathrm{~min}$ \\
\hline HER2 & F; SP3/Thermo Scientific & $1: 100$ & Mocrowawe oven $15 \mathrm{~min}$ \\
\hline Epidermal growth factor receptor (EGFR) & M: 31G7izymed & 1:200 & 0.1\% Pronase KT, 15 min \\
\hline Basal cytakeratin 5,6 (CK5/6) & M: D5/16B4/Dake & 1:100 & Mocrowave oven $15 \mathrm{~min}$ \\
\hline
\end{tabular}

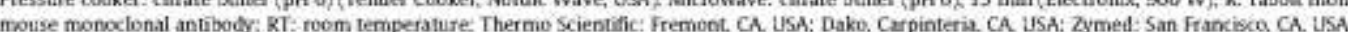




\title{
ARTICLEIN PRESS
}

\author{
R. de Drus Maura ef ad / The Breast ox (2025) i-7
}

Table 2

Criteris used for the approximation of molecular classification according to the immunnhistochemistry panel

\begin{tabular}{|c|c|c|c|c|}
\hline \multirow[t]{2}{*}{ Moleculat subrype } & \multicolumn{4}{|c|}{ Immutnohistochemical ptofle } \\
\hline & $E R$ and/ar $P R$ & HER2 & $\mathrm{ki}-67$ & CKS $/ 6$ and $/$ or EGFK \\
\hline Liminal A & + & - & $<18 \pi$ & $+1=$ \\
\hline Luminal B/HER2- & + & - & $>14 \%$ & $+1-$ \\
\hline HER2 & - & + & Any & $+1-$ \\
\hline Luminal B/HES2 + & + & + & Amy & $+1-$ \\
\hline Basal-tike & - & - & Any & + \\
\hline Triple negative & - & $=$ & Amy & - \\
\hline
\end{tabular}

Abbreviations: [R, estrogen receptor, PR, progesterone reoptor, $\mathrm{CX}$, cytokeratin: EGFR, epidermal growth factor reseptor. Madified frem 12th St Gailen subtype classification $[18$ )

regions. On the other hand, the sample of patients in this study is very representative of the Brazilian population and included cases from the federal district plus 23 of the 26 Brazilian States and from 58 different cities.

Table 3 shows the main clinicopathological features of breast cancer in this cohort. Pregnancy history was obtained for $20 \mathrm{pa}-$ tients. Nine patients developed breast cancer after pregnancy and

Table 3

Clinicopattological characteristics of breast canoer in very young women $(<25$ years?.

\begin{tabular}{|c|c|}
\hline Variasle & $N(x)$ \\
\hline \multicolumn{2}{|l|}{ Pregnancy histacy $(\mathrm{N}=20)$} \\
\hline Pregnaby before cancer diaznosis & $9\langle 45.0\rangle$ \\
\hline Negative history for pregnancy & $11(55.0)$ \\
\hline \multicolumn{2}{|l|}{ Family history of breast cancer $(N=18)$} \\
\hline Breast cancer in mother or sister & $2\langle 11.1\}$ \\
\hline Breast cancer in other family members & $2\langle 11.1\rangle$ \\
\hline Negative & $14(778)$ \\
\hline \multicolumn{2}{|l|}{ Hissological se:ytype $(N=149)$} \\
\hline In situ dectal carcinoma" & $11(7,4)$ \\
\hline In situ lobelar carcinuma" & $2\langle 13\rangle$ \\
\hline Invasive ductal carcinena & $125(83.9)$ \\
\hline Invasive carcinoma with medullary features & $4(27)$ \\
\hline Other invasive carcisoma subtypes & $7\langle 47\rangle$ \\
\hline \multicolumn{2}{|l|}{ Notringham histobogic grade $(\mathrm{N}=136)$} \\
\hline Grade 1 & $15\langle 11.0\rangle)$ \\
\hline Grade II & $59\langle 43.4\rangle$ \\
\hline Grade III & $62(45.6)$ \\
\hline \multicolumn{2}{|l|}{ Tunor size $\{\mathrm{N}=68$ ] } \\
\hline$<2 \mathrm{~cm}$ & $21(309)$ \\
\hline$>2 \mathrm{~cm}$ and $<5 \mathrm{~cm}$ & $30\langle 44.1\rangle$ \\
\hline$>5 \mathrm{~cm}$ & $17\langle 25.0\rangle$ \\
\hline \multicolumn{2}{|l|}{ Molecular chssification $(N=96)$} \\
\hline Luminal $A$ & $\mathbf{B}\langle 83\rangle$ \\
\hline Lumina B/HER2. & $32\langle 33.3\}$ \\
\hline HER2 & $11(115)$ \\
\hline tumina B/HER2+ + & $19\langle 198\rangle$ \\
\hline Basal-like & $11(11.5)$ \\
\hline Triple nezative & $15(15.6)$ \\
\hline \multicolumn{2}{|l|}{ Estrogen receptor $[N-104]$} \\
\hline Pesieve & $62(59.6)$ \\
\hline Negative & $42(40.4)$ \\
\hline \multicolumn{2}{|l|}{$H E R O L N=131 Y$} \\
\hline Positive & $43 \div 328\}$ \\
\hline Negative & $88(67.2)$ \\
\hline \multicolumn{2}{|l|}{ Surgikal treatment $t^{4}(N-45)$} \\
\hline Total mastectomy & $30\langle 66.7\rangle$ \\
\hline $\mathrm{BCI}$ & $12(26.7)$ \\
\hline Na surzicat procedere & $3\langle 67\rangle$ \\
\hline \multicolumn{2}{|l|}{ Chemotherapy $(N=46\rangle$} \\
\hline Yes & $43(93.5)$ \\
\hline No & $3(6.5)$ \\
\hline \multicolumn{2}{|l|}{ Neoudjuvant therapy $(\mathbb{N}=31)$} \\
\hline Yes & $16(51.6)$ \\
\hline No \{only adjevant therapy? & $15(484)$ \\
\hline
\end{tabular}

Table 3 [continued]

\begin{tabular}{|c|c|}
\hline Variable & $N(\infty)$ \\
\hline \multicolumn{2}{|l|}{ Chemotherapy regimens $(\mathrm{N}=3 \mathrm{~B})$} \\
\hline Toxane-ples-anthracycline-based & $21(55.3)$ \\
\hline Anthracycline-based & $5(112)$ \\
\hline Taxane-based & $4(105)$ \\
\hline CMF-hased & $2(5.3)$ \\
\hline other & $6(158)$ \\
\hline \multicolumn{2}{|l|}{ Anti- HER2 therapy $(N-15)$} \\
\hline Yes. & $11(733)$ \\
\hline No & $4(26.7)$ \\
\hline \multicolumn{2}{|l|}{ Radivtherapy $(\mathrm{N}=44)$} \\
\hline Yes: & 37 $(84.1)$ \\
\hline No & $7(159)$ \\
\hline \multicolumn{2}{|l|}{ Lymph rodes status $(\mathrm{N}=\mathrm{B})$} \\
\hline No metastasis & $23(38.3)$ \\
\hline Presence of metastasis & $37(61.7)$ \\
\hline \multicolumn{2}{|l|}{ Distant metastasis $(N-41)$} \\
\hline Aosent & $21(51.2)$ \\
\hline Present & $20(48.8)$ \\
\hline Bones & $10(24.4)$ \\
\hline Brain & $7(17.1)$ \\
\hline Iner & $z(17.1)$ \\
\hline Lung & $4(9.8)$ \\
\hline other & $3(73)$ \\
\hline \multicolumn{2}{|l|}{ Follow-up data $(N=46)$} \\
\hline Alive without tumsor & $23(50.0)$ \\
\hline Alive wirh local recurrence & $2(4.3)$ \\
\hline Alive with distant metastasis & $5(109)$ \\
\hline Tumor-related death & $16(34.7)$ \\
\hline
\end{tabular}

"Absence of infiltrating carcinoena.

tother imvasive catcinoma types indude apoctine, in situ ductal carcinoma with mòcroenvasica lobelar, metaplastic, mucinoes mixed mucineus and bobsiar and secretory (ooe case for each of these vopes)

Ey immunahistochemistry ar ASH.

"Total Mastectomin: removal of all hreast tissue generally including the nipple and areoly BCT (breast conserving therapy); includes "partial miastectomies". Tampectomies", and "quadrantectomies"

F Other includes non regional lymph nodes (2 cases) and 1ignored.

11 patients had no history of pregnancy. All nine patients developed breast cancer after pregnancy. The following number of pregnandes were present as follows: one patient, 3 times, four patients, 2 times, two patients, 1 time, and in 2 cases we were unable to obtain the number of pregnancies. No woman was pregnant at the time of cancer diagnosis. We were able to obtain information about family history in 18 patients. Only two patients had a first-degree relative with breast cancer. Other two patients had other family members with breast cancer history (cousin and great-aunt).

The distribution of cases with in situ and invasive components was as follows: $8.7 \%(13 / 149)$ presented with in situ disease only (11 ductal in siru carcinomas (DCIS) and 2 lobular in situ carcinomas (LCIS)) and $913 \%$ (136/149) were invasive carcinomas, One hundred and twenty five of all invasive carcinomas were of the ductal type [91.9\% (125/136) of all invasive caranomas]. Sixty-two cases [45.6\% (62)136) of all invasive carcinomas] were of histological grade III (Nottingham histologic score). Tumor size information was available in 68 invasive carcinomas and exhibited a median tumor size of $2.7 \mathrm{~cm}$ (range $0.3-11.0 \mathrm{~cm}$ )

\section{Imimunohistochemical findings and molecular subtypes}

Approximation of molecular classification was completed in 96 infiltrating carcinomas with the following results: Luminal A: $8.3 \%$ $(8 / 96)$, Luminal B/HER2-: $33.3 \%$ (32/96), HER2: $11.5 \%(11 / 56)$. Luminal BjHER2 +: 19.8\% (19/96), Basal-like: $11.5 \%$ (11/96) and Triple Negative: $15.6 \%$ (15;96). Overall, ER was positive in $59.6 \%$ (62/104) of cases, and HER2 overexpression (score $3+$ and/or HSH ration $\geq 2.0$ ) was observed in $32.8 \%(43 / 131)$ of cases. 
Treatrient and follow-up

Data about surgical procedure was available in 45 cases of invasive carcinomas. Total mastectomy was the most common surgical procedure performed $(66,7 x ; 30 j 45)$, Information about the patients receiving or not chemotherapy was collected from 46 patients. Forty-three of these patients received chemotherapy (93.5\%; 43/46). The most common chemotherapy regimen included taxane-plus-anthracycline-based (55.3\%; 21/38). anthracycline-based $(132 \%$; 5/38) [such as FAC (Fluorouracil, doxorubicinjadriamycin, cyclophosphamide; 3 patients), FEC (fluorouracil, epirubicin, cyclophosphamide; 1 patient) and $4 A C$ (doxorubicinjadriamycin and cyclophosphamide; 1 patient)]. taxane-based (10.5\%; 4/38) and CMF-based [cyclophosphamide. methotrexate and fluorouracil $(5.3 \% ; 2 / 38)]$ chemotherapy regimens. Neoadjuvant therapy data was obtained in 31 patients. In these patients, neoadjuvant therapy was administered to $51.6 \%(16)$ 31). In HER2-positive tumors, anti-HER2 therapy information was available in 15 cases, being performed in $73.3 \%$ of those cases $(11)$ 15). Thirty-seven patients received radiotherapy (84.1\%; $37 / 44$ women with available data).

Follow-up information revealed that 37 patients developed axillary bymph node metastases $\{61,7 \% ; 37 / 60$ invasive carcinomas $)$ and $20(48.8 \% ; 20 / 41$ invasive carcinomas) developed distant metastatic disease. The most common metastatic sites were bones $(24.4 \% ; 10 / 41)$, brain $(17.1 \% ; 7 / 41)$, Iiver $(17.5 \% ; 7 / 41)$ and lung $(9.8 \%$; 4/41). Sixteen patients suffered tumor-related death $(34.7 \% ; 16 / 46)$ with a median follow-up of 39 months (range 6-131 months).

Tumor size was significantly larger for tumors associated with the molecular dassification groups HER2 and Triple Negative ( $p<0001$ : Table 4). There was also a significant association between molecular classification and Nottingham histologic grade ( $p<0.001$; Table 5). However, we were not able to demonstrate significant association between molecular classification and axillary lymph node metastasis, distant metastasis and/or disease. related deaths. On the other hand, overall survival time differed significantly between groups. Statistical analysis using Breslow test to analyze the significant differences between the groups showed that HER2 and Basal-like group curves had an overall survival expectation of $<24$ months (Breslow $-22.16, p<0.001$; Table 6 and Fig. 1).

\section{Discussion}

Few studies in the literature have evaluated breast cancer in very young women ( $\leq 25$ years) and the number of cases in those scarce studies was too low to draw definitive conclusions about pathological and immunohistochemical findings $|12,19-22|$. Because it seems that age plays a role in the biological behavior of breast cancer, we decicled to study the pathological and immunohistochemical characteristics in a relatively large number of very young patients ( $\leq 25$ years old) with breast cancer.
In relation to the pathological characteristics of the rumors found in very young patients, in our study, the median size of the tumors was $2.7 \mathrm{~cm}$ (range 0.3-11 cm), and $69.1 \%$ of tumors were larger than $2 \mathrm{~cm}$; these results are similar to those obtained in other studies of the same age group $[12,19-21,24]$. in other studies involving women less than 35 years of age with breast cancer, the frequency of patients with tumors measuring $>2.0 \mathrm{~cm}$ varies between $47.9 \%$ and $84.3 \%[9,25-28]$. In South Korea, Ahn et al. found that $659 \%$ ( $940 / 1427$ ) of patients $<35$ years old had tumors $>2.0 \mathrm{~cm}$ in comparison to $60.1 \%(5021 / 8359)$ of patients $35-50$ years old with similar tumor sizes $[29]$. An important reason for the development of larger tumors in young patients is the lack of screening programs in that population. However, early detection may reduce tumor size at diagnosis, which could lead to a reduction in mortality in young women [30]. The Brazilian National Cancer Institute) Health Ministry recommends that clinical exams should only be performed in women older than 40 years and that mammography should be performed in women older than 50 years. Even for women that belong to high-risk groups for breast cancer, the recommendation is to begin screening in women $\geq 35$ years old [31].

With respect to histological type and grade, we found that the vast majority of our cases were invasive ductal carcinomas [91.9\% (125/136) ] with the most prevalent histological grade being grade III $[45.6 \%(62 ; 136)]$. Only one invasive carcinoma was of the lobular type $(0.7 \%: 1 / 136)$. Our data are different when compared to the data obtained for the general population with breast cancer, that reveal a prevalence of invasive ductal carcincma type in $56-80 \%$ of cases [32-34]. This higher frequency of the ductal type and lower frequency of the lobular type in young women has also been observed in other studies $[16,28,35]$, It has been shown previcusty that an association exists between young age and high histological grade $[26-28,35,36]$. Cancello et al, studying patients $<35$ years, found that very young women ( $<25$ years) have significantly higher prevalence of histological grade 3 tumors $(81.8 \%)$ compared to patients $25-29$ years $(66.7 \%$ ) and $30-34$ years ( $56.5 \%$ ) [22/. A genetic basis may account for the prevalence of high-grade tumors in young women. Germline mutations in BRCA1 and TP53 are associated with early-onset breast cancer and lead to an increased frequency of high-grade tumors 137 .

In our study, $8.7 \%$ of patients presented with nonirnvasive-only carcinomas (11 DCIS and 2 LCIS). Similar results were obtained by Rosen et al. ( $8 \%$ of tumors- 10 DCIS and 2 LCIS) 38 ) and Kothari et al. (13X) [20]. In contrast, in the USA 64,640 new cases of in situ carcinomas ( $21.8 \%$ of all female breast cancers) are expected to have been diagnosed in 2013 [2]. In situ carcinoma is not frequently diagnosed in young women and, in the USA only $3 \%$ of the DCIS are diagnosed in patients younger than 40 years old [39]. This difference is related to mammographic screening and biopsy of suspicious lesions, which dees not cover most of the young patients $[40$.

Estrogen receptor was expressed in $59.6 \%(62 / 104)$ of our cases. ER positivity is observed in lower frequency in the very young

Table 4

Relationahip between tumar saze and malecular groc.ps.

\begin{tabular}{|c|c|c|c|c|c|c|c|}
\hline \multirow[t]{2}{*}{ Molecular dassification } & \multirow[t]{2}{*}{$\mathrm{N}$} & \multirow[t]{2}{*}{ Average } & \multirow[t]{2}{*}{ Standard deviation } & \multicolumn{2}{|l|}{ C95: } & \multirow[t]{2}{*}{ Minimum } & \multirow[t]{2}{*}{ Maximum } \\
\hline & & & & u & SL & & \\
\hline Inminal A & 5 & 2.38 & 2.01 & -0.11 & 487 & 0.8 & 5.80 \\
\hline Luminal BYHEKR- & 11 & 205 & 0.70 & 1.59 & 252 & 07 & 3.00 \\
\hline HER2. & 5 & 7.34 & 2.49 & 4.25 & 1042 & 400 & 10.00 \\
\hline Leminal B/HEFO + & 11 & 2.45 & 135 & 1.54 & 3.35 & 09 & 5.20 \\
\hline Brat-like & 5 & 2.78 & 2,71 & 0.65 & 491 & 03 & 5.00 \\
\hline Inple Nezative & 9 & 4.91 & 2.73 & 2.82 & 7.01 & 1.40 & 10.00 \\
\hline Total & 46 & 3,40 & 2.45 & 267 & 412 & 03 & 10 \\
\hline
\end{tabular}

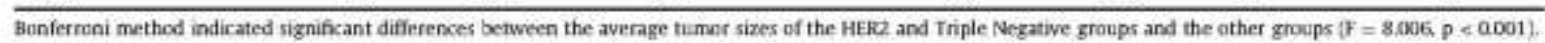




\section{ARTICLE IN PAESS}

\section{R. de Deus Mours et af / The Breast xax (2015) 1-7}

Table 5

Relabonship between histolagical grade and molecalar gruups.

\begin{tabular}{|c|c|c|c|c|c|}
\hline \multicolumn{2}{|c|}{ Molecular classification } & \multicolumn{3}{|c|}{ Nottingham histologic grade } & \multirow[t]{2}{*}{ Total } \\
\hline & & 1 & II & III & \\
\hline \multirow[t]{2}{*}{ femisual A } & $\mathrm{n}$ & 5 & 3 & a & 8 \\
\hline & x & $62.5 \%$ & 37.58 & 08 & $100 \%$ \\
\hline \multirow[t]{2}{*}{ tuminal B'HEKZ2- } & n & 6 & 17 & 9 & 32 \\
\hline & $x$ & $18.8 x$ & $53.1 \%$ & $28.1 x$ & $100 \mathrm{~s}$ \\
\hline \multirow[t]{2}{*}{ HER2 } & n & 1 & 7 & 3 & 11 \\
\hline & 8 & $9.1 \mathrm{~s}$ & $63.6 \%$ & 27.38 & $100 \mathrm{~s}$ \\
\hline \multirow{2}{*}{ Luminal $\mathrm{B} / \mathrm{HER} 2+$} & $\mathrm{n}$ & 1 & 8 & 10 & 19 \\
\hline & $x$ & 5.38 & $42.1 x$ & $52.6 \mathrm{X}$ & $100 \%$ \\
\hline \multirow[t]{2}{*}{ Rasal-like } & $\mathbf{n}$ & 0 & 1 & 30 & 11 \\
\hline & $\mathrm{s}$ & dos & $9.1 \mathrm{~s}$ & $90.9 x$ & $100 \%$ \\
\hline \multirow[t]{2}{*}{ Triple negative } & n & 0 & 4 & 11 & 15 \\
\hline & $x$ & $0 \pi$ & $26.7 x$ & 73.35 & 1008 \\
\hline Total & $\mathrm{N}$ & 13 & 40 & 43 & 95 \\
\hline
\end{tabular}

A significant association was ohserved between molecular classification and Nottinghtam listologic grade $\left(x^{2}-40,496, p<0.001\right)$.

The bold values indicates higher number of each grade in each group.

Table 6

Overall-survival acconting so molecular groups.

\begin{tabular}{lll}
\hline Melecular Classifcation & Overall sarvival time (months) & a $95 \mathrm{X}$ \\
\hline Luminal A & Not estimable: & - \\
Lumieal B;HER2- & 99 & {$[71-127]$} \\
HERZ & 20 & {$[18-22]$} \\
Lumital BiHER2- & 78 & {$[71-84]$} \\
Basal-like & 22 & {$[16-28]$} \\
Triple Negative & Not estimable & - \\
\hline
\end{tabular}

Overall sarvival time differed significantly between groups (note disjunction confidence interval for groups HER2 and Basal-libe). Overall survival time coetid not be estimated for luminal $A$ and triple negative graugs because $>905$ of patients remained alive daring, the fnllow up period.

women when compared to older women $161.5 \%$ in $\leq 25$ y versus $68 \%$ in $46-55$ y versus $75 \%$ in $56-65$ y] [20], We found a very high frequency of HER2 overexpression in invasive carcinomas $(32.8 \%$; 43/131). Mast of studies demonstrates lower frequencies of HER2 overexpression in older women when compared to younger patients $|16,28,29,36,37,41,42|$. Cancello et aL found that HER2 overexpression is higher in younger patients than in older patients $(21 \%$ in $<35$ years versus $14.5 \%$ in $>35$ years) |28|. However, when the same authors compared 3 subgroups of young women $(<25$ years, $25-29$ years and $30-34$ years), they could not find significant differences in HER2 overexpression. One possible reason is the small number of parients < 25 years (only 22 women) [22\}, These data suggest that the HER2 gene may play an important role in a high number of cases of breast cancer in very young patients.

Cancello et al. investigated the prognosis of young patients (below 35 years) in comparison with older premenopausal patients (aged 35-50) using an immunohistochemical classification [28]. Less tumors identified as Luminal A were found in the group of patients $<35$ years oid ( $9.2 \%$ versus $21.2 \%$ ) and more Triple Negative tumors $(16.2 \%$ versus $7.5 \%)$ were found in this group when compared to older patients. In comparison, our results show a similar prevalence of Luminal A cases $(8.3 \% ; 8 / 96)$, but a higher proportion of cases negative for ER, PR and HER2 (triple negative): $27,1 \%(26 / 96)$, Collins et al. found a larger proportion of Luminal A cases $(29.8 \%)$ in patients $\leq 30$ years but a similar proportion of Triple Negative cases (23.4\%) [43\}. Our group has also previously reported a higher prevalence of Luminal A cases [22.5\% (48/213)] and of Triple Negative cases $[34.7 \%(74 / 213])$ in young women $\leq 35$ years old $[16]$. In the present series, we also demonstrated that both the HER2 and Basal-like molecular classification groups had a worse course than the Luminal A group, with an overall survival expectation of <24 months (see Kaplan Meler survival curves: Fig. 11. Similar findings were previously described by other studies involving all age groups $(44.45)$.

Breast conserving therapy (BCT) for breast cancer in young women is still controversial. On the one hand, no increased risk of death is observed among wormen who receive BCT when compared to women who underwent radical mastectomy regardless of age at diagnosis $(46)$. When surgical techniques are optimal and free margin status is obtained. it appears that young age at the time of diagnosis does not need to be a contraindication for $\mathrm{BCT}[47]$. On the other hand, it appears that women $\leq 35$ year old undergoing $\mathrm{BCT}$ are at higher risk of local recurrence than older women $(48-50)$, in the 13th St Gallen International Breast Cancer Conference, it was recommended that in young women ( $<35$ years). breast conservation should be executed with caution because it can increase the risk of relapse [51]. In the present study, the most

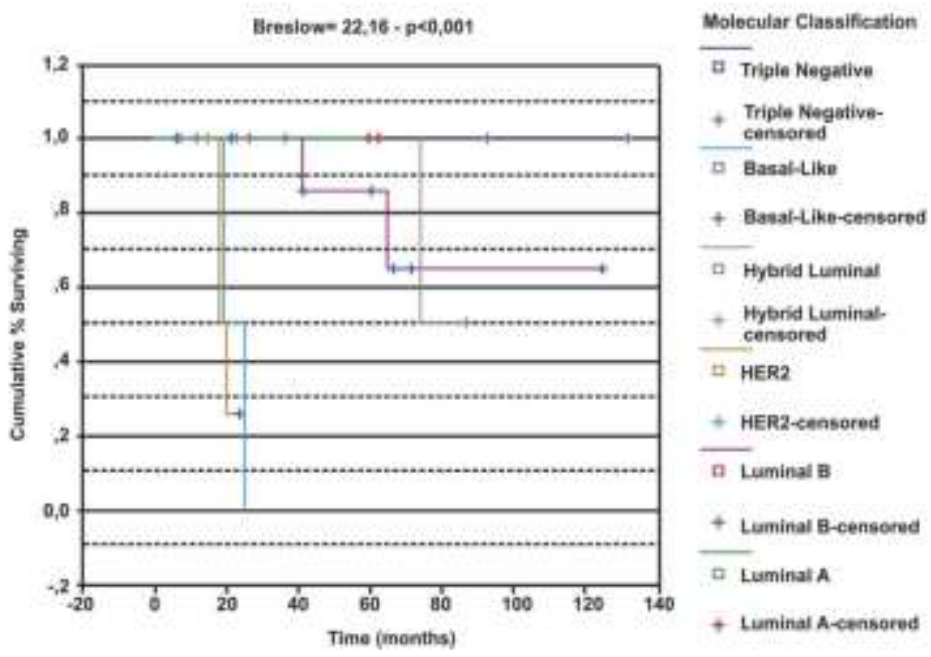

Fie 1. Overall survival of patiens according to movecular gocups. 
common initial surgical procedure was total mastectomy (66.7\%: 30/45), followed by BCT $(26.7 \% ; 12 / 45)$. Three cases $(6.7 \% ; 3 / 45)$ were unresectable. Han et al. performed a study including 351 women $<30$ years old with breast cancer and found similar results with $64.1 \%(221 / 345)$ of women $<30$ years old undergoing total mastectorny [52]. Interestingly, they demonstrated that the proportion of patients who underwent breast conservation surgery was greater in the youngest age group than in patients $>30$ years old.

In our study. 34.7\% of patients with available follow-up suffered from tumor-related death (16/46), with a median follow-up of 39 months (range 6-131 months). In Brazil, National Cancer Institute (INCA) estimates 5-years survival in patients with breast cancer of 80\%, [53], In a series with 346 patients < 35 years with breast cancer, Livi et al. found similar results, with $62 \%$ alive after 6.8 years of median follow-up $[25]$. They also showed that patients $<30$ years had a worse prognosis

\section{Conclusion}

In our large cohort of very young women with breast cancer, we found that $0.4 \%$ of all breast cancer cases occurred in patients who are $\leq 25$ years. According to the results obtained, breast cancer in very young wamen exhibits large size, high histological grade. low prevalence of in situ carcinoma component only and low frequency of lobular carcinoma subtype, Immunohistochemical findings showed a high prevalence of cases with HER2 overexpression and triple-negative cases, a high frequency of positive lymph nodes and distant metastases and dose correlation with worse progncsis in patients who belong to the HER2 and basal-like groups.

\section{Conflict of interest statement}

None declared.

\section{References}

(1) Feriay f, Soerjomataran L, Ervik M. Dikshit R. Eser S. Mathers C, et al. GLoBOCAN 2012 v10. Cancer incidence and mortality worldwide: IARC CancerBase No, 11 |Internet| tyon. France (cited 2013 03/27/2014); Available from hatto:firbobocan iarcfi,

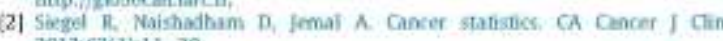
$2013 ; 63(3) 011-30$

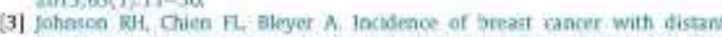

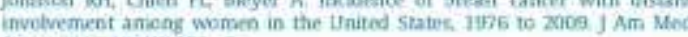

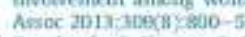

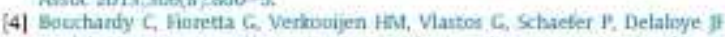
et at keoent increase of breast cancer incidence aming wonvo inder the age

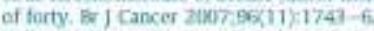

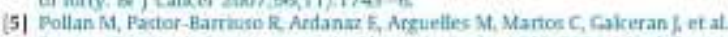
esent chaneise in breast cancer incidence in Spain, 19p0-2004 I Natt Cances int 2009,101222$) 1584-91$.

[6] Aben WK, van Gaal C, van Gils NA, van der Giral WT, Zielheit GA. Canver in acidesronts and young adults (15-20 years' a popolation-Sased study in the Netherlands 14m9-2009 Acta Oncol 2012;51 (7) $=922-33$.

77 Hawlader N, Nonoe AM, Krapcho M, Garshell I Neyman N Alteknuse SF, et al. SEER cancer statistirs review, 1975-2010. Bethesda, MD: Natoonal Cancer instifute; 2012 [updated fune, 2013; ca

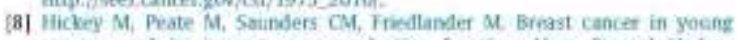
women and its impact on reptoductive fenction. Hum Reprod Update
$2009.15939323-39$.

(9) 1 S Sashir NQ, Seoud M. Khalit MK, Charafeddine M. Sabem ZK, Geara Fi, et al Elects of youing age at presentation on sirvival in breat cancer. BMC Cance 2006, 604

[10] Bleger A, Flan R. Hays-Lattio B, Themas D. Elis C Anderson B. The distioctive biology of cancer in adolesceots and yoseng adelts. Nat Rev Cancer $2008: 25$ ? $288-98$.

(11) Azins ) HA, Michiets S, Bedand TL, Singhal SK, Crisotietb C, Ignatuatis M, et at Elccisating progness and biology of bceast cancer arising in young women

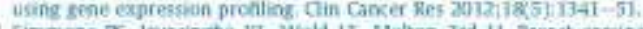

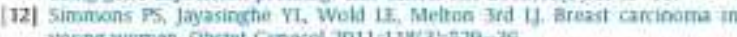

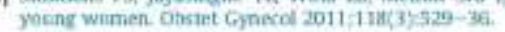

[14] Kataoka A Tokrnaga E Maroda N Shien I, kawalata $k$, Mivashita M. Clinicopathologrcal features of young pauents $(<35$ years of ape) wuth berat cupathoiogrcal features of young patients (c 35 years of age) weth beeast
cancer in a Japanese fireast Cancer Society appotted strady. Hireast Cancer

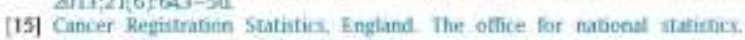
Newpart Crown Copyright 2013; 2011.

[16] Bacchi IM, Cospa M, Santoc WW, Hacchi CE, Carvalthe FMt Estrogen rereptorposilive beeart carcinomat in yoinger women are diflerent from those of

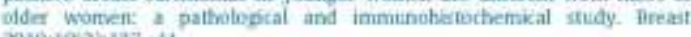
$2010 ; 19: 2) \div 137-41$.

[17] Woir AC Hammond ME, Hecks DG, Dewsetr M. Meshane DM, Allisen EH, et al.

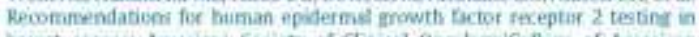
bresst cancer: American Socxely or Claical Oncology/Callege of American

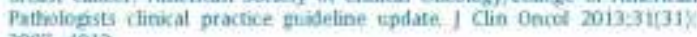
$3097-4013$

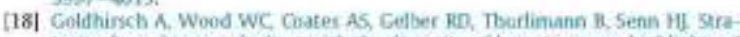
tegres for mubrypes - itealing with the diversity of breast cancer: himilghis of the St Gatlon fnternational Expert Conomspls an the prinary therany of early

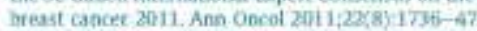

[19] Aceto GM, Solano AR Neuman Mi, Veschi 5 Morsano of. Malnesta 5 , es al Higthrisk heman papilloma virus infection, himor pathepheootypes, and BECA1/2 and TP53 status in jovenile oreast cancer. Proast Cancer fos Treat 3010:122[3]:67]-83,

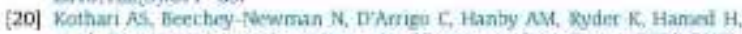

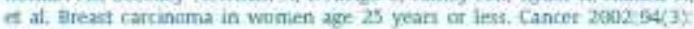
606-14

[21] Paillocher N, Lacourtoisie SA Fondriniet E, Catala L. Morand $C$ Deursier J, et al. Infittrating breast cances in women younger than 25 years: 13 rases Presse Med 2006:35( II f न 1):1618-24.

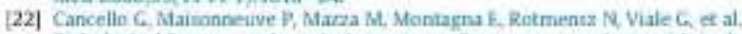
Paltologisal featumes and zurvival nutcumes of very youns patients with earhy breast ancer, how much it "very young"? Breant 2013;22:6):10006-51.

$[24$ Alipour S. Omw anipuit R, Jahumzad L, llaghen K. Very young treast rancer in a neferral centes in tehran fran teview of 3.1 cases aged 25 or less throughout 33 years Aaian Par / Cancer Prev 2013,14(11) 65:29 32.

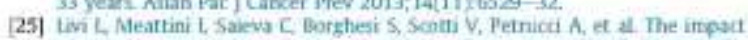
of youne we on hreatit cancer enteome, fiet J Surg Oncel 2010:36:7\% $639-45$

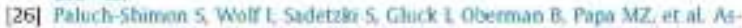
sncistion between very young age and adverse charactentitia of areast cancer

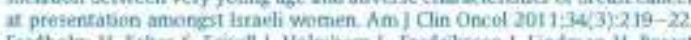

27 Fredhodm It Laker S, Frsell L, Holmbers L Fredriksson I, Landman H. fireast

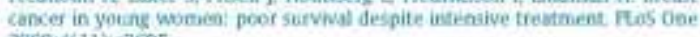

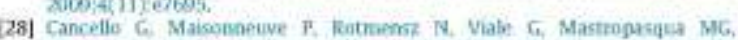
Pruneri C. et al Protnosis and adjurvant treatment effects in selected breast cancer subtypes of Wery yoting women ( 35 years) with operable breast

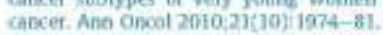

[29] Arin SH, Son BH. Kim SW, Kin SL, poon J, So SS, et aL. Foot outrome of botmone rocoptor-poritive breast cancer at very young abe is due to tamaxifen resirtance: ratsouwide survivaf datz in Konea-a report froai the Korean

[30] Narad $\triangle A$ Agre of diagnosis, tumat size, and survival after breast cancer im. plicahons fir mammographic screening. Breast Cancer Fes Treas 3011;128(1) $259-66$

[31] Centrole do Cincer de Mama - Durumento de Cacsensa Rio de faneun. Ministerio da Saúde; 2004

(32) Rakha EA, Manti TC, Abd II Rehim DM, Paith C, Green AR Powe DC, Et al. Morptrologazal and immumphenotypic analysit of breast carcinomas wath hasal and myocpithelial differentiation. I Fathol 2006,200\% 4/495-506,

[33] Lowwman MW, Vriezien M, van Beek MW, Noithenius-Pcylaert MC, van der Sangen MJ, boumen RM, et al Uncaminon breast tumnes in perspective incidence, treatment and strevival in the Netherlands. Int I Cancet $2007: 121(1): 127-35$

[34] Weazelt 8 . Geyer TC Reis-fillwo 15: Histological types if breast cancer how specisl ate they? Mol Oocot 2010:43):192-208.

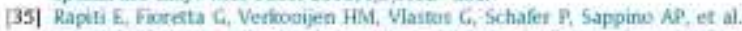
Suryival of youas and olide treast canter purients in Genevs frum 1990 to

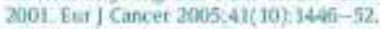

[36] Colleoni M. Kotmensz N. Rosertson C, Oetande L. Viale G. Kenne G, et at Ven

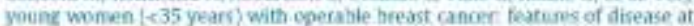
presentation Ann Oncol 2002:13(2) 273-0

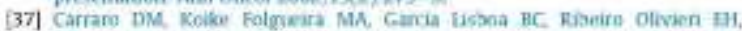

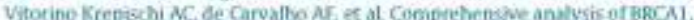
BaCA2 and TP53 gemline mutation and tumer charaderiation a portrait of

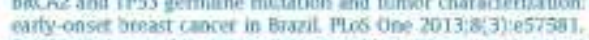

[38] Rosen F. Lesser ML, Kanne DW. Beattie E. Hirest carcinasa in wamen 35

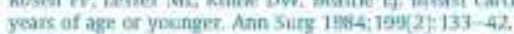

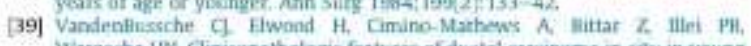
Warsecthe HR. Clinicopathologic featires of ductal cascinuma in uftu in young women with an emghass in malecular subtype. Heim Pathol $2013.44(17 \%$ Women
$2487 \rightarrow-72$

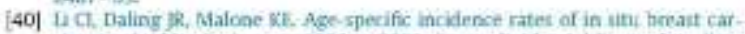
cinomar by histologic type, 1980 to 2001 . Cancer Epidenainl linmarkers Frev cinamiar by hastologic 


\section{ARTICLE IN PAESS}

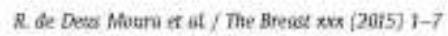

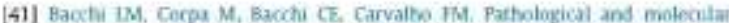
characterivatios of breast catcinomas of young women. Rev Bras Mastol 2005: 19:2):42-6.

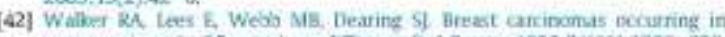

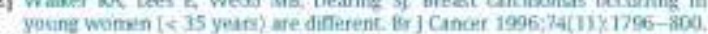

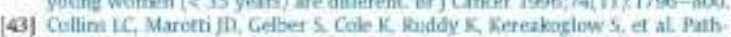
olvogic fearuies and molectilar phenotype ivy patient aze in a large cobort of

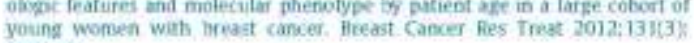
young
iosi-5.

[44] Garta Feroandez A Gimenez N, Frale M, Conzalex 5. Chahrera C. Torrar M. et al. Servisal and clinicopathoogical charscterister of breast cancer patent

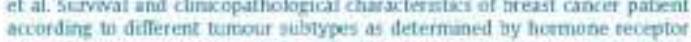

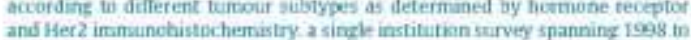
and Her2 immunchistbchemistry a sit

[45] o'Bren KM. Cole SR. Tse CK. Peroes CM, Caney LA, Foullhes Wro et at intrinsic

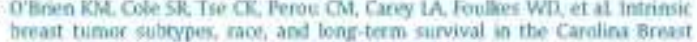

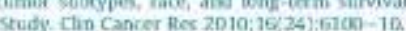

[40] Kruman N. Hoitveg H Wohlfahurt J. Jensen MB, Muuridsen HIt, Hlichert Yoft Me et at. Eflect of aneast-conserving therapy wesous radical mastectomy of peognasia for young wamen with breast carcisurta. Cances 2004,100(4)

[47] Zhou P, Recit $A$ Young age and ceitcome for women with einly-stage invastve livest catcinoma. Canori 2004:101(6) 1264-74

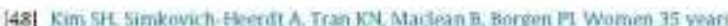
of sge or ynuger have higher liscoreginal retaper rater atter Lnderpoing

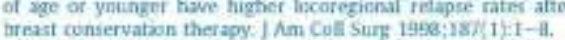

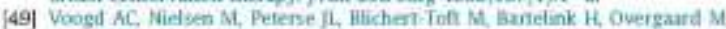
is al Differences in rok Foton for local and distant recurrence after breast. canserving therapy ir mastextang fie stage I and III breast cancer pooled

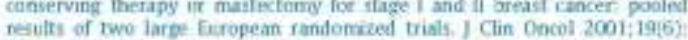
resulti of
$1688-97$

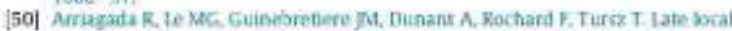
recurrioges in a randoenised trial comparing cosreryatwe treatment with

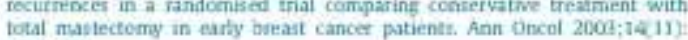
$1697-22$

151) Ch ngliano G, Criscitiello C, Andere I, Colleoni M, Di Leo A. Highilights foum the 13th St Gallen Internatinnat fireast Cincer Cisnference 2013. Access to innd vation for patients with oweast canceri how to speed if up? Ecancernieth calscience zor

[52] Han W, Kang SY, Felationshup thetweren age at diagnesis and cutrogie of

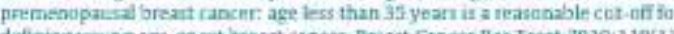
defining young age-enset breast cancer, Rreast Cancer Res Treat 2010:319[1] $193-200$

153) Estimativa 2014 inciuentia de Cancer bo Brasal. Riv de fanciro: Institute

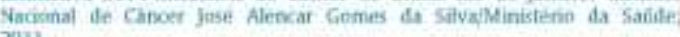
2011.

Please cite this article in press as: de Deus Moura R, et al. Breast cancer in very young women: Clinicopathological study of 149 patients $<25$ years old, The Breast (2015), hitt: HidxdoLorg/10.1016)j.breast 2015.04.002 
Anexo 
Anexo 1 - Aprovação do Comite de Ética em Pesquisa.

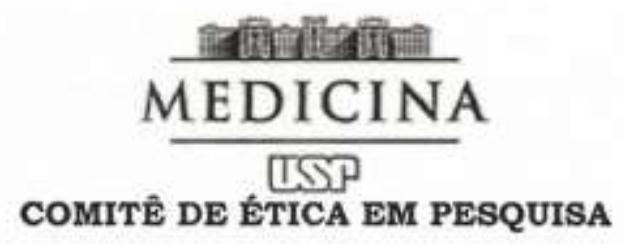

\section{APROVAÇÃo}

O Comitê de Ética em Pesquisa da Faculdade de Medicina da Universidade de São Paulo, em sessão de 10/o8/2011, APROVOU o Protocolo de Pesquisa $n^{\circ}$ 236/11 intitulado: "CÂNCER DE MAMA EM PACIENTES MUTTO JOVENS ( $\$ 25$ ANOS): CARACTERÍSTICAS ANÁTOMOCLÍNICAS, FATORES PROGNÓSTICOS E PREDITIVOS " apresentado pelo Departamento de Patologia.

Cabe ao pesquisador elaborar e apresentar ao CEPFMUSP, os relatórios parciais e final sobre a pesquisa (Resolução do Conselho Nacional de Saúde $n^{\circ} 196$, de 10/10/1996, inciso IX.2, letra "c").

Pesquisador (a) Responsável: Carlos E. Bacchi

Pesquisador (a) Executante: Rafael de Deus Moura

CEP-FMUSP, 16 de Agosto de 2011.

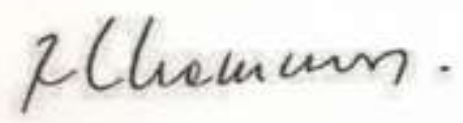

Prof. Dr. Roger Chammas

Coordenador

Comitê de Ética em Pesquisa 